\title{
ADIPOSIS AND LIPOMATOSIS
}

COASIDERED IN REFERENCE TO THEIR COXSTITCTIONAI RELATIONS AND SXMPTOMATOLOGY *

IRVING PIILLIPS LYON, M.D.

BLFFALO, X. Y.

\section{Synopsis}

Introduction. l'ersonal observations (20 cases, 19 plotographs). Consideration of special clinical rarieties or syndromes-groups of cases. Group I. Adiposis dolorosa. Group II. Obesity. Group III. Todular circumscribed lipomatosis. Group IV. Diffuse symmetrical lipomatosis (Fetthals. Madelung: adéno-lipomatose symétrique à prédominance cerricale, Laurois and Bensaude). Group V. Teuropathic edema, psendoedema, pseudolipoma and lipoma. Group VI. Adipositas cerebralis (Fröhlich, Madelung and others). Consideration of the combined groups. General summary (including special subjects, arthritism. heredity, etc.). Etiology (including glands of internal secretion). Treatment. Conclusions. Billiography.

\section{IXTRODUCTIOX}

The object of this study is to simplify or unify the clinical classification of abnormal subcutaneous fat deposits by correlating the symptomatologr and constitutional relations common to the sereral rarietics or clinical groups that have been separated under descriptive designations according to their predominant characteristics. It is with special reference to Dercum's "adiposis dolorosa" that this study is undertaken. I shall present in evidence a series of personal observations and then proceed to take up in order the different clinical varieties of abnormal fat deposit, showing the blending of these several varieties by their common features and emphasizing the constitutional relations and srmptomatology of the process in general.

\section{PERSOTAL OBSERTATIOX}

CAse 1.-Summary. - Typical case of Dercum's syndrome. elephantiac form. Woman, 61; family history of insanity; enormous diffuse adiposity limited to legs, thighs and hips: marked tenderness: asthenia : deafness: rheumatoid pains; insanity; suicide.

* Presented in alstract before the Association of American Physicians. twentyfourth amnual meting. Washington. Nay 11. 1909. 


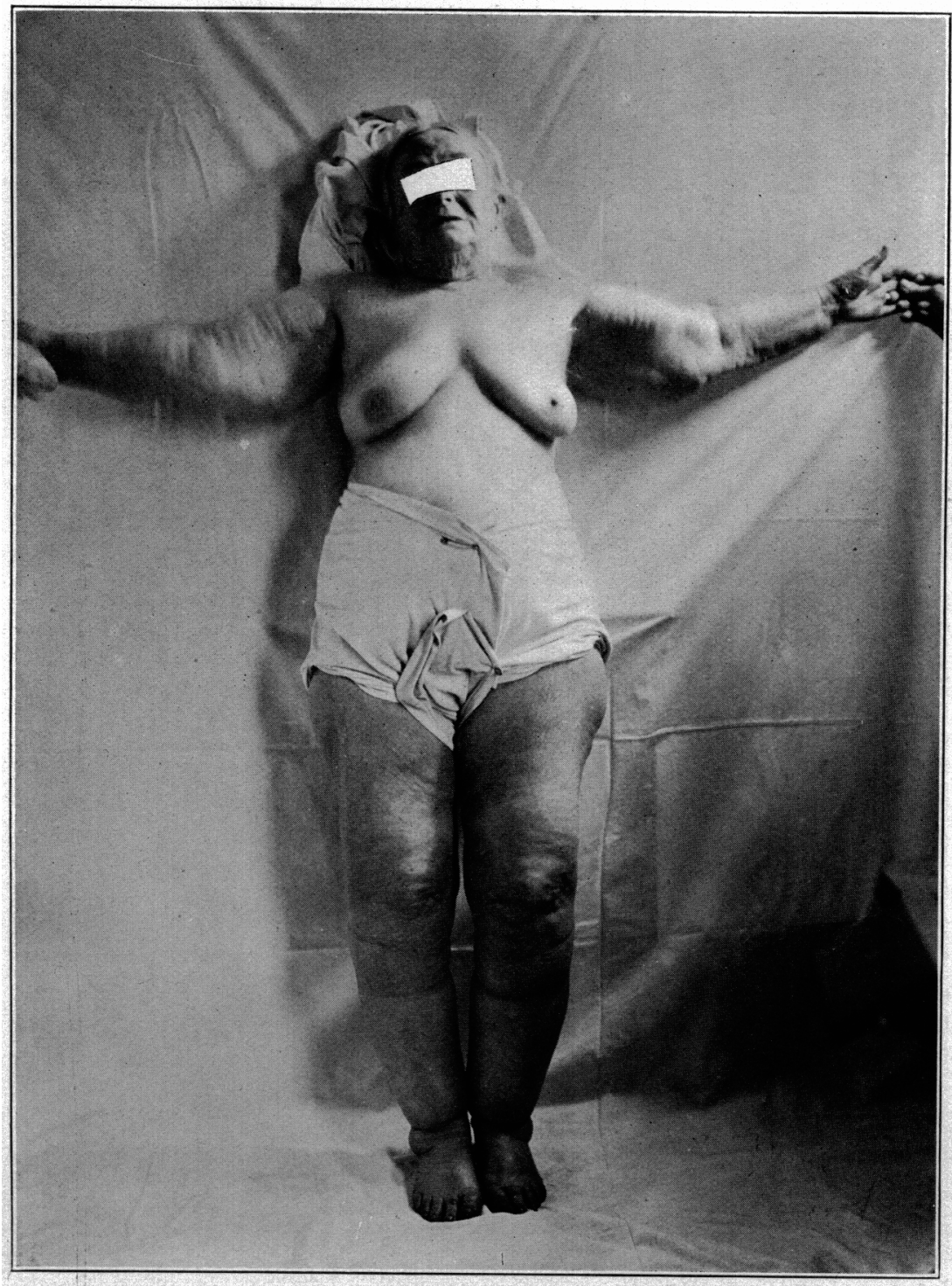

Fig. 1.-Patient 2; typical Dercum's syndrome. 
Patient.-Mrs. L., aged 61, born in United States, widow, no children, no misearriages, admitted to the Buffalo State Hospital (Hospital No. 11157) Jan. 23, 1909, discharged July 14, 1909; diagnosis: acute toxic-exhaustive insanity, adiposis dolorosa, chronic bronchitis, chronic nephritis.

Family History.-Mother said to have been insane and to have attempted suicide; otherwise negative.

Personal History.- - Ssual weight is 245 pounds. In consequence of obesity and asthenia the patient has been compelled to lead a very inactive life. No statement of the duration of the adiposity, pain and asthenia. History of rheumatoid pains in fingers and legs (not in joints), which her "physician did not regard as rheumatism." Deafness in both ear has been developing gradually for six years; pneumonia in November, 1908, followed by mental depression and insanity with attempted suicide, requiring her commitment in January, 1909.

Physical Fxamination.- Made on admission to the Buffalo State Hospital, Jan. 23, 1909.) "Excess of fat especially in the lower limbs, which are monstrously enlarged, and where the rolls of fat are very sensitive to the touch (adiposis dolorosa); below the knees are many varieose veins." Skin everywhere soft and normal; no edema. Terminal joints of the fingers thickened. Vision imperfect; patient wears glasses; no hemianopsia. Hearing very lefective; watch cannot be heard on contact with either ear. Knee-jerks active, no ankle-clonus. Dyspnea constant, soft mitral bruit, signs of general bronchitis, systolic blood-pressure $190 \mathrm{~mm}$.; some arteriosclerosis palpable in radicals and visible in temporals. Urinalyses show considerable albumin, granular casts and pus cells.

Subsequent History.-An interview with the patient was arranged for me for July 28, 1909; when I called at the house in the afternoon the door-bell was not answered, and later it was found that the patient, who had been left alone at home, had committed suicide by hanging. I examined her body after death the next morning. The exeessive fat deposit. diffuse, involved the legs, thighs and hips only, the rest of the body showing only a moderate pamniculus adiposus. No other abnormality was apparent. Necropsy refused.

I am indebted to 1)r. Arthur W. IIurd, superintendent of the Buffalo State Hospital, for the privilege of reporting this case.

CAse 2.-.Summary.- Typical case of Dercum's syndrome, elephantiac form (Figs. 1, 2, 3, 4). Woman, 75; history of trauma at 25 followed by mental irritability; asthenia; areas of edema with local soreness; painful adiposity. Marked vasomotor instability; areas of redness and blueness and of swelling with increase of local pain; hemorrlatges from the nose and mouth followed by relief of pains; anidrosis: macroglossia. History of symmetrical, painless lipomata in a liysterical daughter.

I'atient.-Mrs. D. T.. aged 75, married; five children; born in United States: height, 5 feet and 1/2 inch; weiglit, 176 pounds; seen in consultation with Dr. Joseph S. Lewis, April 24, 1909.

Family History.-Negative, except that father and mother were of the highstrung, nervous type and that a daughter of the patient developed in early childhood two symmetrically-placed, painless lipomata, one on each side of the back in the region of the lidney, alout the sime of a hen's egg, which remained unchanged and symptomless until her death from typhoid ferer at twenty. This daughter also had a paralysis and was unable to walk for several years until she was suddenly cured by a few electrical treatments in a quack medical institution (hysteria).

Personal History.-Menses always normal, menopause at 58 without notable symptoms. At 25 the patient fell down stairs, receiving a "concussion of the spine," from which she dates her subsequent trouble. Following this accident she beame very irritable and nervous: worried over trifles: suffered pain over the 


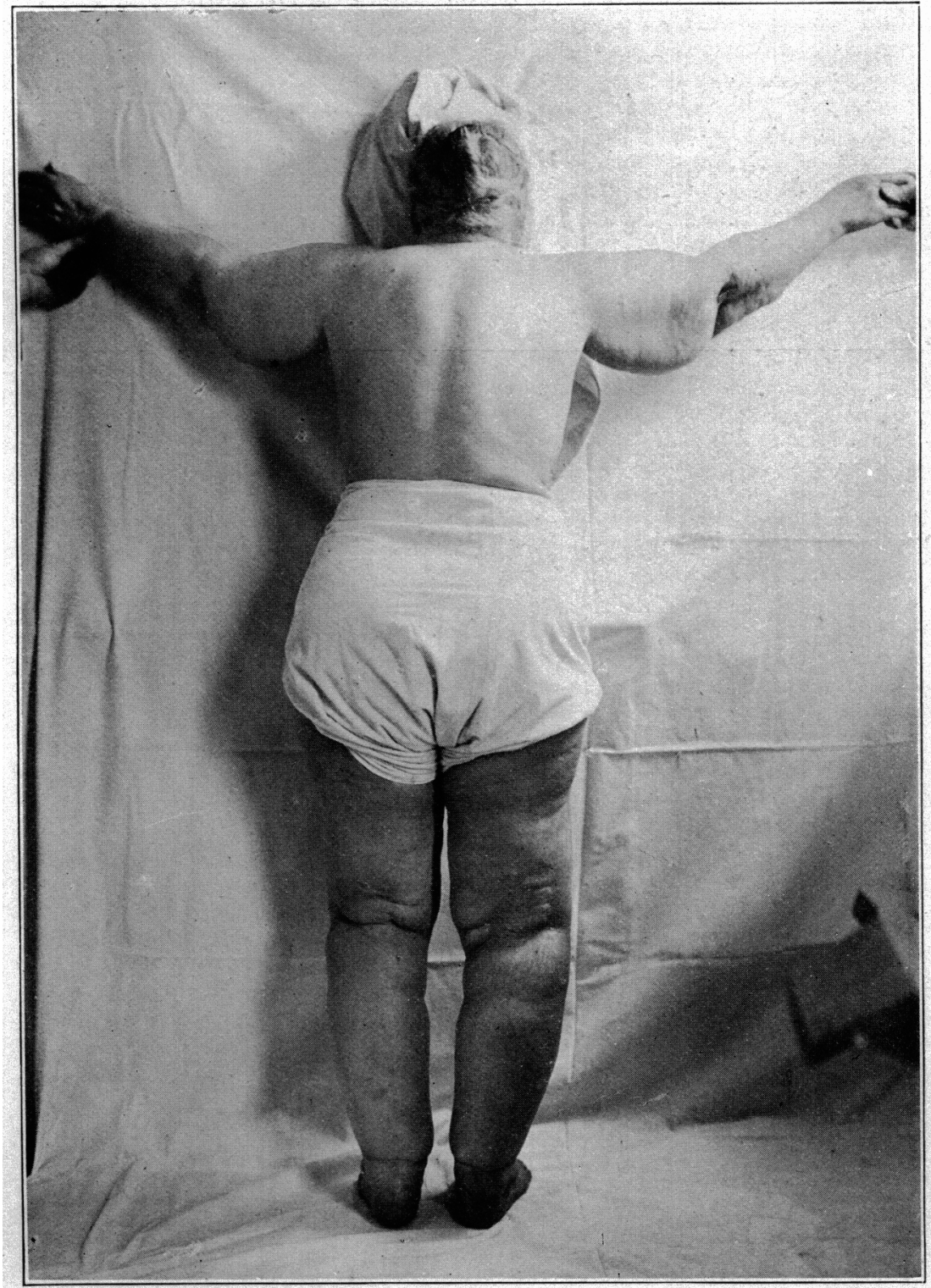

Fig. 2.-Patient 2; back view. 
dorsal spine and grew weak. Soon thereafter she noticed a condition of "bloating" in various parts of the body, especially over the knees and ankles, with soreness in the affected parts, both relieved considerably by rest in bed for a few days. At the same time she gradually put on fat and became stout. The fat has always been more or less tender and painful on pressure and the painfulness has always been increased by work, with spontaneous aching in the legs and arms. The pain has never been referred to the course of any special nerves. After the birth of two of her children, during the puerperium, both legs became greatly swollen and jainful, kepping her in bed for five months or longer. Since middle life she has

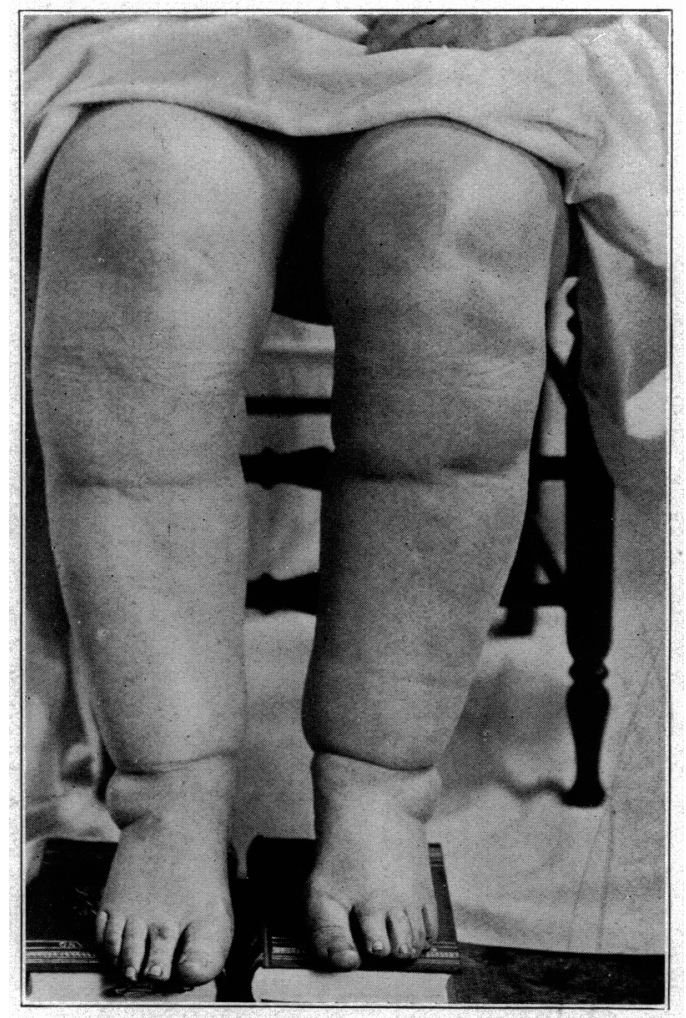

Fig. 3.-Legs of Patient 2.

suffered more or less constantly with a "poor circulation," manifested by chilly sensations and numbness over the body, especially in the fect and legs. During the past seven years she has noticed after hard work areas of redness and bluemess over the fatty deposits with increased soreness in the discolored regions, always relieved by rest. During the past four years she has had frequent hemorphages from the nose and mouth, sometimes very profuse, invariably followed by relief of pain and soreness over the entire body. Occasional headaches for two years. Small pigmented spots on the skin have developed during the past ten years. For a long time the slin has been dry and has flaked, never sweating even 
in summer. The patient does a little light work and supports an invalid husband, but has suffered with some general weakness and ready fatigue since the age of $\mathbf{2 5}$.

l'rescnt Condition.-The distribution of the abnormal fat reposit is so well shown in the accompanying illustrations that no detailed description is necessary. The hands, feet and face are spared and the trunk is not much involved. The legs suggest elephantiasis. The upper arms hang in the form of fat-bags. which on palpation give the feeling of a "bundle of worms." The fat feels irregular or sightly lobulated but nowhere can any distinct lipomas be marle out. Firm pres. sure is everywhere painful, but unequally, being more pronounced in the legs and thighs; hyperesthesia over the dorsal region is apparently increased by the patient's mental excitement and fear of being hurt. 'The skin is everywhere dry and desquamating in small flakes; numerous small pigmented spots over the arms; veins and renules over the fatty tissue enlarged and over the thighs small varicosities; no varicose ulcerations or scars. The tongue is enlarged, rather "too

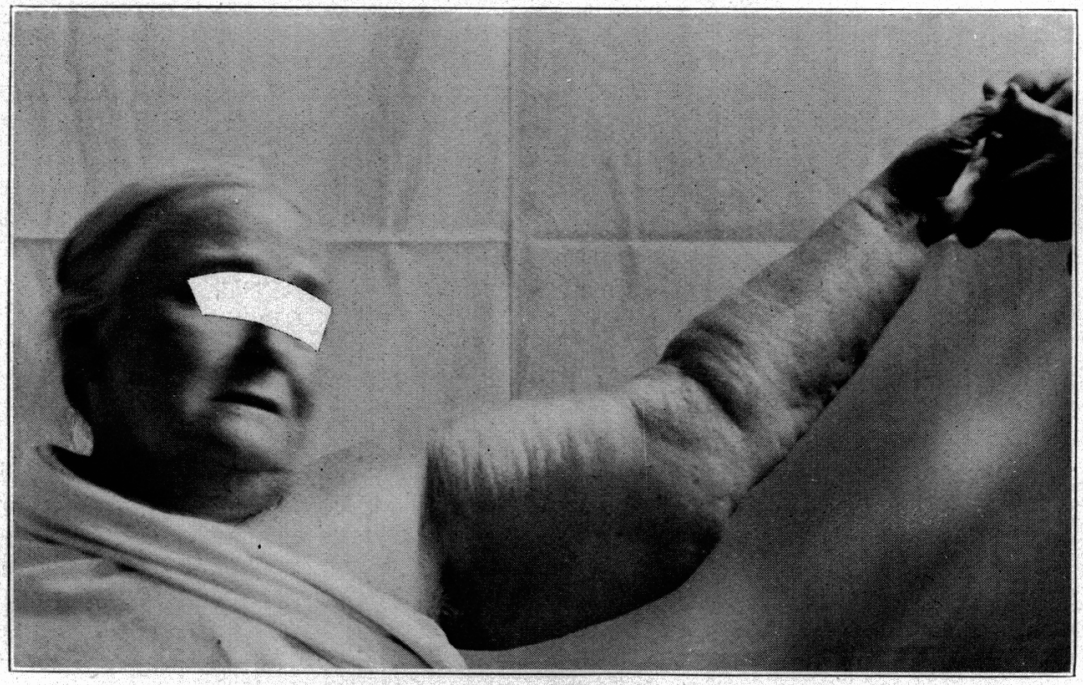

Fig. 4.--Arm of Patient 2.

barge for the mouth" as the patient remarked, and shows many varicose veins along its margin. Ileberden's nodosities on terminal joints of fingers with slight deformity of these joints. Heart shows a soft systolic bruit at the apex, not transmitted; pulse, $70 \mathrm{pcr}$ minute regular, tension normal. Marked asthenia is rident. No psychical disturbance beyond some slight nervousness and irritability: the patient is intelligent and answers questions promptly and accurately. Co anemia. Crinalysis shows a low specific gravity, a trace of albumin and rare hyaline easts.

Treatment.-Tonies and desicated thyroid were given for three months with no notable improvement: the only change ohserved was in the skin, which lost its dryness and desquamation with the return of normal sweating.

For the excellent photograplss (April 25, 1909) I am indebted to Dr. Grover IV. Wende. 
CAsp; 3.-Summary-Dereum's syndrone, generalized diffuse and nodular mixed form (ligs. 5 and 6 ). Woman, 55. from childhood has always had tender flesh with a tendency to bruising, a peculiarity shared by two daughters; maximam weight 244 pounds, reached at 40 ; at 45 ." "donble plantar neuritis and hrsterical edema" of feet and lower legs; at 47 , menopause, followed, at 50 , by development of painful lumps in the subcutaneous fat, asthenia and nervousness; occasional appearance of local redness over the lumps with exacerlations of pain; at 55, severe epistaxis, followed by subsidence of lumps and pain.

Paticnt.-Mrs. P. S., aged 55; born in Inited States, married; nine children: two miscarriages: medium height: weight 235 pounds; admitted to the Buffalo General Hospital April 2I, 1909, for severe epistaxis; seen in consultation with Dr. Charles Cary, April 24, 1909; photographed April 30, 1909.

Family History.-Antecedents normal. Two daughters, aged 34 and 37 years and weighing 150 and 170 pounds respectively, have from childhood suffered from tenderness of the flesh on slight pressure and from a tendency to ready bruising of the flesh from slight blows, a peculiarity shared by the patient. Both of these daughters have always been nervous; one of them (see Case 4) was epileptic from 3 to 8 years of age; for years has had eramps in her feet, legs and thighs, tender, aching shins, tendency to gonse-flesh on excitement, ready flushing of the skin. general nervousness and irritability, and now, on examination, shows fat-bags dependent from both upper arms, considerably painful on pressure. One son, aged 20 rears, weighing 170 pounds, for the past four years has had a pronounced tendency to epistaxis, using on the average about five handkerchiefs a week for nose-blecd. He is strong and hearty.

Personal History.-From childhood the patient has always suffered from a peculiar tenderness of her flesh, the slightest blow causing pain and a black-andblue discoloration. Throughout her childhood this vulnerability required her to guard herself against the rough play of other ehildren. This tendeney has continued ever since to the present time. At 14, she had an attack of epistaxis, from which she sars she almost bled to death. She was married at 17 , at which time she weighed 166 pounds, gradually inereasing to 200 pounds at 30 and to a maximum of 244 pounds at 40 , since which her weight has remained almost stationary. At $4 \tilde{5}$, after arduous work, her legs below the knees and feet became bloated, painful and numb and her gait insecure from a feeling as though her feet were not touching the ground. Dr. William C. Krauss, who treated her at the time informs me that his diagnosis was "double plantar neuritis and hỵsterical edema." Menses were always normal; abrupt menopause at 47 . At about 50 , the patient noticed lumps under the skin, at first three between the shoulder-blades on the left side, small, firm, movable and tender on pressure: soon similar lumps were noticed in the forearms, arms and thighs, in all perhaps a dozen. varying in size from a pea to a walnut. These lumps gradually increased in size and tenderness; variations in the degree of tenderness occurred from time to time and spontaneous aching and soreness in thr lumps was suffered at times. The use of the arms, as in knitting or kneading bread, sometimes led to the appearance of redness of the skin over the lumps in the arms with paroxysns of pains radiating from the lumps upward into the shoulders. neck and head. Sinee the development of the lumps. the patient las noticed an increasing degree of fatigue and weaknoss, feeling tired much of the time, and during the same period she has grown nervous and irritable; at times she has felt peculiar "flashes" run over the lody, leaving her exeited and restless. At 53, hemorrhage oecurred in the left retina, causing permanent loss of sight in that eye. For about two weeks preceding April 20. 1909, the pains in the arms were more severe and constant than (ver. on account of which the patient took a sweat lath on the night of April 20. This was followed in a few lours by profuse epistaxis, from which she fainted. The bleeding contimued until the next day when she entered the Buffalo General Iospital and received surgieal 


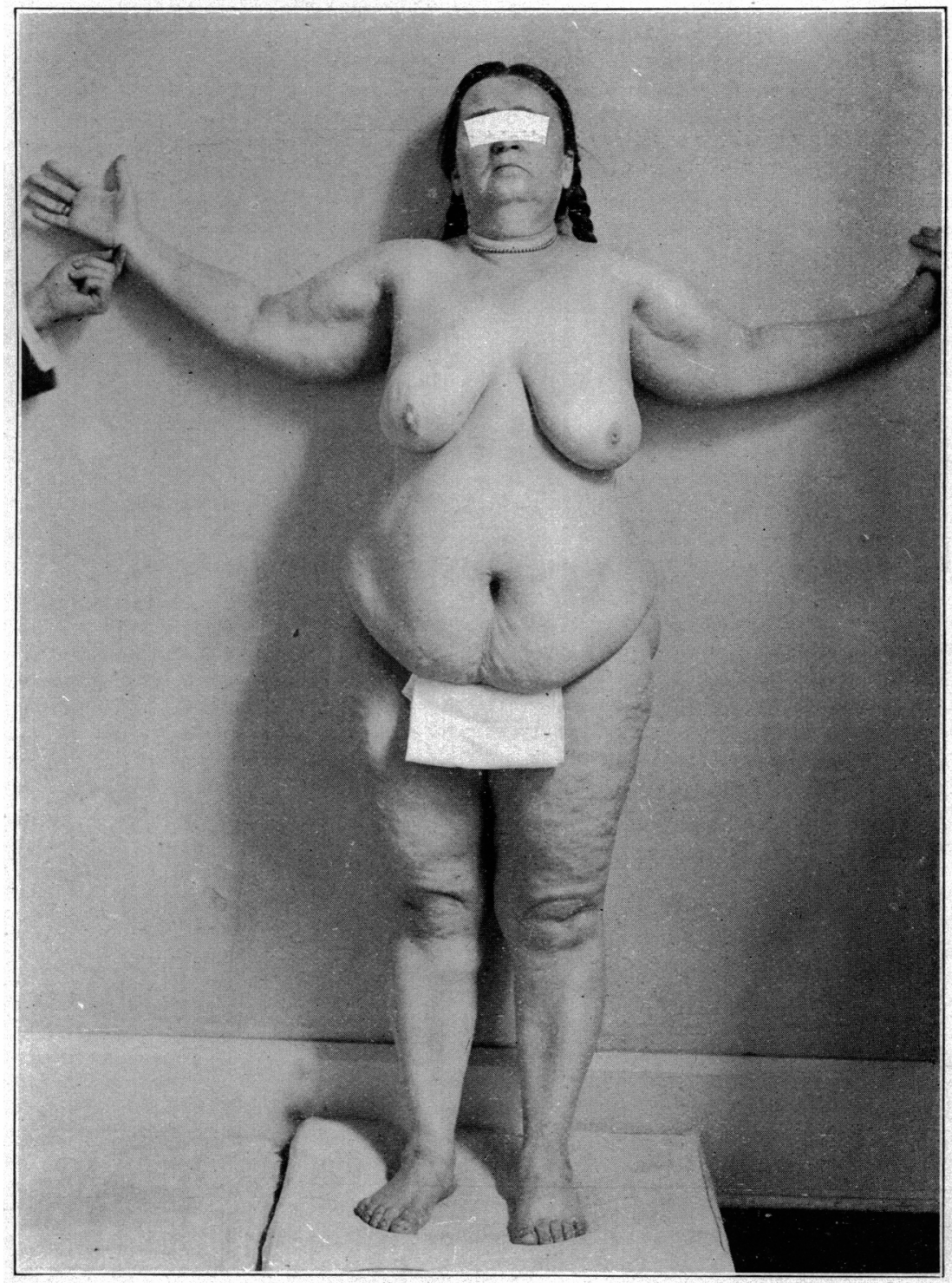

Fig. 5.-l'atient 3; Dercum's syndron:e, generalized difiuse and nodular mixed form. 
treatment. Shortly after the loss of blood, the spontaneous pains in the arms, which had been severe and continuous for two weeks, subsided until in two or three days they had completely disappeared. At the same time the several lumps in the skin lessened in size and tenderness until on April 24 some of them could no longer be found and others were very small and only slightly painful on firm pressure.

Physical Examination.-(April 30, 1909.) The condition of general obesity is shown in the accompanying illustrations. The face, hands and feet are spared. The fat is everywhere sensitive to slight pressure and firm pressure causes marked pain. The larger deposits of fat feel irregular and finely lobulated. In the forearms, arms and thighs several small, firm, movable nodules can be felt embedded in the general fat tissue and at their margins apparently fusing with the surrounding fat. The skin is everywhere soft, moist and normal in texture. General reflexes normal; sensations of the skin normal; hearing, taste and smell normal. Muscular power deficient. Mentality perfectly clear. Thyroid seems to be small. Heart, lungs, abdominal organs, normal; blood-pressure not increased. Urinalyses show a high specific gravity, slight trace of albumin and oceasional granular casts. Blood exmination (April 24) : hemoglobin, 65 per cent.; red corpuscles, $3,100,000$; leucocytes, 10,000 , differential leucocyte count, normal.

Treatment.-Thyroid medication was begun on April 27 but was interrupted by the departure of the patient from the hospital very soon thereafter.

Subsequent Condition.-On Aug. 7, 1909, the patient wrote: "Those fatty lumps have continued to be reduced in size and $I$ think that they are gradually disappearing. They have caused me no pain since my severe nosebleed."

CAse 4.-Summary-Atypical case of Dercum's syndrome, hereditary (Fig. 7). Woman, 34, no unusual fat deposits except moderate fat-bags in upper arms; abnormal tenderness of flesh and marked tendency to bruising of flesh from childhood, a peculiarity shared equally by mother and sister; no asthenia; nervous and excitable; subject to cramps in legs and feet; epilepsy in childhood. Mother (see (ase 3) has Dercum's syndrome now in typical generalized, diffuse and nodular mixed form; a sister has a condition similar to her own; mother and a brother subject to unusual epistaxis.

Paticnt.-Mrs. J. J. M., aged 34; born in Cnited States: married; one child; medium height; weight 150 poumds; seen April 24. 1909; photographed April 30 , 1909.

Family History.-Sce above, Case 3.

Personal History.-From three to eight years of age, the patient had frequent epileptic seizures with loss of consciousness, none since. From childhood she has always had tender flesh so that slight blows or pressure were painful and caused black-and-blue marks, requiring her to protect herself against blows. This tenderness was general but more pronounced over the lower legs and the fleshy pendulous upper arms. Walking often causes her shins and legs to feel sore and to ache, so that she has to rest. She has always been subject to severe cramps in the feet, legs and thighs, coming on while at rest in bed, while sitting quietly, or when exercising. These cramps sometimes cause her feet to be jerked off the floor. She has always been nervous and excitable, frequently flushes and has a marked tendeney to "goose-flesh" when excited. She has always been strong and tireless. The menses have always been irregular in time and amount of flow. She was married at 24 and has had one child; no miscarriages.

Physical Examination.-(April 30, 1909.) The patient is plump, not obese, weighing 150 pounds. The flesh feels normal except in both upper arms, where it hangs in moderate-sized "bags of fat," as she describes them. These dependent fatty masses feel slightly irregular, granular and flabby. Pressure on these masses is painful and similarly slight pressure over the shins and legs causes con- 


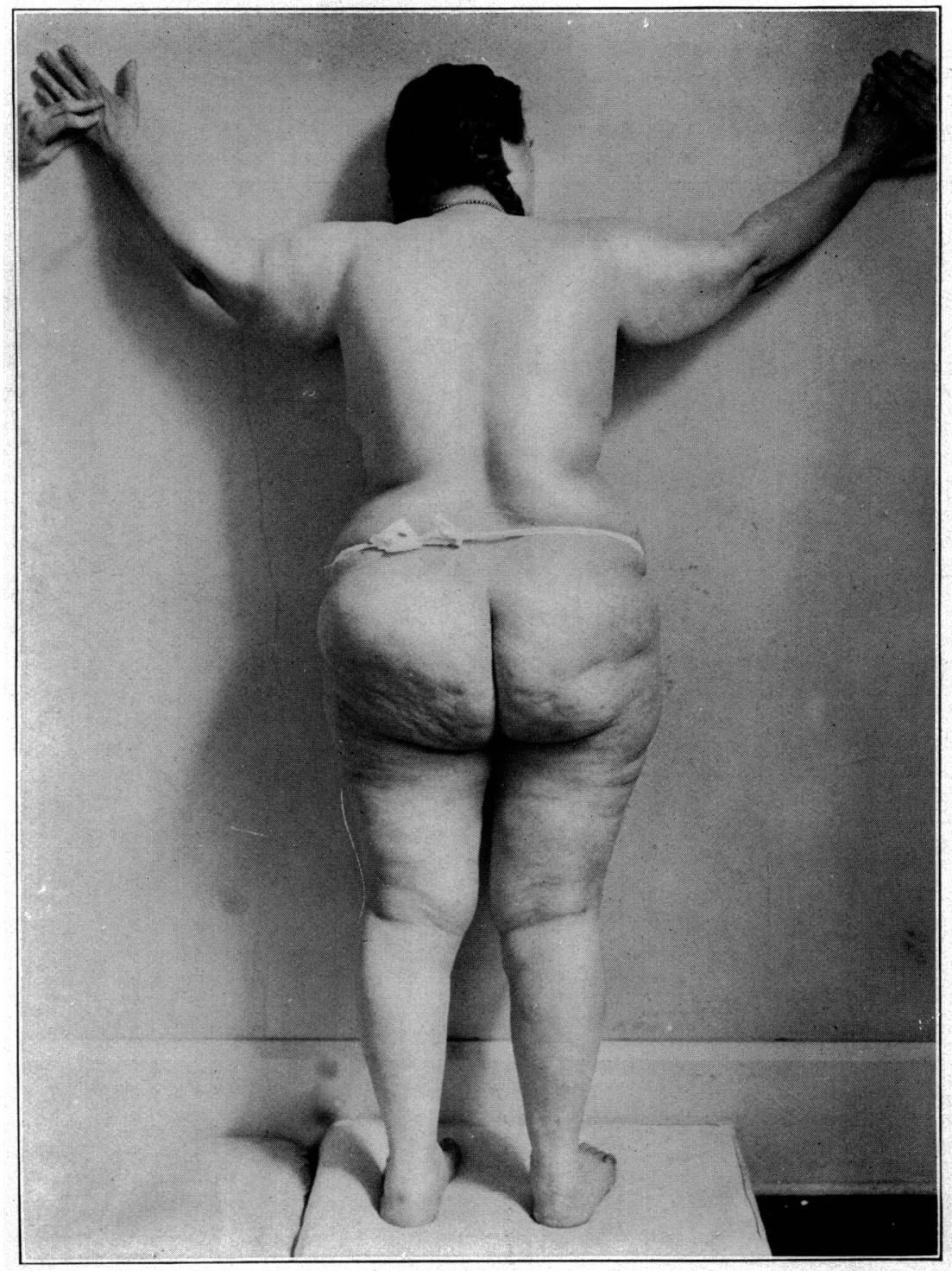

Fig. 6.-Patient 3; back view. 
siderable pain; elsewhere the flesh is abnornally tender but not in the same degree as over the legs and upper arms. The patient's mentality seems normal exeept for a certain degree of nervousness. The thyroid gland is slightly enlarged. The physical examination otherwise show nothing abnormal

Case 5.-Summary.-Atypical case of Dercun's syndrome, localized diffuse and nodular mixed form. IVoman, 64, marked family and persomal history of arthritism; personal history of epistaxis, neuritis, cerebral attacks; tenderness and bruising of the flesh from childhood, a peculiarity shared equally by three sisters and one daughter; during the past five years development of subcutaneous fatty lumps, painful spontaneously and on pressure, and during the same period, loss of strength; during the past year increased adiposity over abdomen and hips. Nentality normal. A similar condition in a cousin.

Paticnt.-Mrs. H., aged 64, born in Cnited States, widow, three children, no miscarriages, about 5 feet in height, weight 163 pounds, seen in consultation witl I)r. Lawrence Hendee several time; during the past four years.

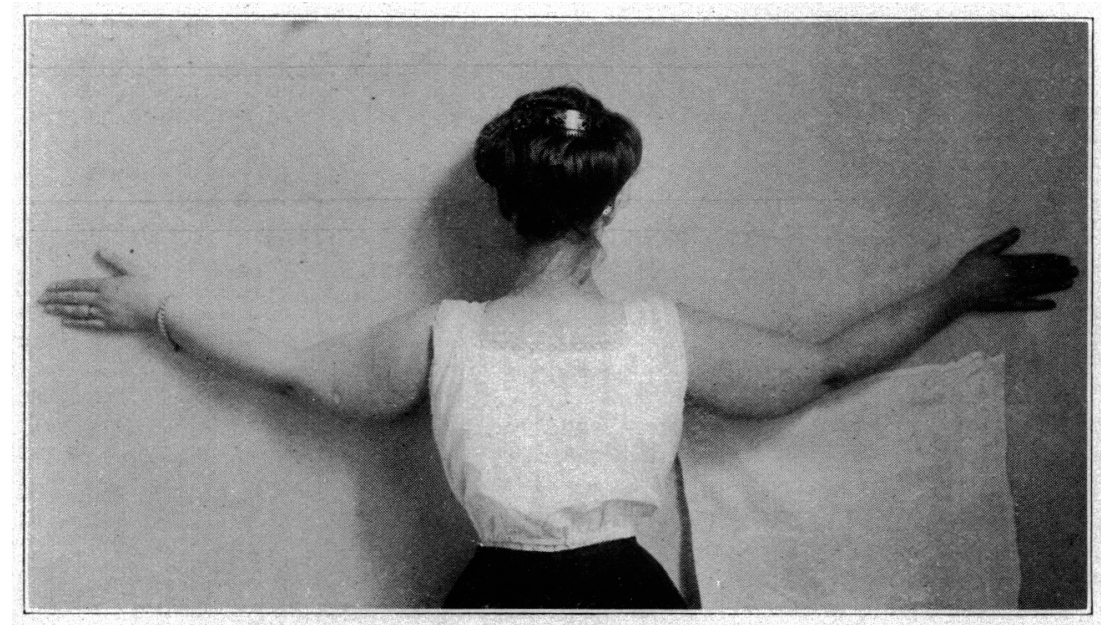

Fig. 7.-Patient 4; atypical Dercum's syndrome, hereditary.

Family History.-Antecedents normal; no nervous or mental diseases or adiposity. A sister was erippled for forty years by arthritis deformans; another sister has attacks of migraine; a third sister is very stout and is now suffering with a cerebral condition with headaches, vertigo and attacks of vomiting; a brother had attacks of lumbago; a niece has gout; a daughter and a son are subject to neuralgias and another son to lumbago. Like herself, the patient's three sisters and only daughter have always from childhood suffered with a condition of tenderness and bruising of the flesh from slight blows or pressure, requiring them to protect themselves. A cousin, A. R. M., son of her father's brother, aged 51 , height 5 feet 8 inches, weight 190 pounds, was examined on Feb. 2, 1910, by Dr. Lawrence Hendee, who has kindly furnished the following notes: Symmetrically placed in the lumbar region just below the location of the kidneys, there is a pair of soft, indistinctly lobulated lipomata, about the size of a half orange, quite painful to pressure. These lumps were first noticed about six years ago and have varied in size and consistency from time to time. They have been always tender 
to pressure, constantly painful, and subject to paroxysmal inerease of pain corresponding to the periods of increase of size and consistency. With these exacerbations pains radiate from the tumors down the back into the thighs. Another pair of small symmetrical lipomata is found in the dorsal region between the shoulder-blades, readily felt but not seen, embedded in the abundant subeutaneous fat deposit, distinctly painful to pressure. For the past few years the flesh has been growing flably without any actual increase in weight. The flesh is everywhere slightly but definitely tender on moderate pressure, more than in a normal person. There is a marked history of ready bruising with black-and-blue discoloration from trifling causes; several attacks of cervicobrachial neuralgia; very ready sweating; headaches; mentality somewhat neurasthenic of late. Patient has had "heart trouble;" no asthenia, arthritis, hemorrhages, or edema.

Personal History.-Tenderness and tendency to bruising of the flesh from slight blows or pressure have been present from childhood (see above, Family IIis. tory). From 15 to $3 \tilde{5}$, patient had attacks of severe exhaustion after any hard work. Menstruation began at 13 , was usually painful, ceased abruptly at 44; patient had three children, no miscarriages. At $2 \bar{\sigma}$, three days after birth of her second child, she had convulsions for three days and inflammation of the right re, since which vision has been blurred (one-fifth normal vision). At 32 , one year after the birth of her last child, she had repeated epistaxis, exhaustion and headaches, continuing for about a year. At 33, after a period of menorrhagia, she had two ehills with fever followed at once by a condition of delirium and semicoma; this lasted about six weeks and was followed for a period of a year by difficulty in maintaining the balance on standing. At 54 , after a serere mental shock, she had an attack of semicoma alternating with delirium lasting four days and severe headache lasting about two weeks longer; at 56 , slight attack of sciatica, left side; at 60 , left cervicobrachial neuralgia or neuritis witl torticollis, double episcleritis, dead and waxy fingers in left hand, lasting about a year. Swelling in the left supraclavicular region was noticed at this time. With the same illness, she had also marked cercbral symptoms consisting of vertigo, in which things seemed always to revolve in the same direction, faintness, headaches and romiting. I saw ler at this time and considered the possibility of cerebral tumor. All of these symptoms gradually disappeared in the course of one year. At 62 , there was slight effusion in both knee-joints, without local pain, redness, or fever; at the same time there was marked pain and tenderness in both lower legs, apparently following the course of certain nerves. The patient has never had inflammatory rheumatism. For several years Ileberden's nodosities have been developing in the terminal joints of the fingers. Alout five years ago she first noticed some small lumps on the back, which were painful on pressure and became more so with time; similar lumps appeared later at other points. They all tended to increase somewhat in size; none ever disappeared or fluctuated in size more than slightly. Spontaneous pains and soreness are felt in and near these lumps at times. The pains and tenderness are increased by exercise, fatigue or emotional excitement. Since the appearance of these lumps there have been noticed some loss of strength, not very marked, and easily induced fatigue. During the past year her weight has increased from 147 to 163 pounds, the increase of flesh being limited almost exclusively to the region of the abdomen and hips.

Physical Examination.-(May 2, 1909.) A somewhat stout woman, whose trunk, arms and legs are well proportioned, with a pendulous abdomen from excessive fat deposit and marked fatty deposits over the hips and buttocks. The entire body is somewhat tender on pressure but this feature is not very pronounced. Embedded in the subcutaneous fat of the back four firm lumps can be readily felt, symmetrically placed on the right and left sides below the ribs. Four similar lumps are found, two between the shoulder-blades, one on the back of the neck on the left side, and one on the flexor aspect of the left forearm. These lumps vary 


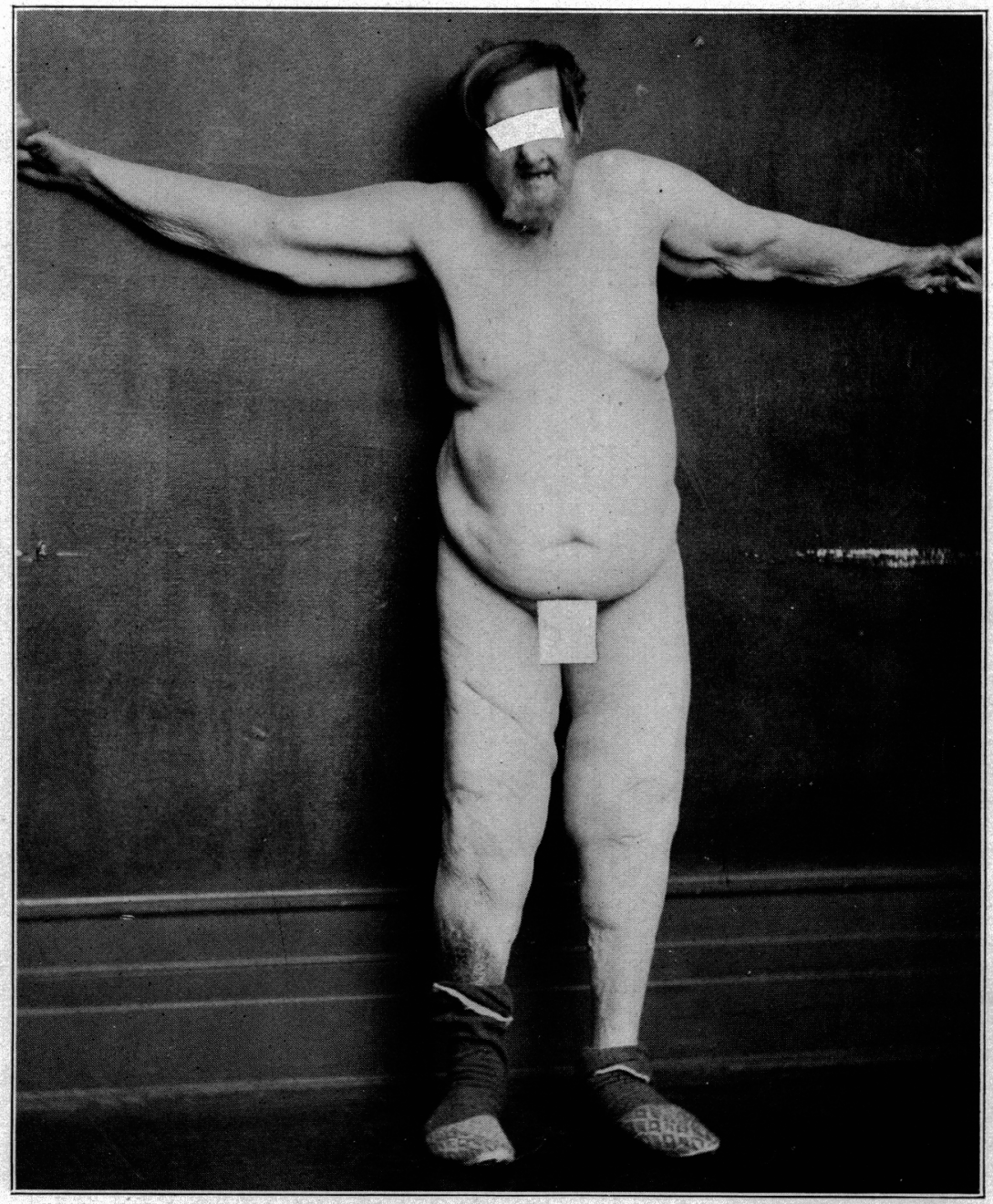

Fix. S.-Patient $f$ : atypical bereums symbome. exemeralized difuse form. 
from the size of an almond to that of a small walnut, are firm, somewhat flattened, indistinctly lobulated, movable, and are not well defined from the surrounding fatty tissue with which they seem to fuse. They are all painful on pressure and manipulation, but in varying degrees. The overlying skin is freely movable. Small Heberden's nodes on the terminal joints of the fingers. Slight ereaking in the knee-joints on manipulation, without pain. Slight varicosities over both legs and thighs. No gouty deposits anywhere. Reflexes and sensibility of the skin normal. IIeart, lungs and abdominal viscera negative. The radial arteries are not markedly sclerosed: blood-pressure normal. The thyroid gland shows no appreciable change. Urinalyses show no noteworthy changes. Nentality normal.

('ASE 6.-Summary-Atypical case of Dercum's syndrome, generalized diffuse form, in a man, developing with senility (Figs. 8, 9, 10); late appearance of
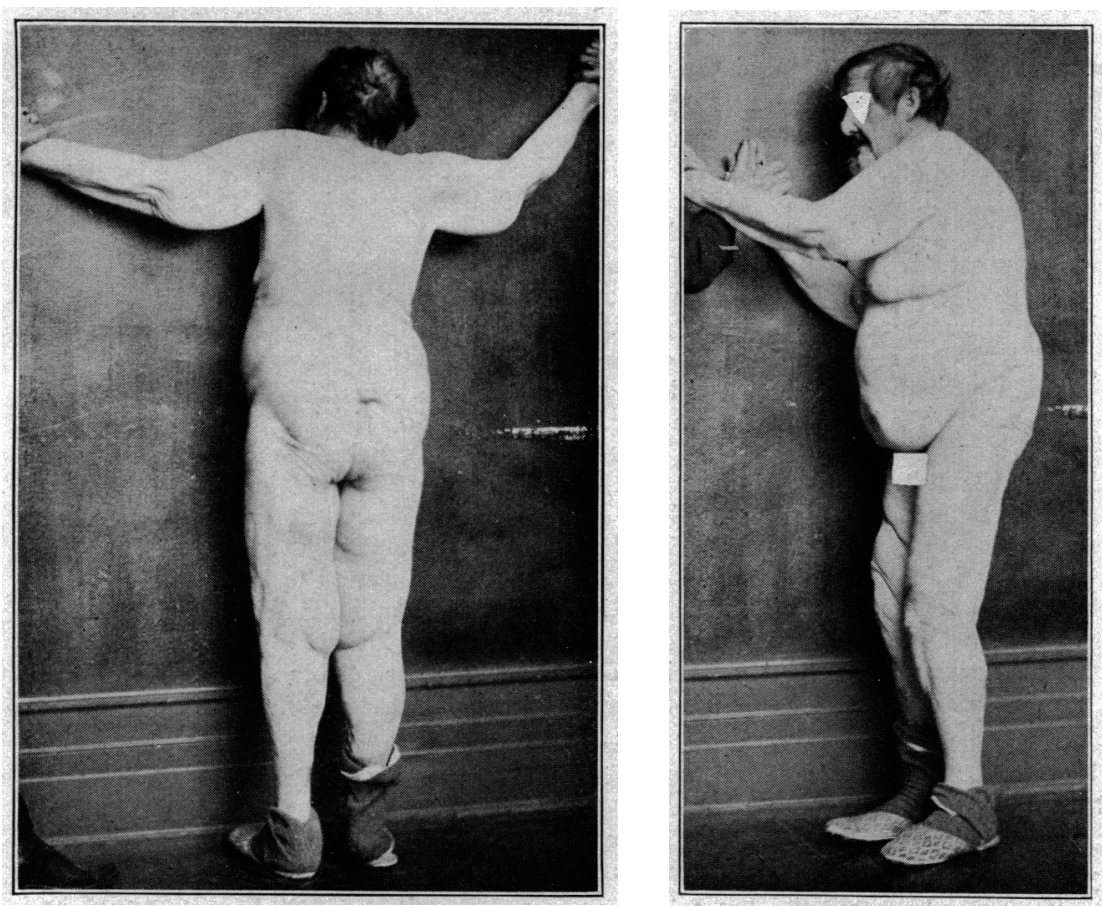

Figs. 9 and 10.-Patient 6 , back and side views.

tenderness occurring with marked loss of flesh. later complete disappenrance of tenderness, and still later temporary reappearunee of painfulness of flesh locally; marked asthenia ; senile mentality: sudden onset of paralysis of lower extremities.

Iatient.-Mr. H. G. aged 82; born in England: widower: several children: medium height: weight 155 pounds: seen in the service of Dr. Charles Cary, Buffalo General Hospital (ITospital No. 57.343). December, 1908.

F'amily History.-Negative for adiposity or nervous diseases.

Personal II istory.-Fracture of shoulder in early life. At 30, the patient had a fall and was in hospital for six weeks. At 40 he broke the right femmr in two places. with no permanent disability. At 48 he had "nervons prostration." was 
"numb all over," "shook a great deal," and was weak in his legs; also at this time he developed a chronic varicose ulcer on the right leg. He has had muscular "rheumatism" off and on for many years; never has had inflammatory rheumatism. For several years he has had a small epithelioma on the nose, which has not increased in size materially. At 55 he noticed a marked increase of weight which gradually continued until he weighed 230 pounds. During the past few years his general strength has failed and he has had spells of weakness in his legs with a tendency to fall: during the same time his mental faculties have gradually become enfeebled and his hearing has become impaired on the left side. For the past two years he has complained a great deal of "sore flesh" over the entire body so that he has eried out with pain when his grandchildren have touched him carelessly, and during the same period he has lost greatly in weight so that his clothes no longer fit him. In June, 1908, he was suddenly seized at table with severe pain in the back and abdomen and found himself unable to walk. The pain disappeared in the course of two weeks but the paralysis persisted, on account of which he entered the Buffalo General Hospital, July 23, 1908.

Physical Examination.-(December, 1908.) The general adiposity is shown in the accompanying illustrations, the photographs for which were taken in December, 1908, by Dr. Grover W. Wende. The weight is 155 pounds; skin loose and wrinkled, giving evidence of marked loss of flesh; pamiculus thick, irregular, pultaceous, flabby, hanging in folds on the upper arms, aldomen and thighs; scar and pigmentation of healed varicose uleer on right leg and sear from old fracture on front of right thigh; slight varicosities over both legs: no edema; small epithelioma (diagnosis by Dr. Grover W. Wencle) on the nose; complexion pallid. The fatty tissue everywhere is excessively painful to pressure or manipulation. Pressure over the larger nerves is no more painful than elsewhere. Pain is complained of in the back and lumbar region, especially on the left side, and dull pain in the left ankle is mentioned. There is evidence of marked general asthenia; the grip of the left hand is weaker than the right; paralysis of both lower extremities, confining the patient to bed. Mentality is clear lout senile. Knee-jerks absent. no ankle-clonus, Babinski reflex alsent, no spasticity, tactile and thermal sensations intact. Pupils unequal, the right larger than the left, react to light and aceommodation; cataract in the left eye. Taste and smell normal. Hearing deficient in the left ear. Thyroid gland feels small. Ileart, lungs and abdominal organs negative. Radial arteries somewhat sclerosed, blood-pressure normal. Crinalyses show a trace of albumin and a few granular casts.

Subsequent Course.-The patient left the Buffalo General Hospital and entered the New York State Soldier's' and Sailors' Home at Bath, New York, on Dee. 10, 1908, where he has since remained. I am indebted to Dr. Clayton K. Haskell, surgeon in charge, for the following notes on his condition:

April 28, 1909: "Since admission here the pain on pressure over the fatty deposits has disappeared, his weigit has remained stationary (155 pounds) and no change is noticeable in the growth on the nose. He is at present fairly comfortable, spends most of every day in a chair, eats and sleeps well and is apparently contented and happy."

August 3, 1909: "Mr. G.'s conclition since my last letter has been practically unchanged with one exception. Early in July he complained of vague indefinite pain and on examination the areas over the fatty deposits just below the gluteal folds were markedly tender on pressure. This tenderness disappeared in a day or two and since then has not recurred. The growth on the nose (which, by the way, we think is lupus) remains the same as when admitted in December of last year. I have just had him weighed and am informed that he now weighs 174 against 155 pounds four montls ago."

Feb. 15, 1910: "Mr. G. remains practically the same as when I last wrote you. The fatty deposits are slightly tender on pressure. The absence of senile 
changes generally is striking in this man. No arteriosclerosis, low arterial tension, little whitening of hair, memory for events of immediate past unimpaired, no thickening or harshness of the skin, nails of hands and feet those of a young man, no arcus senilis; in fact, with the exception of his cataracts and slightly impaired hearing there are none of the evidences of senility to be seen in the average man of $84 . "$

CASE 7.-Summary.-Case presenting three of the four cardinal symptoms of Dercum's syndrome-no tenderness; elephantiac form (Fig. 11). Woman, 69; diffuse adiposity involving chiefly the legs; absolutely no tenderness; moderate asthenia; insanity; rheumatoid pains and cramps; development after menopause.

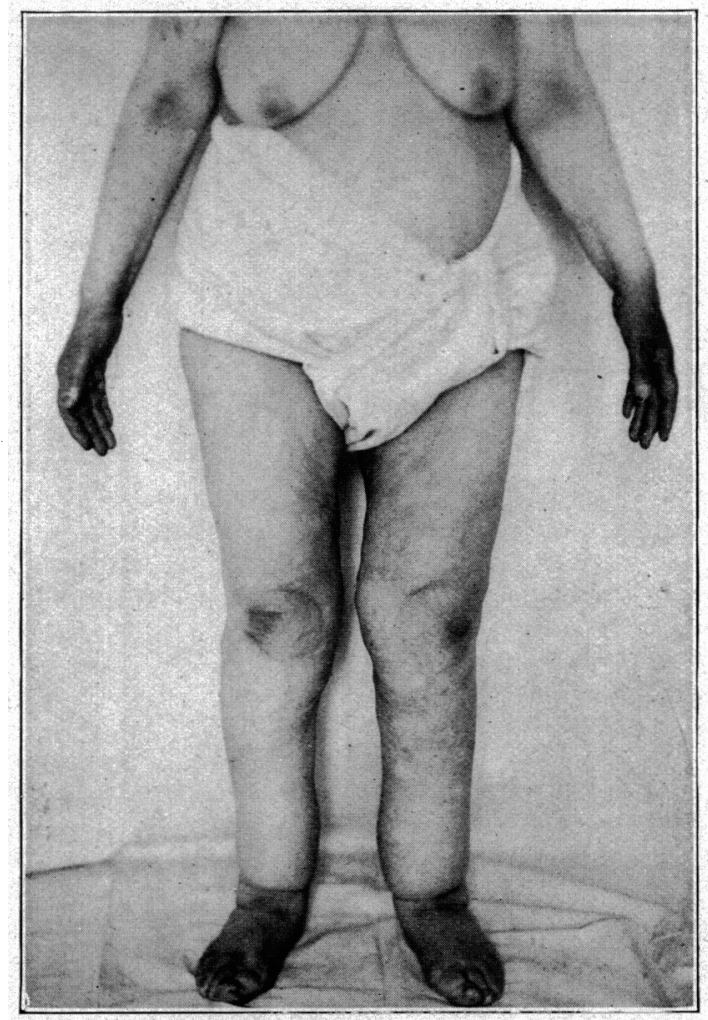

Fig. 11.-Patient 7, presenting three of the four cardinal symptoms of Dercum's syndrome, elephantiac form.

Patient.-Mrs. McC., aged 69; born in Ireland; height 5 feet; widow; two children; two miscarriages; admitted to the Buffalo State Hospital, 1898 (Hos. pital No. 6400,) still confined. Diagnosis: dementia, adiposity.

Family History.-Negative.

Personal History.-Menopause at 42, followed in about two years by beginning adiposity involving especially the lower legs; weight before menopause, 149 pounds; weight at 59 years 213 pounds. The flesh has never been painful or ten- 
der on pressure. The hospital history contains notes on several oceasions of rheumatoid pains of a dull, aching character in the knees, thighs, hands and arms; also slight "cramps" in the thighs have been complained of at times; occasional severe headaches for many years; no swelling of joints or signs of arthritis. General weakness, varying in degree, usually slight, since the development of the adiposity. Mentality has been impaired for at least eleven years; the patient was committed for acute mania in 1898, since which she has become rather dull and stupid. No history of hemorrhages; perspiration has always been normal. The hospital record contains the following note: "The legs at first sight suggest elephantiasis, but on closer examination little support for this idea is obtainable." Patient denies ever having had milk-leg.

Present Condition.-On July 22, 1909, when I examined the patient, her condition was as follows: The adiposity involved chiefly the legs, to a less degree the thighs, and only slightly the abdomen; fat-bags in the upper arms, hanging like a pouch when the arms were lifted, and on palpation feeling like a "bundle of worms" (Dercum); the abnormal fat was everywhere somewhat irregular, lobulated or slightly lumpy, without distinct separate lipomas. Firm pressure elicited no evilence of pain or tenderness. The skin was soft, flabby and wrinkled, apparently from loss of flesh; occasional small pigmented patches over the skin, especially of the arms; considerable capillary dilatation with resulting blueness of the skin over the abnormal fat deposits, especially in the lower legs; no varicose ulcerations or scars; no edema; double flat-foot. Moderate asthenia. Thyroid felt small. Heart showed no significant changes. Radial arteries not specially thickened, pulse pressure felt normal. The eyes showed slight nystagmus; sight good. Crinalyses, negative.

For permission to report this case I am indebted to Dr. Arthur W. Hurd, for the illustration, to Dr. John L. Eckel and Mr. Dustin.

CASE 8.-Summary-Atypical case suggesting Dercum's syndrome without adiposity. Woman, 34; no abnormal adiposity; for ten years diffuse tenderness and soreness of flesh, gradually increasing; also spontaneous, more or less constant, dull aching pains throughout both arms and legs, especially on the left side; paroxysms of general pains and cramp-like pains in various parts of body; accompanying fatigue and moderate asthenia; nervous mentality; hemorrhagic chorioiditis: lierpes zoster.

l'atient.-Mrs. X. A. M.. aged 34, born in Lnited States; married; no children: no misearriages: medium height; weight 146 pounds; referred by Dr. Grover W. Wende. Dec. 31, 1908, for complaint of pains.

Family History.-Mother is obese and "rheumatic."

l'ersonal History.-The patient has had several attacks of tonsillitis; never had inflammatory rheumatism or swollen joints; double hemorrhagic chorioiditis at 20; herpes zoster in the right lumbar region at 32 ; menses began at 11 , have always been scanty and irregular; no children, no miscarriages. About ten years ago the patient began to have aching pains all over the body and the flesh became sore and painful on pressure; the aching pains were more marked in the legs and arms and especially on the left side. The general soreness and aching at times became more acute and cramp-like pains were felt in different parts of the body. Extreme heat and cold aggravate the pains and depress the patient's vitality, requiring her to go south or north according to the weather. The pains have tended to grow worse since they started about ten years ago. During the same time she has grown nervous and irritable and has lost strength so that she tires easily.

Physical Examination.-A plump woman with well-developed panniculus adiposis, not obese, and with no localized deposits of fat. The flesh is everywhere abnormally painful to pressure, not more so over the course of the larger nerves 
than elsewhere; the breasts are specially sensitive. IIer mentality is neurasthenic; muscular power somewhat deficient. Jeart normal; radia] arteries not thickened: pulse-pressure normal; blood examination negative. Ablominal organs negative. Thyroid gland not appreciably changed. Tonsils enlarged. No edema. General refiexes and pupillary reflexes normal, Romberg's sign absent, ye examination negative, no evidence of luetic taint. Lrinalysis shows indicanuria and oxaluria. Permission to photograph refused.

CAse 9.-Summary-Atypical case suggesting Dereum's syndrome. Woman. aged 72 , moderate obesity, moderate tenderness of fat, slight asthenia, normal mentality, chronic arthritis, attacks of sciatica. Distinct improvement of all symptoms from thyroid medication.

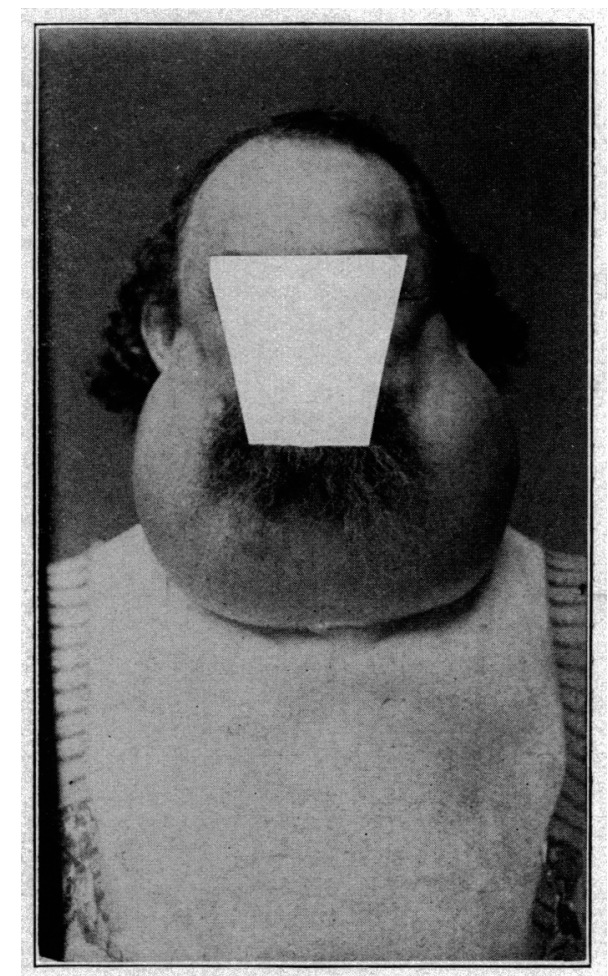

liig. 12.-Patient 10; typical "fatneck" or symmetrical diffuse lipomatosis of the neck.

Patient.-Mrs. G., aged 72, born in Lnited States, widow, several children, medium height, weight 180 pounds, seen in eonsultation with Dr. Frederick J. Parmenter, Dec. 7, 1909.

Family History.-Negative, except that mother had "reformed finger-joints."

Personal History.-Menses always normal; menopause at 50, without marked sequelie. From the age of 35 she gradually grew stout. the weight roaching a maximum of 180 pounds at about 60 , since when jt las not increased. From the 
age of 35 the subcutaneous fat has been more or less distinctly tender to pressure. never in a marked degree and no more so now than after the first appearance of this peculiarity. During the past ten years the patient has suffered on several occasions from pain and swelling of the ankle and knee joints, without fever, and from chronic pain and stiffness in these joints, resulting in considerable incapacity in walking. During the past ten years there have been also several mild attacks of sciatica.

I'resent Condition.-The patient is moderately obese, and everrwhere the flesh is abnormally sensitive to pressure, especially in the thighs and legs, but this tenderness is nowhere excessive. Perspiration and the texture of the skin are normal. The thyroid gland is doubtfully pajpable. Manipulation of the knee-joints causes pain and there is some swelling about them. Asthenia is evident, but not more than could be explained by the incapacity produced by the chronic arthritis. The mentality is normal.

Postscript.-Desiccated thyroid in small doses was taken from Dec. 8, 1909. to the present time, Jan. 28, 1910. The articular pain and swelling began to lessen soon after the treatment was begun, and the improvement has been progressive. At present there is no swelling and only slight pain and stiffness in the affected joints. There have occurred some loss of weight and Iessening of tenderness in the fatty tissue. Dr. Parmenter states that the patient's condition is greatly improved in all respects.

(Ass: 10.-\$ummary.-Typical cake of "fatneck" or symmetrical diffuse lipomatosis of the neck (Fig. 12) ; symptomless except for chronic "rheumatism" and sciatica dating from the beginning of the fatneck: operation attempted and abandoned.

Patient.-Mr. II., born in Germany: marrjed: several children: short, not obese; plotographed in 1893 ; died in 1902 , aged $\vec{t} 1$ rears.

f'umily Ilistory-Negative.

I'ersonal History.-When a boy the patient fell into al well and was dragged out by his hair, to which he attributed the subsequent development of fatneck. IIe drank beer freely, as was the custom among Germans. At the age of 40 , sym. metrical fatty masses appenred behind the ears and gradually oxtended until they finally encircled the entire neck in a huge collar of fat, presenting in front beneath the chin as a large unsightly mass and extending downward behind so as to form a hump over the upper part of the back at the base of the neck. The growth was gradual and uninterrupted from its first appearance at forty to the time of death at seventy-one. There were never any sudden fluctuations in its size and it was never painful nor tender. Its removal was undertaken in 1888 by Dr. Ernest Wende but was abandoned because of its diffuse character. There were no other fatty masses on the body. The patient was short and thick-set but not obese, though the immense projection from the neck and the low stature gave the impression of a rather stont man. From the age of 40 . when the fatneck first began, he was subject to "rheumatism" and sciatica and during the rest of his life suffered much from frequent attacks of pain and swelling in lis feet and ankles and of pain in both seiatic nerves. With these attacks he never had fever. Otherwise he was a strong well man, never asthenie or nervous. Tle died at 71 years of age with edema of the Jungs.

The history and photograph are furnished iny Dr. Grover WV. Wende and members of the patient's family. Ho was known to me only as a familiar example of street pathology.

CASE 11.-Dummary.-Symmotrical diffuse lipomatosis: type "fatneck" (Figs. 13, 14, 15): unusual distribution: tenderness: asthenia; deficient mentality: chronic sciatica; "rheumatism;" hemorrlages: anidrosis; dýsmenorrhea. Hís- 
tory of same condition in two of patient's sisters, beginning in all at the same time, at puberty, and reaching full development before maturity; one of these sisters insane; one brother and one sister have chronic "rheumatism;" one brother has chronic sciatica, and one brother is obese.

Patient.-Miss A. D., aged 33: born in Lnited States of Irish parentage; height 5 feet 2 inches; weight 130 pounds; was admitted to the Buffalo General Jospital (Hospital No. 43,473) June 13, 1903, in the service of Dr. Henry R. Hopkins, complaining of "rheumatism;" photographed Aug. 1, 1903.

Family History.-The patient's father is alcoholic; her mother is somewhat nervous; both strong and well. One brother has been crippled with chronic "rheumatism" for thirty years; one sister has lad chronic "rheumatism" in the knees for seven years; another brother has had frequent attacks of sciatica on both sides for ten years; and another brother is obese. Another sister, who died in childbed at 31 , had a fatty mass in the throat nearly as large as that of the patient, large masses behind the ears. smaller masses in the parotid regions, a large roll of fat over each shoulder, and a large hump between the shoulders. Another sister, aged 26. has a similar fatty mass in the throat. about half the size of that of the patient, also moderate fatty deposits over both shoulders and also in the upper arms. This sister has had delusions and melancholia for three vears. In both of these sisters, as in herself, these fatty masses first appearnd at puberty, with or just after the establishment of the menses. and reached their full growth before maturity, at the age of about 18 to 20 . Neither sister has ben asthenic, alcoholic; has ever suffered pain or tenderness in the fatty masses, or noticed fluctuations in the size of the masses.

Personal History.-The menses began at 14 . were at first irregular, scanty and painful; for the past ten years lave been regular, scanty and painful. The fatty masses made their first appearance at 15. gradually grew. reached their maximum size at about 20, and since then have tended to diminish somewhat. They have never fluctuated in size. They appeared simultaneously in the different locations. During their active growth she "felt tired and dead all the time." Since about one year after the masses first appeared she has always bern subject to frequent attacks of sciatica, occurring at intervals varying from one week to three months. Damp weather, getting the feet wet. hard work and fatigue seem to predispose to these attacks. For the past three months she has had "rheumatism" in her knces, legs and ankles. with pain and swelling of the joints, slight fever at the onset. and painful lumps in the skin near the knees. She has been moderately asthenic since the fatty masses first appeared, easily tiring and able to do only light work. At school as a child she was dull and always behind other children of her own age in her studies. For years she has been subject to frequent epistaxis and blecding from the gums. She does not sweat even in lot weather. She has dyspnea on slight exertion. The fatty deposits have never ached or pained spontaneously but have always been somewhat tender on pressure. She says that this sensitiveness in the fatty masses has been such that she could never stand the pressure of any one leaning on her shoulders. She has never taken alcohol in any form and denies all symptoms of syphilis.

Physical Examination.-The photographs make a detailed description of the fatty masses superfluous. The circumference of the neck orer the mass is $21 \frac{1}{2}$ inches. The dependent breasts measure 8 inches in their vertical diameter. The symmetrical folds covering the back measure verticalyy from above downward 5 , 6 and 4 inches respectively. The consistency of the masses surrounding the neek varies from semicystic behind the ears to rather firm in the dependent portion in front. Embedded in the mass in front. two firm, discrete, hickory-nut-sized, movable nodules can be felt, one in the median line an inch below the chin, the other just to the right of this. The overlying skin is not adherent except in front 


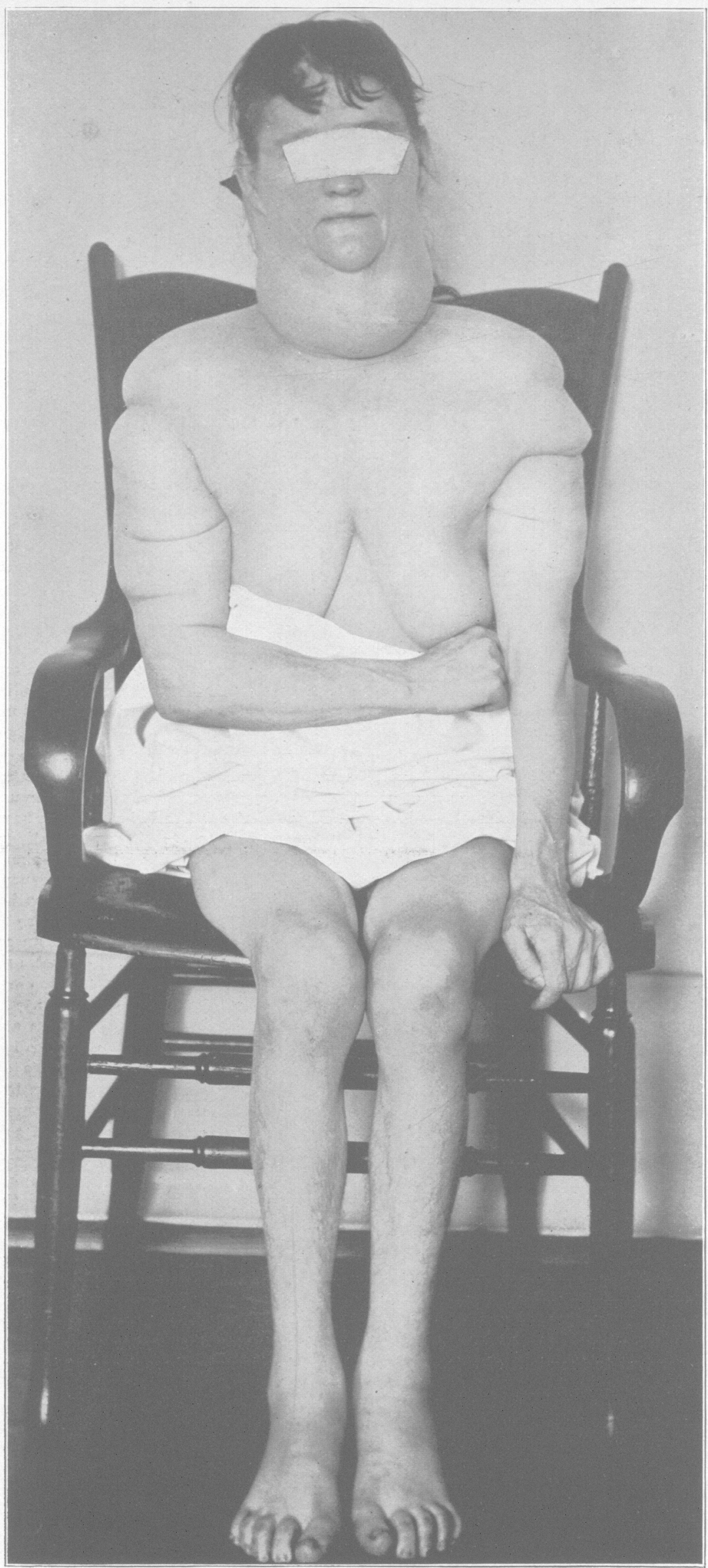

Downloaded From: by a University of Chicago Libraries User on 04/12/2018use linomatosis tyne "fatnect " " 


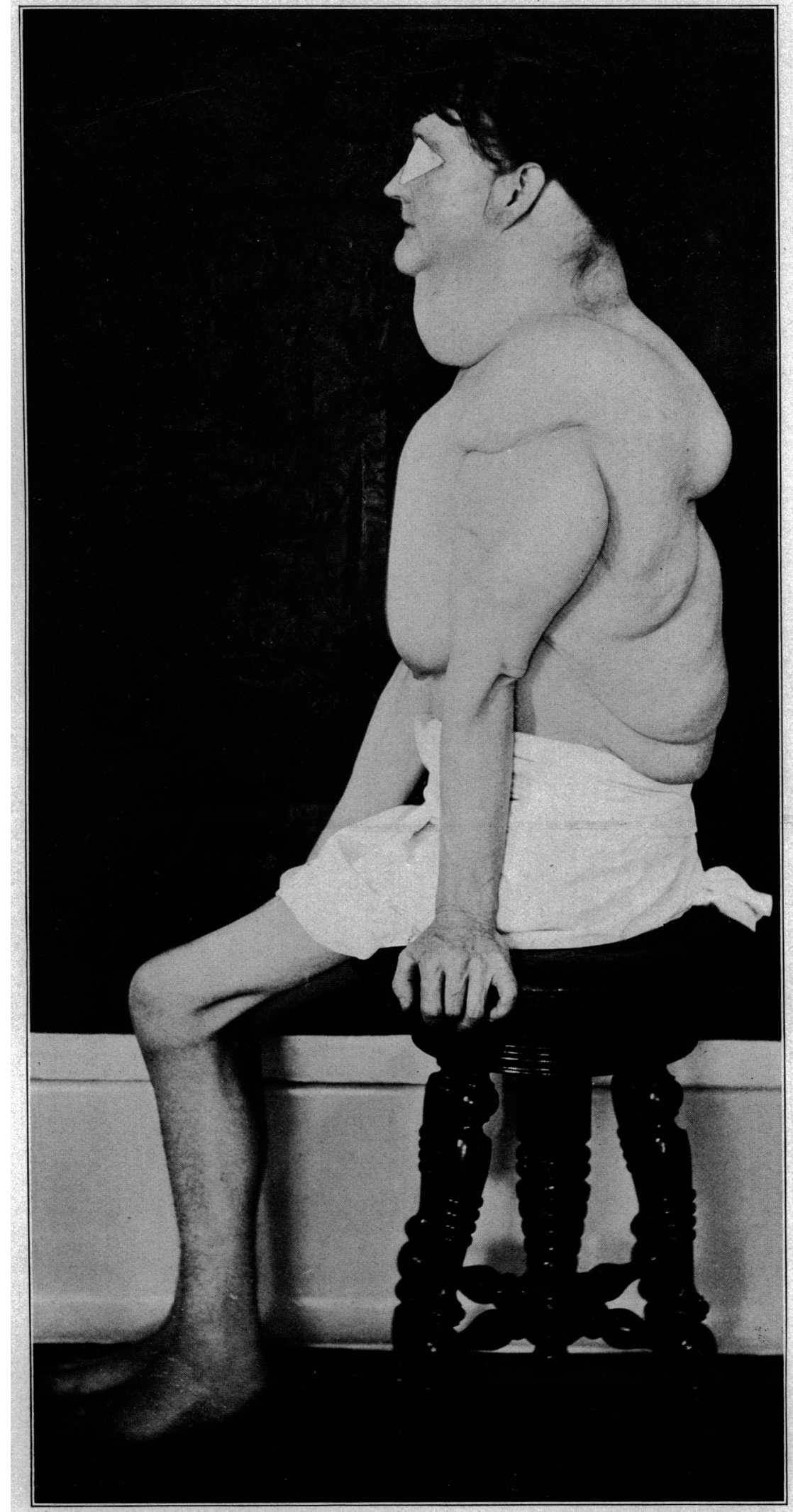

Fig. 14.-Patient 11; side view, showing unusual distribution of fattr masses. 


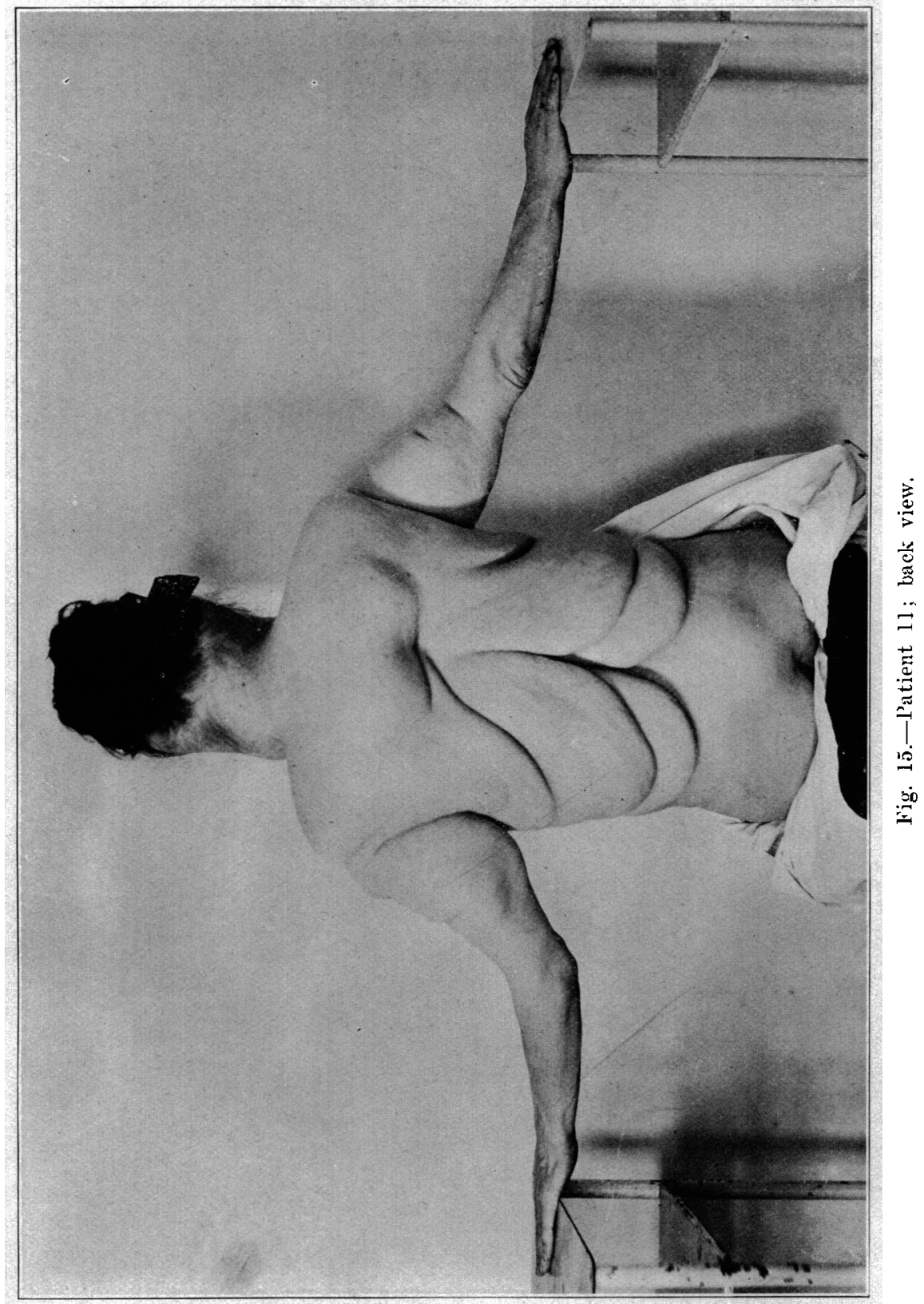


over the dependent portion. The breasts in their lower portion feel rather firm. The liump between the shoulders is soft and elastic. The folds on the back are soft and flabby. The skin over them is somewhat adherent. The fat-bags dependent from the upper" arms are flabby and feel like a "bundle of worms" (Dercum). There is no pitting on firm pressure anywhere in the several masses. The point of the chin is prominent, caused by an elastic, firm, fatty deposit. The masses are generally tender on moderate pressure, distinctly more so than the rest of the body or than would be expected in a normal person. The general muscular power is deficient. The mentality is clear but deficient and imperfectly developed for a person of her station. The general physical examination, including heart. lungs, abdominal organs, reflexes, sensations, organs of special sense, etc., reveals no abnormality. The thyroid gland cannot be felt.

Treatment.-Thyroid was administered for nore than two months without any apparent benefit or effect on the fatty masses.

Subsequent History.-Writing May 19, 1909, almost six years since I saw her. the patient said: "Well, I can't see as there is any change in the lumps, but other ways I feel pretty well; my rheumaties bothers me some but 1 am not lame. My sister is dead." The sister referred to is the one who was insane and with fatty masses.

CASE 12.-SUmmary.-Diffuse symmetrical lipomatosis; slight tenderness; fatigue; no mental sympton!s; several attacks of neuralgia and neuritis.

I'atient.-Mrs. J. R., aged 40: born in ('anała; married; one child: no miscarriages; tall; weight 160 pounds; consulted me June 22, 1906, complaining of "lumps in legs."

Personal History.-At 25 neuralgia in right side of neck and hack of aar. At 35. pain and soreness of both Achilles tendons, morc marked on right side. At 36. neuritis of right arm, lasting two months. Fatty lumps appeared on the inner aspect of both knees ten years ago, on the right hip seven years ago. and below both external malleoli about a year and a laalf ago. On account of the increase in size of the lumps on the ankles the patient now consults me. These deposits have never pained spontaneously but lave been subject to "soreness" on pressure. The patient has always been strong. No history of inflammatory rheumatisn. She has one child $t$ years old; no miscarriages.

Physical Examination.-A large well-built woman, with a well-developed pannieulus adiposis, not obese. Below each external malleolus there is a soft, diffuse pal of fat, about the size of half a hen's egg. On the inner aspert of the legs, at the knees, similar larger deposits of fat are found. and on the right buttock there is a single diffuse fatty mass about the size of half an orange. These masses are not circumseribed and appear to fuse with the surrounding fat. They are all slightly but definitely painful on pressure. Equal pressure exerted elsewhere over the body is not painful. Museular power normal, mentality normal.

Subsequent History.-The patient consulted me asain on June 15. 1907. since which I have not seen her. She was then suffering with an attack of sciatica on the left side, which she had had for a month. The fatty masses were of the same size as a year before but were entirely painless on firm pressure. The only additional information of interest obtained was the statement that she was always tired, wanted to sleep all the time, never waked refreshed and was not as strong as she used to be.

CAse 13.-Summary.-Multiple encapsulated lipomata, symptomless.

Patient.-T. M. W. aged 30: born in Inited States; single: a medical stu. dent; height 5 feet 10 inches; weight 160 pounds; was referred to me by Dr. Grover W. Wende, April 26, 1909 . He was a strong healthy young man, without nervousness, with a good family history, whose only complaint was the develop- 
ment during the past two years of small lipomas in the left forearm and left thighl. They had never been painful, could be firmly pressed with impunity, and were increasing in size and number. They were firm, discrete, lobulated, varying in size from a pea to a cherry, situated as follows: four on the flexor surface of the left forearm, radial side, arranged longitulinally over a distance of six inches, one on the back of the left forearm on the radial side and one on the front of the left thigh. No history of rheumatism, neuralgia, neuritis, or other symptoms.

SASE 14.-Summary.-Solitary lipoma, painless, symptomless except for "rheumatism." Recurrence after complete excision. Son had multiple, partly symmetrical, encapsulated lipomas and is "rheumatic."

Patient.-Dr. H. H., aged 52; born in United States; married; several children; height 5 feet 10 inches; weight 200 pounds; had a solitary Jipoma, lemonsized, excised from the posterior inner aspect of the left thigh by 1)r. Fugene $A$. Smith, in 1887. After about three years a similar tumor appeared at the same site and enlarged until it reached its maximum size in 1905 . It is now (April 30,1909 ), on examination, found to be soft, lobulated, sharply defined, and about the size of a small orange. It is not painful or tender on firm pressure and never has been. The patient is a strong man, with a normal mentality and has had no symptoms except atypical articular "rheumatism," from which he has suffered on several occasions. His son (Case 15) is also "rheumatic" and has multiple, partly symmetrical, painless lipomas.

CASE 15.-Summary.-Multiple, partly symmetrical, encapsulated painless lipomas, symptomless, except for "rheumatism." Father has a solitary lipoma.

Patient.-H. W. H., aged 26; borm in United States; married; one child; height, 5 feet 10 inches, weight 200 pounds; presents lipomas distributed as follows: seven on the front and inner aspect of the right thigh, two on the front of the left thigh, one in the left popliteal space, one on the back of each forearm, and one on the back. 'They are all firm, encapsulated, lobulated, painless to pressure, and vary in size from a pea to a large walnut. They have never been painful or tender. The patient says that they tend definitely to increase in size when he is quiet and inactive and to diminish in size with hard work. He is strong, has a normal mentality and is not nervous. He had an attack of "rheumatism" (pain) in the right knee two years ago, lasting a few days. The lipomas have been increasing in number and in size for about twelve years. His father (Case 14) has a solitary, painless lipoma and is subject to "rheumatism."

CASE 16.-Summary-Multiple, symmetrical, nodular lipomatosis, hereditary (Fig. 16). Each new growth preceded by local burning pain, followed in a few days by black-and-blue discoloration and then by the appearance of the tumor. No asthenia or mental symptoms. Inflammatory rheumatism, neuralgia, phlebitis of the left saphenous vein. Rheumatic family history.

latient.-H. B. M., aged 49, single; born in Canada; height 6 feet; weight 189 pounds; referred by Dr. Joseph S. Lewis, Sept. 21, 1909.

Family History.-His father had the same condition of symmetrical fatty tumors with the same distribution in the forearm. These tumors were symptomless so far as patient knows, as he never heard his father complain about them. He weighed for over thirty years before his death 257 pounds and died at the age of 85. Other members of his father's family were stout. Two brothers and one sister of the patient have had inflammatory rheumatism, the sister several times.

Iersonal History. - The fatty tumors began at the age of 18 in the left forearm and thereafter appeared successively during the next twenty years in the different locations, tending to increase in size even up to the present time. In every instance each new tumor was preceded by burning or stinging local pain lasting a few days and followed by the appearance of a small tumor and a black-and-b]ue 
discoloration over it. This discoloration soon faded and disappeared. Otherwise the tumors have never been painful or tender. He attributes each of the tumors to some kind of preceding traumatism, such as strain from jumping or moving a piano. He had severe inflammatory rheumatism involving many joints at the ages of 14,16 and 35 , and severe neuralgia of the face and neck at the age of 20 , lasting two months, and slight attacks on several other occasions. He has noticed varicose veins in the left thigh for a few months and about two months ago had phlebitis of the left saphenous vein, while under the care of Dr. Joseph S. Lewis.

Present Condition.- $\mathrm{He}$ is a strong, athletic, well-museled man, of good color and normal mentality. The fatty tumors are distributed somewhat symmetrically in both forearms, arms, thighs and back in lumbar region. They vary in size from a bean to a large hen's egg, forming conspicuous deformities especially on the forearms. They are lobulated, circumscribed, typical lipomata. Firm pressure causes no pain. He perspires normally and has no other stmptoms of note. Photographed Feb. 17, 1910 .

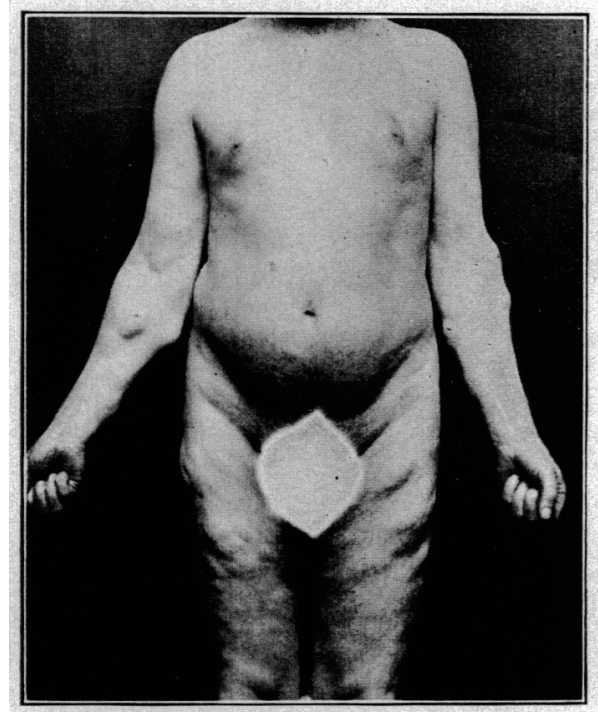

Fig. 16.-Patient 16; multiple symmetrical nodular lipomatosis, hereditary.

Treatment.-He was plaeed on desiccated thyroid from Sept. 21, 1909, to Feb. 17 , 1910 , with periods of interruption, without any notable effects except a gain in weight from 189 to 202 pounds.

CASE 17.-Summary-Multiple, symmetrical, nodular lipomatosis, painless and symptomless except for "rleumatism" and lumbago (Fig. 17).

Patient.-I. A., aged 48, born in Lnited States; married; several children: medium height; weight 160 pounds; seen in the service of Dr. Charles Cary, Buffalo General Hospital (Hospital No. 58,397), to which he was admitted in Decem. ber, 1908, suffering with lumbago.

Family History.-Negative.

Personal History.-No history of traumatism; uses beer and whisky usually moderately, sometimes to excess; has always been strong; chancre at 25 , without any sequelæ; gonorrhea at 27 and 28 ; at 17 had "rheumatism" with pain in legs 
and arms and stiffness and soreness of joints, without fever or swelling; later had attacks of pain and stiffness in the left shoulder; at 40 had two attacks of lumbago; during the past six weeks has been suffering with lumbago. The fatty tumors began to appear when he was about 10 years old, first in the region of the groins, then over abdomen, chest, arms, legs, etc., multiplying and increasing in size until he was about twenty years old. During the past seven years they have reduced in size considerably and some, the patient thinks, have disappeared. Only once, in his early life, was there ever any pain felt in these tumors, and then only slightly in a single tumor in the abdominal wall when it was first appearing.

Physical Examination.-A strongly built, well-museled, powerful man, with no superfluous panniculus. Numerous, smal], subeutaneous lumps are seen and felt widely distributed over the forearms (front and back), arms (back), thorax (front), abdomen (front and sides), and thighs (front and sides). The face, neck, hands, shoulders, upper part of the back, feet and legs below the knees are spared. The distribution of the lumps is strikingly symmetrical. The lumps

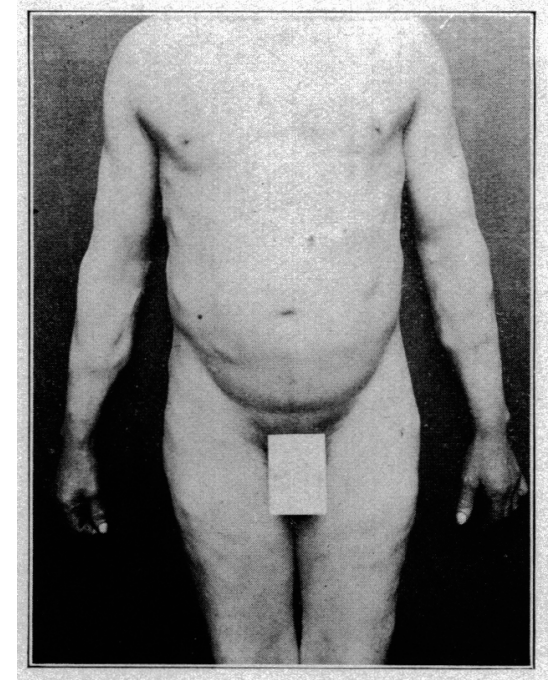

Fig. 17.-Patient 17; multiple, symmetrical, nodular lipomatosis.

vary from the size of a small seed to that of a butternut. They are firm, lobulated, somewhat flattened, round or oval, not adherent to the superjacent skin, and freely and equally movable longitudinally and laterally. In some places they appear in chains, corresponding to the course of nerves. They are painless on firm pressure. The photographs were taken April 18, 1909. The thyroid gland feels rather full and firm, but not notably so. A careful general physical exam. ination otherwise reveals no abnormality.

CASE 18.-Summary.-Multiple, symmetrical, nodular, painful lipomatosis (Fig. 18); no asthenia ; slight nervousness; recurrence after excisions; onset of each new growth announced by preeding local pain, tenderness and blueness. Mieroscopic examination of smallest tumor shows a small nerve within the growth.

Patient.-Mrs. E. M. E., aged 42; born in United States; height 5 feet 8 inches; weight $1 \overline{5} \overline{5}$ pounds; married; three children; no miscarriages, referred 
April 17, l!n!, by Dr. Cirover W. Wonde for painful fatty tumors; photographed April 18, ]909.

Family History.-Negative for obesity, tumors, insanity, nervous diseases, alcoholism, etc.

I'ersonal History.-Menses began at 15 , always normal; three children, no miscarriages; no history of syphilis, alcoholism or rheumatism; occasional headaches; has always been strong, works hard and is not easily fatigued; las always been somewhat nervous, excitable and easily worried. The tumors first appen red in both forearms when the patient was 25 , and were all excised three yoars later by Jr. Grover W. Wende. Within a year new tumors appeared, some directly under the scars of the previous incisions and others at new points, all being located in the forearms except one in the left axilla. When the patient was $3 \tilde{5}$ all the tumors, about fifteen, were again removed by Dr. Wende. The largest tumor was about three inches in diameter and all, according to the statement of 1)r. Wende, were typical encapsulated lipomata. Since the second removal new tumors have appeared, as before, in the sites of the excised growths and elsewhere. In every instance the growth of a new tumor has been announced by preceding

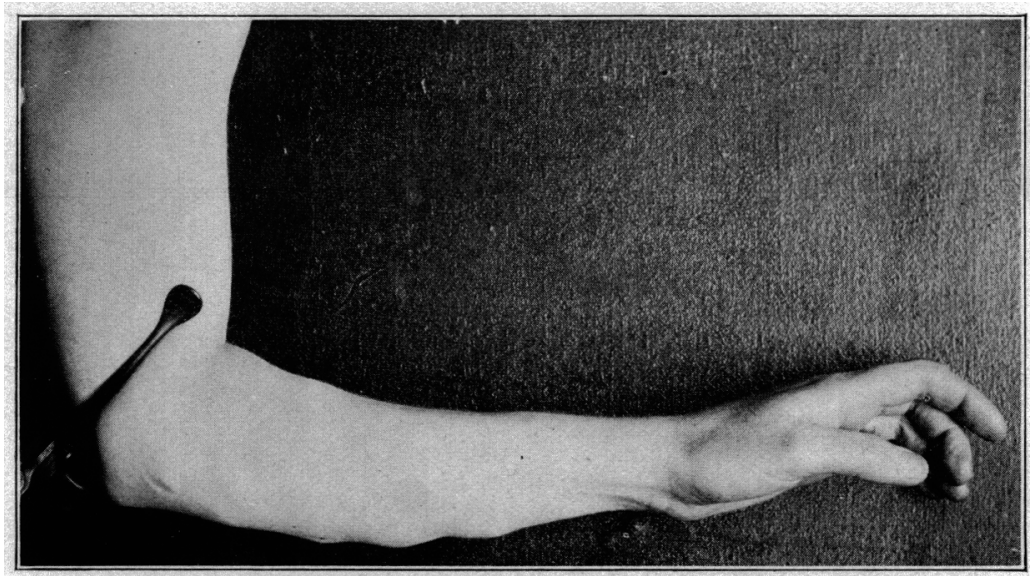

Fig. 18.-Patient 18; multiple, symmetrical, nodular, painful lipomatosis.

local pain. On examination a small blue area, painful to pressure, is found, and within a week or two a small shotty nodule can be felt under the skin. The spontaneous pain usually disappears soon after the nodule is felt but tenderness on pressure continues. The area of blueness sometimes enlarges and remains with the growth of the tumor, sometimes disappears. Spontaneous aching pain in the tumors and shooting pains in the arms are sometimes excited by using the arms as in washing and ironing, but are always relieved by a night's rest. No sudden fluctuation in the size of the tumors has ever been noticed.

Physical Examination.-The patient is a tall, sparely built woman, weighing 155 pounds, with a normal panniculus. She has a good color and looks strong and well. Ifer expression and manner suggest a nervous temperament. The muscular power is normal. Heart, lungs and abdominal organs normal. Radial pulse normal, blood-pressure not increased. Thyroid gland normal. Knee-jerks somewhat exaggerated. Pupils moderately dilated, equal, react to light and accommodation. Fine varicosities on both thighs and legs. A soft, lobulated fibroma molluseum, about an inch and a half long, attached by a narrow peduncle, 


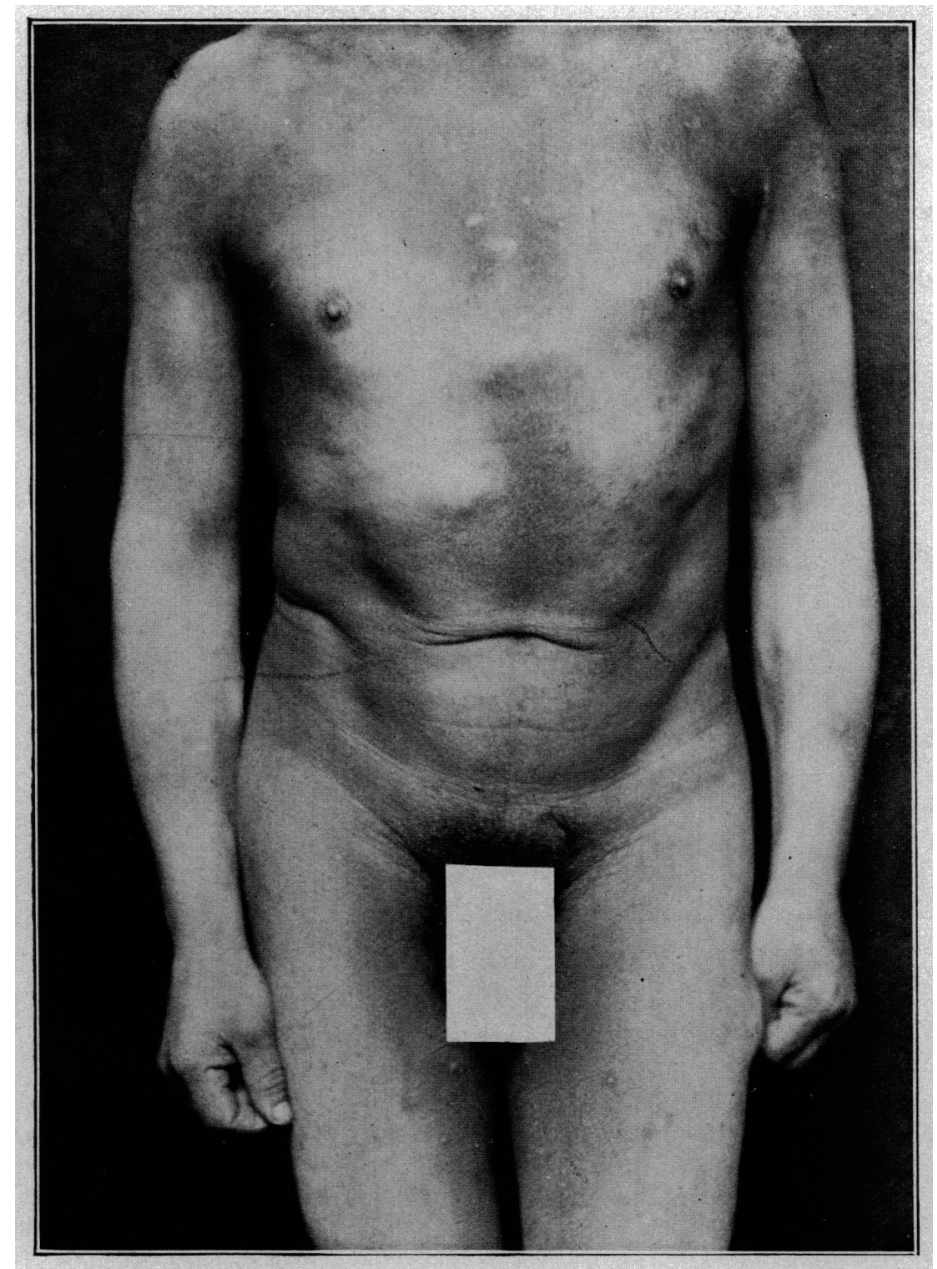

Fig. 19.-Patient 20; multiple, symmetrical, encapsulated lipomatosis. 
is found in the right axilla. Urinalysis negative. Fifteen tumors are found located as follows: eight in the left forearm, front and back, four in the right, forearm, front and back, two in the right arnt just above the elbow, and one in the back of the right thigh, just below the gluteal fold. They vary from the size of a buckshot to a walnut, are round or oval, subcutaneous, not adherent to the skin, freely movable in all directions, circumscribed, firm, slightly lobulated. A few of these tumors are situated exactly beneath small linear scars. The tumors in the forearms are not entirely symmetrical in arrangement and number, but in general a considerable degree of symmetry is clearly indicated. The distribution tends to be longitudinal in the axis of the arms, thereby suggesting a relation to the course of nerves. At a glance the forearms appear nodular or lumpy. The smallest tumors are indicated by a distinct blueness, evidently caused by congestion beneath the skin; a slighter grade of blueness is seen over some of the larger tumors but is entirely absent over the largest lumps. The smallest tumors (blue) are very painful to pressure; the largest tumor is so sensitive that it can hardly be touched without eausing pain, although it is entirely free from any blueness; a few of the medium-sized tumors are not at all tender. There is no tenderness in the general subcutaneous fat and the larger nerve-trunks are not sensitive. The smallest tumor that could be found (duration six weeks), distinctly blue in color and tender, was excised from the arm, April 18, 1909, and examined microscopically. It was not larger than the head of a match. It was found to be an encapsulated lobulated lipoma. A small nerve bundle was found in its center within a connective-tissue septum. The axis cylinders stained poorly, were shrunken, and the connective-tissue nuclei were increased in number above what might be expected in so small a nerve bundle, giving the impression of an interstitial neuritis.

CASE 19.-Summary.-Painful solitary lipoma, chronic rheumatoid pains. Microscopic examination: no nerve fibers.

Patient.-Dr. T., aged 24; height 5 feet 6 inches; weight 158 pounds; born in Canada; seen April 18, 1909.

Family History.-Both parents are somewhat stout and father has had chronic "rheumatism."

Personal History.-For five years has had rheumatoid pains near the joints, especially the right hip and right shoulder, occurring irregularly in attacks, without swelling, redness or fever. About one year ago some local pain directed his attention to a small subcutaneous nodule located in the right forearm, which has since increased in size. This nodule has always been tender on pressure and in addition at times aching pain has radiated from it through the forearm. A similar nodule may perhaps be developing in the front of the right thigh, indicated by a point of pain and a doubtful induration felt on palpation. He is otherwise in all respects well and normal.

Examination of the Tumor.-The nodule in the right forearm was excised by Dr. Grover W. Wende, July 28, 1909. It was about the size of a pea, encapsulated, lobulated, was readily shelled out and had the gross appearance of a simple lipoma. On microscopic examination it was found to be a definite lipoma, invaded by considerable diffuse connective tissue. No nerve elements could be found in the sections.

CASE 20.-Summary.-Multiple, symmetrical, encapsulated, painless lipomata (Fig. 19) ; dementia ; asthenia; chronic "rheumatism."

I was invited during the early part of this year (1909) by Dr. Grover W. Wende to see this case but missed the opportunity. The history is furnished by Dr. Wende, briefly as follows: A peddler, about 50 to 60 years of age, was admitted to the 
Erie County Hospital for pediculosis, general feebleness and chronic "rheumatism." There was a mild dementia. He was well nourished, not obese, and exhibited multiple, symmetrical, small lipomata in the forearms, back, abdomen and thighs. They were not tender to firm pressure and the patient said they had never troubled him. The general pigmentation is due to pediculosis.

CONSIDERATION OF THE SPECIAL VARIETIES OR CLINICAL GROUPS OF ABNORMAL FAT DEPOSIT

GROUP I : "ADIPOSIS DOLOROSA," DERCUM'S DISEASE

Since Dereum, ${ }^{43}$ in 1892 , first proposed the name "adiposis dolorosa," this designation has become generally adopted in medical literature, and the syndrome thus named has been widely accepted as representing a new and distinct morbid entity.

The affection is described in the text-books as a well-defined condition presenting characteristics that make its recognition easy. Little or nothing is said of the occurrence of atypical cases suggesting Dercum's syndrome, but varying from its classical form in different respects. After one has encountered several such atypical cases to one that conforms to the picture of the disease as described, one might reasonably be justified in questioning the propriety of raising the syndrome to the position of a true entity. One must either entertain this doubt or take the alternative of being unable to classify the majority of cases under any satisfactory nosological group.

Such a dilemma has confronted me on several occasions, and.I have repeatedly seen the diagnosis of adiposis dolorosa in atypical cases both affirmed and denied by equally competent clinicians.

It will be necessary to pass in review a description of adiposis dolorosa before undertaking to correlate with it the various forms of fat deposit associated with constitutional symptoms-the object of this paper.

Symptomatology.-The name, "adiposis dolorosa," proposed by Dercum, at once emphasizes the chief characteristics, pain and fat deposit or painful adiposity. To these two chief symptoms Vitaut ${ }^{192}$ added two others, asthenia and psychic manifestations, regarding all four as cardinal symptoms. To this view Dercum ${ }^{45}$ gave his qualified approval in the following language :

While fatty deposit and pain are the two most prominent symptoms of the disease, marked or even grave asthenia and psychic or general nervous symptoms were so prominent in all the cases which I have myself observed, that I am equally disposed to ascribe great importance to both of these last-mentioned symptoms.

Vitaut's classification has since become the one most generally adopted, as shown in the following outline: 


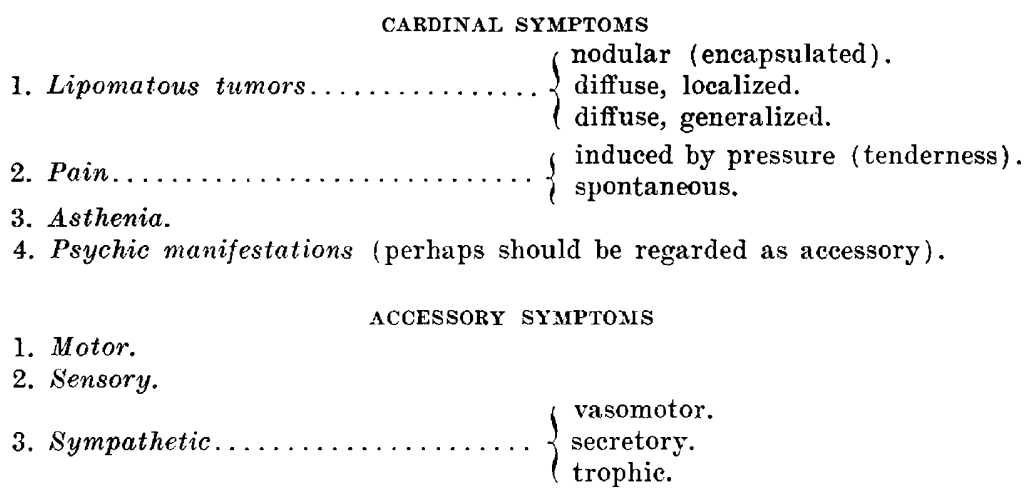

To show the comprehensiveness of this classification, I have collected, incompletely, a list of the symptoms mentioned in the cases reported in the literature, as follows:

Cardinal Symptoms.-Fat Deposit: Dercum emplasized the irregularity of distribution of the deposits and mentioned in particular their character in places as nodular, lobulated, resembling the caking of milkbreast, as though filled with a bundle of worms, like a varicocele, etc. These special characteristics, however, have not been constant in the case reports. The deposits of fat include almost every known variety, both in form and distribution. Diffuse deposits may involve a single small area or a portion or the greater extent of one extremity, or may be symmetrical or even almost universal, sparing usually the face, hands and feet. Even these locations have been invaded in rare instances. ${ }^{137}$, 179

On the other hand, the form of the deposit may be strictly nodular and encapsulated, single, multiple or symmetrical. The inclusion of this last-named variety within the embrace of adiposis dolorosa was apparently not contemplated by Dercum before the publication of Vitaut's thesis, and considerably enlarges and at the same time weakens the conception of the affection as an entity, as will presently be shown. Mixed forms of diffuse and nodular (encapsulated) deposits, in great variety, have been described.

Pain: This may be of two kinds, induced by pressure (i. e., tenderness) and spontaneous. The former, involving the abnormal fat deposit alone, is more or less constant, though varying in intensity in different cases and. in the same case from time to time and in different locations. The absence of this symptom in any given case would seem to exclude such a case from the classification of adiposis dolorosa, as an entity, a consideration that will be discussed below. The tenderness on pressure is often characterized by exacerbations, associated with and perhaps 
dependent on local changes of circulation, i. e., stasis, with increased firmness, tension, lobulation and size of the fat deposits and discoloration (redness or blueness) over the affected areas. Sometimes the tenderness is so slight as to be either not mentioned or even actually denied by the patient and discoverable only to the satisfaction of the examiner.

The second type of pain, spontaneous, is less constant and characteristic, exceptionally being entirely absent. Spontaneous pains are of every kind and description, occur often in paroxysms, are described variously as dull, aching, throbbing, burning, tearing, shooting, etc., and are referred commonly to the location of the fat deposits, sometimes to unrelated parts of the body. The very common pains in special nerves (sciatic, lumbar, cervicobrachial, tibial, peroneal, plantar, etc.), described as neuralgic or neuritic, and in joints, tendons and muscles, as arthritic, rheumatic, rheumatoid, cannot be differentiated from other forms of spontaneous pain and belong to the symptomatology of the affection. Rheumatism or neuritis is a very common diagnosis in the early stages. In some instances these pains precede the development of the fat deposit.

Asthenia: This, following Vitaut's classification, has generally been regarded as one of the cardinal symptoms in spite of its complete absence in some cases and its frequent insignificance in many more. It varies in degree from weariness, a tired feeling and readily induced fatigue to extreme muscular weakness with prostration. While in many instances it is explainable as secondary to the incapacity produced by fat deposits and pain, in other instances these factors are clearly insufficient to account for it.

Psychic Manifestations: While Vitaut placed psychic manifestations among the cardinal symptoms, he admitted that possibly they should be placed among the accessory symptoms. They are lacking more frequently than any of the cardinal symptoms. They include the whole range of mental changes, as follows: Irritability, quarrelsomeness, instability, modification of character, impairment of memory, insomnia, neurasthenia, hysteria, hypochondria, melancholia, hallucinations, delusions, stupor, coma, mania, attempts at suicide, imbecility and dementia.

Accessory Symptoms.-Motor Symptoms: In addition to asthenia, classed as a cardinal symptom, the motor symptoms include: tremor, twitchings, cramps, torticollis, epilepsy, impairment of locomotion, paralysis, slowness of speech, aphasia, changes of reflexes, i. e., increased, diminished, abolished.

Sensory Symptoms: In addition to pain, these include: anesthesia hyperesthesia, paresthesia, involving the senses of touch, pain. temperature and position. 
Sympathetic Symptoms: The symptoms arising from disturbances of the sympathetic nervous system are among the most constant and characteristic, embracing the vasomotor, secretory and trophic functions, as follows:

Vasomotor Symptoms: These include the widest range of symptoms of vasomotor instability, and are present in some degree and form in most of the cases. They include the following: poor circulation, dermatographia, urticaria, transitory or persistent edema and swellings or lumps, pallor of the skin, flushings and redness, local redness or blueness over the tumors, tendency to bruising of the flesh, varicosities, hemorrhages (epistaxis, hemoptysis, hematemesis, menorrhagia, purpura, bleeding from the tongue, retinal hemorrhage, etc.), icterus, syncope, tachycardia, palpitation, dyspnea, etc.

Secretory Symptoms: These are relatively unimportant, including chiefly anidrosis and hyperidrosis.

Trophic Symptoms: Besides the fat deposit, the following trophic changes have been described: desquamation, pigmentation, loss of hair, ulcerations, bedsores, blebs and bullæ, herpes zoster, scleroderma, macroglossia, anemia, goiter, exophthalmic goiter, muscular atrophy from neuritis, arthropathies and arthritism (including rheumatic or rheumatoid manifestations, arthritis deformans, Heberden's nodosities, etc.), osseous dystrophies.

In addition to the above-named symptoms, arranged according to Vitaut's classification, may be mentioned the following, arranged according to the organs involved:

Symptoms of the Genital Organs: Disturbances of menstruation (including irregularity, menorrhagia, amenorrhea, premature menopause), sterility, impotence, anaphrodisia, hypoplasia of the genital organs.

Symptoms of the Digestive Organs: Nausea, vomiting, epigastric distress, hyperchlorhydria.

Symptoms of the Organs of Special Sense: Eyes: contraction of the visual fields, hemorrhagic retinitis or chorioiditis, choked disc, blindness, exophthalmus, nystagmus, episcleritis. Ears: deafness, tinnitus. Odor and Taste: impairment.

It must not be understood that in the above formidable list of symptoms, all are referable to the pathology of the affection; many are so, others are probably accidental, arising from complications. 


\section{FAMILY HISTORY}

A neuropathic predisposition is commonly noted in the family history. Direct heredity $(a)$ in the transmission of the affection is denied by nearly all writers. Hammond $d^{80}$ has reported, as "adiposis dolorosa," the cases of two sisters presenting symmetrical painful lipomata in the arms.

\section{SEX AND AGE}

Females outnumber males about six or seven to one. Middle life, from 45 to 60 years of age, is the period of greatest incidence. At this period the affection has developed with or followed the climacteric in many instances in women. Exceptionally it has begun in childhood, as early as the eleventh and twelfth years (White, ${ }^{200}$ Strübingi79), or in old age as late as the eightieth year, as in Case 6 of this series.

\section{COURSE}

The onset is usually insidious and the development gradual. Exceptions are noted in case reports of rapid development. In many cases the progress is accentuated by exacerbations with increase in the size and consistency of the fat deposits and in the pains. Periods of remission are common. Death finally ensues from asthenia, cardiovascular-renal complications, intercurrent infections, etc.

\section{TREATMENT}

The treatment is chiefly symptomatic, including massage, hydrotherapy, electricity, $x$-ray, analgesics, sedatives, tonics, ete. In addition to such general agents, a specific therapy has been sought for in thyroid extract on the hypothesis that the affection is in some obscure way connected with perversion of the thyroid function. Thyroid extract has been tried in many of the reported cases, but without the specific effect that was hoped for. Only two instances of $\operatorname{cure}^{137,151}(b)$ from its use have been claimed. Improvement in varying degrees has been reported in many cases, indicated by reduction in the fat deposits, relief from the pains, improvement in the mental state and in the general condition. In many instances no appreciable benefit has been noted. No instance of treatment by pituitary extract has come to my attention.

(a) Chevers"2a case of symmetrical lipomatosis, reported as "adiposis dolorosa," in a man and his father and sister, is properly excluded in this connection as pain and other symptoms were lacking.

(b) Price, ${ }^{151}$ in a personal communication, states that Dercum's case mentioned by him was an unpublished case presented by Dercum in a clinical lecture. 


\section{PATHOLOGY}

Only nine autopsies have been recorded: three by Dercum, ${ }^{43,44}$ two by Price, ${ }^{151}$ and one each by Dercum and McCarthy, ${ }^{47}$ Burr, ${ }^{23}$ Ballet, ${ }^{8}$ and Guillain and Alquier. ${ }^{70}$ The more important findings were, as follows:

Subcutaneous Fat.-In three cases ${ }^{23,44,47}$ separate encapsulated lipomata embedded in the diffuse fat were noted. In one case ${ }^{23}$ the subcutaneous fat was invaded by much fibrous connective tissue. In two cases ${ }^{23,47,122}$ hemolymph nodes were found; in both in the subcutaneous fat and in one ${ }^{47}$ also in the separate lipomata embedded in the general fat. In both of these cases the spleen was more or less cirrhotic.

Interstitial Neuritis.-A condition of chronic interstitial neuritis involving the finer nerves of the painful fat deposit was found in five $3,23,44,47,151$ out of six cases in which a special examination was made; not looked for in three cases ${ }^{43,70}$ not mentioned in one case. ${ }^{151}$ Similar changes in the nerves of the underlying muscles were found in one case $\mathrm{e}^{21}$ and "some thickening of the endoneurium" of the radial nerve in one case. ${ }^{151}$

Thyroid Gland.-Changes in this gland were found in eight cases; in only one case ${ }^{47}$ was the gland perfectly normal by gross and microscopic examination. The principal changes described were: reduction ${ }^{43,44}$ or enlargement ${ }^{43,151}$ in the size of the gland in two cases each, sclerosis in seven cases, ${ }^{8,23,43,76,151}$ compensatory hypertrophy in three cases, ${ }^{44,151}$ colloid degeneration in three cases, ${ }^{23,44,76}$ calcareous degeneration in three cases, ${ }^{23,43}$ and inflammatory round-cell infiltration in two cases. ${ }^{23,}{ }^{251}$

Pituitary Body.-This was examined microscopically in six cases and changes were found in all except one, ${ }^{44}$ which was absolutely normal. The changes found were: adenocarcinoma in one case, ${ }^{47}$ glioma in one case, ${ }^{23}$ sclerosis and hypertrophy with increase of the eosinophilic and basophilic cells in one case, ${ }^{76}$ normal in size but showing microscopic areas of round-cell infiltration in the glandular lobe and invasion of the nervous lobe by glandular cells in two cases. ${ }^{151}$

Genital Organs.-Eight of the nine autopsies were in females. In five cases no mention was made of the condition of the genital organs. In two cases ${ }^{23}, 151$ the ovaries were sclerotic, and in a third case ${ }^{43}$ an ovarian cyst with hydrosalpinx was found. In the only male ${ }^{47}$ in the series the testicles were undeveloped and showed no evidence of functional activity; the penis was small and the hair on the pubis was scanty. 
Adrenal Glands.--In one case ${ }^{47}$ "the right suprarenal gland was about twice the normal size; it showed no abnormality on section"; the left gland could not be found in the surrounding fat. In one case ${ }^{151}$ mention was made of "no abnormalities, except certain irregularities in staining."

Hemolymph Glands.-See above, Subcutaneous Fat.

Spleen.- "Telangiectatic angioma" and "slight interstitial hyperplasia" were found in one case ${ }^{4 r}$ and cirrhosis in another case. ${ }^{23,122}$ In these two cases new-formed hemolymph glands were found in the subcutaneous fat, as above stated.

Kidneys.-Chronic nephritis was reported in five cases, ${ }^{43}, 44,151$ acute parenchymatous nephritis in two cases, ${ }^{23,47}$ and multiple cysts in one case. $^{44}$

Liver.-Fatty infiltration or degeneration was mentioned in six cases, ${ }^{8,23,43,47,151}$ congestion in one case, ${ }^{151}$ cirrhosis in two cases. ${ }^{8,44}$

Heart.-Fatty infiltration or degeneration was noted in six cases, ${ }^{43,44,47,151}$ hypertrophy in two cases, ${ }^{43,151}$ dilatation in one case, ${ }^{43}$ pericardial effusion in one case. ${ }^{43}$

Lungs.-Edema in four cases, ${ }^{23,43,44,153}$ emphysema in two cases, ${ }^{43,}{ }^{151}$ hypostatic congestion in one case, ${ }^{151}$ old pleural adhesions in two cases, ${ }^{44,151}$ pleural effusion in one case. ${ }^{43}$

Stomach.-Dilatation in one case, ${ }^{43}$ chronic gastritis in one case. ${ }^{43}$

Brain.-In addition to the changes in the pituitary body, the following changes were found: unusual pigmentation of the cortical cells in one case, ${ }^{44}$ edema of the brain and pia in one case, ${ }^{43}$ "anomalous arrangement of the cortical convolutions" in one case, ${ }^{47}$ internal hydrocephalus (associated with glioma of the pituitary body) in one case. ${ }^{23}$

Spinal Cord.-Slight degeneration of the columns of Goll in one case, ${ }^{44}$ considerable dorsal hydromyelia (secondary to internal hydrocephalus) in one case. ${ }^{23}$

\section{ETIOLOGY}

Of the etiology nothing definite is known. Various hypotheses have been advanced, but all lack the substantial basis of demonstration grounded on a known pathology or on experimental production of the affection.

Dercum" suggested: "It is not inconceivable that, as a result of deranged thyroid action, some substance was thrown into the circulation. which at one and the same time prevented the proper oxidation of the hydrocarbons of the food and tissues, and also acted as a cause of neuritis and nerve degeneration." 
Vitaut" concluded: "The action of the nervous system in the genesis of adiposis dolorosa is absolutely undeniable." "The cause which sets in operation this mechanism is very probably a thyroid intoxication."

Price" said: "It seems, therefore, that sufficient attention has not been given the hypophysis, and I will suggest that etiologically it is of almost as much importance as the thyroid gland. May not the symptomgroup of adiposis dolorosa result from a primary disease of either of those structures, the other being involved secondarily through their close interrelation?"”

Ballet ${ }^{8}$ concluded: "Dercum's disease seems to result from a toxenia, the nature of which is undetermined, but which is neither alcoholism, syphilis, nor probably a thyroid intoxication. Perhaps the toxemia is caused by the defective functioning of a gland of internal secretion, which one we do not know. Whatever it is, according to this hypothesis, the toxemia causes both the lesions of the peripheral nerves and the encephalopathy."

Miquel $^{129}$ thought that the pathological findings "indicate a change in the nervous system, due probably to an autointoxication arising from disturbance of function of certain glands of internal secretion."

Strübing ${ }^{179}$ found the cause of the disease in "disturbances of the nervous system," a "trophoneurosis."

Thimm" ${ }^{185}$ also thought that the origin of the disease "is to be sought for with great probability in certain central nervous causes."

These several views, it will be observed, center on disturbances of function of certain glands of internal secretion, the thyroid, pituitary, etc., or of the nervous system either primary or secondary to a toxemia arising from the glands of internal secretion.

As factors in the etiology the following have been mentioned: alcoholism, syphilis, traumatism, mental shock, disturbances of function of the generative organs, neuropathic heredity, etc.

\section{DIAGNOSIS}

Is adiposis dolorosa a clinical and pathological entity? The differential diagnosis of adiposis dolorosa, commonly represented as quite easy, hinges on the question whether this affection is a true morbid entity or merely a symptom-complex characterizing certain cases selected out of a larger, more general group that embraces clinical varieties, each showing a tendency to individualization, but still closely related by common features to all and constituting not several entities but a single complex entity. The former view has been adopted by Dercum, ${ }^{47}$ who says: "Both the clinical findings and the results of the autopsies establish the 
fact that adiposis dolorosa is a well-defined clinical entity." Nearly all of the text-books and most of the special writers on the subject seem to agree with Dercum in this opinion. To find any dissent from this view one must search the foreign literature.

Strübing, ${ }^{172}$ while accepting the designation "adiposis dolorosa" as well chosen, regarded adiposis dolorosa, neuropathic edema, neuropathic pseudo-elephantiasis, multiple lipomatosis, and symmetrical diffuse lipomatosis, all as essentially one and the same process.

Thimm" 185 said: "I come to the conclusion that in the painless diffuse and multiple circumscribed lipomata the same pathological process (Grundprozess) and the same genetic cause occur as in adiposis dolorosa and in painful lipomata and that the pain of the latter two conditions is to be explained solely by local conditions."

Fulconis" concluded: "The nosological limits of such a syndrome, i. e., adiposis dolorosa, are not yet clearly defined; its boundaries ought to be enlarged so as to include other forms of lipomatosis and pseudolipomatosis." "Certain cases of painful symmetrical lipomatosis associated with cerebral symptoms (asthenia and psychical disturbances) cannot be separated from Dercum's disease."

Cheinisse" concluded: "All the facts brought in review show that not only 'is Dercum's disease related to the other forms of lipomatosis of nervous origin,'167 but also that it by no means constitutes a new morbid type, since in its essential characteristics it blends itself with the painful symmetrical lipomata."

Miquel"129 concluded: "There has been described for several years a certain number of nervous edemas still incompletely classified, from which it has been attempted to differentiate adiposis dolorosa. These several morbid conditions, which both from the pathogenic and the clinical point of view show an undoubted analogy, have been studied recently under the names oedème névropathique, Mathieu, 1893 ; oedème segmentaire, Debove, 1897 ; trophoedème chronique, Meige, 1899 ; pseudo-oedème catatonique, Dide, 1903.

"Adiposis dolorosa ought to be brought into the class of these different pathological conditions and it does not seem to constitute a well-defined clinical entity.

"All these morbid conditions have a common origin, in changes in the nervous system and in the different glands of the vascular system.

"They are probably, then, only varieties or stages of the same affection which constitutes the category of dystrophies cellulo-conjonctives vasculaires (Dide)." 
With the view that adiposis dolorosa does not constitute a distinct clinical or pathological entity, but is at the most a mere syndrome or symptom-complex characterizing one end of a series of cases of which the several members or varieties share in different degrees a more or less common symptomatology, I fully agree. The evidence supporting this view will be developed in considering the other clinical groups of cases.

\section{GROUP II. OBESITY, ADIPOSITY}

It would be easy to collect from the literature a series of cases of obesity varying in symptomatology from normal to typical adiposis dolorosa. Every step in the upward gradation of symptomatology could be found. Every possible combination of the presence or absence of the different symptoms of adiposis dolorosa could be shown. If one examines the cases reported as adiposis dolorosa, he will find many instances of simple obesity plus one or more of the symptoms of adiposis dolorosa, but falling far short of the typical picture of that affection as described. If one systematically examines his hospital cases of obesity, he cannot fail to observe in them a complexity of constitutional symptomatology; of the four cardinal symptoms of adiposis dolorosa he will find asthenia frequent and of every grade; mental symptoms, while not common in major degree, will be found frequent in the minor form of simple nervousness, irritability, depression, stolidity, stupidity, hypochondria, etc.; pain and tenderness will not be found rare; and the accessory symptoms of adiposis dolorosa will be found in great variety. It will be observed also that the fat in extreme obesity is often disposed over the body irregularly and in places feels nodular, lobulated, like a "bundle of worms," etc., as described in adiposis dolorosa. Furthermore, simple obesity is frequently associated with nervous, neuralgic, arthritic and metabolic disturbances, both personal and in the antecedents, as is adiposis dolorosa. The development of obesity with asthenia and nervous manifestations after the menopause needs only to be mentioned, and the effect of thyroid therapy is well known.

Pain or tenderness is not uncommon in the fat of normal or only slightly fleshy people, if one's attention is directed to this point, as remarked by Osler. (c) Gently pinch the fat of rotund, well-nourished people and many of them will be found more than ordinarily tender. Percussion in the course of routine examination brings out the same fact. Painful tender flesh with a marked tendency to bruising, in the absence of any obesity whatever, occurs even in childhood and persists throughout

(c) Personal communication. 
life, and, furthermore, this peculiarity is exhibited as a trait of heredity, as shown in Patient 3 and her two daughters and in Patient 5 and her three sisters and one daughter. In pronounced obesity similar tenderness has been observed very commonly. Fressineau" says: "It is not rare to find in the obese slight pain on pressure of the fatty tissue." Mitchell ${ }^{130}$ is reported as saying: "It should be emphasized that almost every case of excessive fatty deposit presented varying spots of tenderness, often in fixed positions. . . ."

On the other hand, instances of adiposis dolorosa, so reported, are numerous in which one or more of the cardinal symptoms are lacking. Eshner"2 observed: "There is no obvious reason why pain should necessarily be associated with the condition of fatty accumulation, and the case herein reported may be looked on as belonging to the same class [adiposis dolorosa], but without marked pain." Roberts ${ }^{\prime 163}$ patient had no tenderness and had spontaneous pain only in the left leg, and that due perhaps to previous fracture. Case 7 presents three of the four cardinal symptoms of adiposis dolorosa, namely, adiposity, asthenia and mental symptoms (insanity), and in marked degree, yet lacks completely pain and tenderness in the abnormal fat. Case 8 presents three of the four cardinal symptoms, but lacks abnormal adiposity! Fressineau ${ }^{66}$ pointed out that asthenic and mental symptoms, one or both, may be lacking. Strübing ${ }^{179}$ made the same observation, and in general his cases failed to show mental symptoms or asthenia beyond that resulting from the incapacity produced by the local fatty deposits. Spiller's ${ }^{176}$ Cases 2 and 3 showed no asthenia, no mental symptoms. Three of my cases (2,3 and 4) showed no mental changes beyond irritability or simple nervousness, and two ( 5 and 9 ) presented a normal mentality. Similarly asthenia was slight, amounting only to readily induced fatigue in Cases 3 and 5 and was entirely lacking in Case 4 . Patient 9 showed moderate obesity, moderate tenderness, no more asthenia than was explainable by the incapacity resulting from chronic arthritis of the knee and ankle joints, no mental symptoms. Similar instances abound in the literature.

Anders" has described under the title "adiposis tuberosa simplex" cases of common obesity with separate fatty lumps embedded in the general subcutaneous fat, felt on deep palpation, and characterized by varying degrees of tenderness and pair in the lumps and disappearance of the lumps with the reduction of the general fat under treatment. Such cases demand no special designation and only illustrate the possibilities of variation in the clinical picture of simple obesity. Similar 
instances of the mixing of types of fat deposit in the same case are seen in Dercum's syndrome and in nearly all of the clinical groups to be described.

GROUP III. NODULAR GIRCUMSCRIBED LIPOMATOSIS, SOLITARY, MULTIPLE, OR SYMMETRICAL

The next obstacle to considering adiposis dolorosa an entity is encountered in certain cases of this group, presenting a symptomatology similar in every respect to that of adiposis dolorosa as originally described. This fact was soon recognized and frankly met by including such cases within the classification of adiposis dolorosa, as already indicated in Vitaut's classification. In fact, the single case personally observed by Vitaut (Observation 12) was one of multiple, nodular, painful lipomata. Dercum promptly accepted Vitaut's classification, as almost all later writers have also done. This acceptance of painful simple lipomata within the meaning of adiposis dolorosa seems, therefore, to remove such cases from controversy or further consideration in this connection, but it remains to show that pain is only one of many constitutional symptoms that may characterize simple lipomata and that all the other symptoms of adiposis dolorosa, one or many, may be found in varying degree and combination in individual cases of simple lipomata. We can, then, better appreciate the fact that individual cases of this group that happen to conform to the description of adiposis dolorosa by the occurrence of pain do not constitute thereby an entity, but merely a variation in a complex constitutional symptomatology.

Koettnitz ${ }^{97}$ was perhaps the first writer to emphasize the occurrence of constitutional symptoms in simple lipomata. He divided lipomata into two classes, cases with symptoms and cases without symptoms. As examples of the first class he collected fourteen cases exhibiting constitutional symptoms, especially nervous manifestations, including pain, menstrual disturbances, and rheumatic or rheumatoid symptoms. These general symptoms as well as the symmetry of distribution of the lipomata in certain cases, stamped the process as a trophoneurosis, he thought. Later Thimm, ${ }^{185}$ Spitzer $^{177}$ and other writers also called attention to the constitutional symptoms of lipomatosis.

Simple lipomata vary in different cases from a condition absolutely symptomless to one with marked constitutional symptomatology, including the full picture of adiposis dolorosa, as will be shown in the following abstracts of cases personally observed and in the literature:

LYoN (CAse 13).-Multiple nodular lipomata; absolutely symptomless.

Lyon (Case 14).- Solitary, circumscribed, soft lipoma; rheumatic symptoms only; son has multiple lipomata (heredity). 
Lron (Case 15).-Multiple nodular lipomata; rheumatic symptoms only; father has a solitary lipoma (heredity).

Lyon (Case 16).-Symmetrical nodular lipomata, painful and with black-andblue discoloration only at the time of the first appearance of each tumor; inflammatory rheumatism, neuralgia. Father had painless symmetrical lipomata in the forearms, exactly as in the patient's case (heredity).

Lyon (Case 17).- Symmetrical nodular lipomata, sciatica, "rheumatism;" local pain before the appearance of only one of the early lipomata.

LyoN (CASE 19).-Solitary, small, nodular lipoma, tenderness on pressure and spontaneous pains in and radiating from the lipoma in paroxysms, rheumatic symptoms, no other symptoms.

Chevers.29-Multiple lipomata, without symptoms; same condition in father and sister (heredity). (Reported as adiposis dolorosa.)

Hamon.$^{80}$-Multiple lipomata, painful, no other symptoms; sister has same condition (heredity). (Reported as adiposis dolorosa).

Lyon (Case 18).-Multiple nodular lipomata, marked tenderness present in some, absent in other tumors, paroxysmal radiating pains, blueness over the tumors, slight nervousness, no asthenia or other symptoms.

Koetrnitz ${ }^{97}$ (Case 1).-Symmetrical nodular lipomata. Woman, aged 65; at 26 gave birth to a child and thereafter she menstruated only three times; in place of the menses there appeared attacks of severe pains in the arms, legs and trunk and at the same time lumps in the parts of the body attacked by pains; these lumps grew larger and more numerous with each monthly attack of pains; at 54 the pains and formation of new tumors ceased.

SpITzer. ${ }^{17}$-Painful, symmetrical, nodular lipomata, asthenia, itching over the entire body, no other symptoms.

Werss. ${ }^{108}$ - Multiple lipomata, great variation in the tenderness and the spontaneous pain in the different tumors, great variation in the size of the tumors from time to time, no other symptoms. (Reported as adiposis dolorosa.)

WEIss. ${ }^{108}$ - (Schlesinger's observation). Following an abortion, eruption of numerous, small, painless lipomata and development of pain in certain preexisting painless lipomata. (Reported as adiposis dolorosa.)

RENoN AND Louste. ${ }^{10}$-Multiple lipomata, tenderness and spontaneous pain in the tumors, fatigue, slight mental changes. (Reported as adiposis dolorosa.)

Hall aNd Walbrach ${ }^{78}$ (Case 1).-Multiple nodular lipomata, painful to pressure and spontaneously, ready fatigue, neurasthenia, hyperchlorhydria, rheumatism. (Reported as adiposis dolorosa.)

Mall AND WaLbRach ${ }^{\text {is }}$ (Case 2). - Solitary lipoma on right hip, developing a few months after a blow at the same point (traumatism), painful to pressure and spontaneously, pain shooting upward to the tumor caused by pressure on the right heel, redness and blueness over the tumor, confinement to bed, mentality irritable and duller than formerly. (Reported as adiposis dolorosa.)

Lyon (Case 20).-Multiple lipomata, slight asthenia, slight dementia, no pain, chronic "rheumatism."

DeBove. ${ }^{40}$-Symmetrical, nodular lipomata, slight tenderness varying in the different tumors, so slight that the patient made no complaint of it and denied pain on pressure though the writer thought that he demonstrated its presence, no spontaneous pain, asthenia (bed-ridden), dementia, herpes zoster, Heberden's nodosities.

Vitaut $^{102}$ (Observation 11, by Galland and Garand; reported also by Garand $^{i 0}$ ). Symmetrical lipomata in forearms, painful cramps in forearms, rheu- 
matoid pains in shoulders, rheumatism, no asthenia, no mental symptoms. Marked reduction in size of all the tumors, some almost disappearing, and complete disappearance of pains from thyroid treatment continued for eight months. (Reported as adiposis dolorosa.)

VItaUT ${ }^{192}$ (Observation 12).-Symmetrical lipomata, pain and tenderness in tumors increased by exereise, blueness over tumors, slight asthenia, no mental symptoms except quarrelsomeness, thyroid enlargement, some reduction in the size of some of the tumors and in the pains from thyroid treatment. (Reported as adiposis dolorosa.)

KoETTNITZ $^{97}$ (Case 2).-Symmetrical lipomata, no tenderness or spontaneous pain in tumors, marked asthenia, restlessness and anxiety, vertigo, fainting spells, ataxia, rheumatic pains in limbs and in joints of hands, knees and feet, migraine, goiter; development three years after menopause.

THIмм. ${ }^{185}$-Multiple lipomata, some painful, others not painful, blueness over tumors, fatigue, marked asthenia, no mental symptoms, headache, arthralgia, cramps, spasms and twitehings in limbs; growth of tumors preceded by local pains. (Reported as adiposis dolorosa.)

ALSBERG. ${ }^{3}$-Multiple lipomata, tenderness on pressure in the tumors, pains in arms and legs, fatigue, loss of strength, no mental symptoms, paresthesia, hoarseness, disturbance of speech, loss of sexual desire; growth of tumors preceded by local pains.

EshneR ${ }^{42}$ (Case 2, Dercum's observation).-Female, aged 36 years, had a severe fall followed by unconsciousness. Miscarriage two weeks later. About six weeks later "seven or eight small swellings, varying in size from a small marble to a walnut, soft to the touch and apparently made up of fatty tissue," appeared on the left forearm. "These were exceedingly painful and tender on pressure." On examination nineteen months after the accident, there were also found on the lower portion of the back and in the sacral region several large, diffuse swellings, soft, painful and tender on pressure. General asthenia, pain in different parts of the body, headache, vertigo, tinnitus aurium, insomnia, indigestion, palpitation, hyperidrosis, increased micturition, etc.

SPILleR ${ }^{176}$ (Case 1).-Female, aged 29 ; at 22 severe attacks of pain in right foot, at 25 swelling of right ankle and right leg just above knee, followed later by painful swelling of the whole right leg. The right leg, thigh, buttock and hip generally enlarged and containing both nodular and diffuse fatty masses. Over right iliac crest a diffuse, orange-sized, fatty mass with a "worm-like" feel. On left forearm one small nodular lipoma. The several tumors were all painful to pressure and subject to paroxysmal pain and swelling; some painful areas in right leg; no obesity, no asthenia, no mental symptoms, no menstrual disturbances; one attack of rheumatic pains. (Reported as adiposis dolorosa.)

Alger. ${ }^{2}$ - Multiple, nodular lipomata, painful to pressure but not spontaneously, in a woman, aged 29, developing during past eight years; increase of weight during past three years from 130 to 206 pounds, the increase of adiposity being unequally distributed over upper arms, back, breasts, buttocks and thighs and sparing the face, forearms, hands, lower limbs and feet; no pain or tenderness in this fat; fatigue, asthenia, melancholia, paresthesia, deep pain in the bones, pigmentation, thyroid treatment ineffectual; growth of the nodular lipomata preceded by local pains. (Reported as adiposis dolorosa.)

ROGERS. ${ }^{104}$ - In "the myxedema, or myxedematoid condition, following thyroidism or exophthalmic goiter ... some of these cases suffer much from lipomata in various parts of the body, and indeed there is much which is suggestive of, if not identical with, the disease called adiposis dolorosa." Supplementing this statement in a personal communication Rogers writes: "My statements in refer- 
ence to adiposis dolorosa are the results of $\mathrm{my}$ personal observation. Painful lipomatosis in more or less marked form has been common in my experience with these cases. I have tried all kinds of organ therapy and believe that thyroid feeding is the only kind of the least assistance, although I have lately had under observation two cases which seemed to follow thyroidism and these are to a considerable extent relieved of pain by feeding with the adrenal nucleo-proteid."

Similar cases in greater number could be produced, but enough have been cited to prove the assertion, above made, that simple lipomatosis is frequently characterized by constitutional disturbances varying from nothing or next to nothing to the full symptomatology of adiposis dolorosa. Between these limits every conceivable combination of symptoms is represented. Of the so-called cardinal symptoms of adiposis dolorosa, namely, pain, asthenia and mental symptoms, in addition to fatty deposit, all may be present, all absent. or any one or more may be present or absent. The so-called accessory symptoms are also represented in great variety and combination. So varied in these different cases are the several symptoms supposed to characterize adiposis dolorosa that it would be impossible in many instances to say whether cases could be classed as adiposis dolorosa or not.

For example, a tiny, solitary, encapsulated lipoma in the forearm (Case 19) is tender on pressure and subject to paroxysmal radiating pains in a patient without other important symptoms. Is this a case of adiposis dolorosa? If not, why, then, is a large solitary lipoma ${ }^{78}$ on the hip, appearing after local traumatism, painful to pressure and spontaneously, confining the patient to bed on account of the pain, with a mentality irritable and perhaps duller than formerly, so regarded and reported $?^{(d)}$ Indeed the conception of adiposis dolorosa as an entity seems to be made untenable by the narration of the diverse and complex symptomatology of simple lipoma, as above sketched.

Special attention may be called to certain features of interest exhibited by this group of cases. Arthritic manifestations, called rheumatic, rheumatoid, arthralgic, etc., frequently characterize these cases, as Koettnitz pointed out. The same manifestations have been specially described in adiposis dolorosa, and, as will be shown below, characterize all the different groups of abnormal fat deposit. The development of

(d) This case became the subject of a claim for damages on the ground that the lipoma, pain and disability all resulted soon after and directly from a severe blow inflicted by a hack upon the site of the subsequent tumor formation. The jury found a verdict for the defense on the testimony of two medical experts that the case was one of "adiposis dolorosa" of the nodular variety, "the black-andblue appearance being recognized as an occasional occurrence in this disease"-a clear case of miscarriage of justice resulting from the misconception of certain symptoms constituting a disease entity. 
lipomata consecutively to the establishment of the menopause occurred in several of the above cases. The same relation in adiposis dolorosa has been emphasized. Traumatism as an exciting influence is illustrated in both groups. Changes in the thyroid gland are found in both. Benefit resulting from thyroid medication in the entire symptomatology is shown in both groups. Local cyanosis, blueness, or black-and-blue discoloration over the tumors is common to both. Paroxysmal increase of pains and of the size and firmness of the tumors is a frequent symptom in both. The occurrence of local pain at the site of subsequent tumor formation is shown in both. The mixing of types of fat deposit, diffuse and nodular, in the same case is exhibited in both groups. The influence of heredity, previously not much considered, is shown in both groups and will be specially considered in reference to all groups below.

One other point may be mentioned in this place in passing. The rule that lipoma once removed never recurs locally, a view generally held, is shown to have exceptions by Cases 14 and 18.

GROUP IV. DIFFUSE SYMMETRICAL LIPOMATOSIS WITH PREDILECTION FOR THE NECK ("FETTHALS," MADELUNG; "L'ADÉNO-LIPOMATOSE SYMéTrique À PRÉdOMINANCE CERVICALE," LAUNOIS AND BENSAUDE)

As this variety of lipomatosis has received very slight and only recent recognition in the United States, a brief summary of its characteristics and references to the important articles in the literature will be given.

The earliest observation was made by Brodie ${ }^{20}$ in England, in 1846. Baker and Bowlby in England, in 1886, reported ten original observations and three cases from the literature, and Williams, ${ }^{202}$ in 1890, reviewed thirty-two eases, including four personal observations. Madelung ${ }^{113}$ in Germany, in 1888, described the affection under the name Fetthals, collecting thirty cases from the literature and adding three personal observations. Madelung's paper was the first systematic treatise on the subject. Marçais, ${ }^{116}$ in 1894, published the first systematic description in France. In 1898, 1900 and 1901, Launois and Bensaude ${ }^{100,101,102,103}$ in France published personal observations, abstracted and illustrated many cases from the literature, and more than any other writers gave prominence to and caused recognition of the affection, describing it under the title l'adéno-lipomatose symétrique à prédominance cervicale. They succeeded in finding references to more than eighty cases in the literature. Shortly thereafter there appeared from Paris three theses on this subject, by Rehns, ${ }^{156}$ in 1898 , Tapie, ${ }^{184} 1899$, and Quéry, ${ }^{153} 1902$, all inspired by Launois and Bensaude. 
In the United States, Warren, ${ }^{194}$ in 1895 , was the first writer to report a case with a recognition of its special features. In 1907, Collins $^{32}$ reported several cases, and, in 1908, Mills ${ }^{128}$ reported a single case, and both writers reviewed the subject. Single cases, without recognition of their special characteristics, have been reported by Huckins, ${ }^{89}$ in 1889; Adler, ${ }^{1} 1893$; Rosenstirn, ${ }^{166} 1893$ (the same case as reported by Adler) ; Kiliani, ${ }^{94} 1909$; and Johnson, ${ }^{93} 1909$. Coplin ${ }^{33}$ has also mentioned a case; Louis B. Wilson ${ }^{(e)}$ of Rochester, Minn., has seen cases at the clinic of the Mayos; George Blumer ${ }^{(e)}$ has recently seen a case in Albany, N. Y., in consultation with Arthur W. Elting; and Grover W. Wende ${ }^{(e)}$ of Buffalo is acquainted with a typical example. Several other American cases, ${ }^{15,43,46,47}$ reported as adiposis dolorosa, probably belong to this group (see abstracts below).

Madelung regarded the condition as a "special clinical form" of lipomatosis, not to be classed with simple multiple lipomatosis. Marçais regarded it as a "well-determined affection." Launois and Bensaude represented it as a distinct entity with a special pathology, although admitting that "perhaps symmetrical adenolipomatosis, adenolymphocele, supraclavicular pseudolipoma, segmentary edema of Debove (neuropathic pseudo-elephantiasis of Mathieu) ought to be grouped in the same morbid series." Later writers have nearly all followed the opinion of Launois and Bensaude and represented the disease as a distinct morbid entity with a special pathology (see below).

The disease is described by Launois and Bensaude ${ }^{102}$ as possessing three chief characteristics, symmetry, diffuseness and special localization of the fatty tumors. The symmetry is pronounced, but the appearance of the two symmetrical tumors is not necessarily simultaneous. The growths are not circumscribed or encapsulated, but diffuse, fusing with the surrounding fat tissue. The location of the tumors indicates a special predilection for the neck, beneath the chin, nape of the neck, base of the neck, preauricular, postauricular, etc. In addition to the neck, other parts of the body are usually invaded, in twenty-one out of thirty-three cases in Madelung's series. The location of the first tumors varied. They appeared on the trunk or extremities before the neck by intervals of two years (Langer ${ }^{90}$ ), three years $\left(\right.$ Bryk $^{21}$ ), eight years (Henningsen ${ }^{83}$ ), twelve years (Bondet, ${ }^{18}$ Fulconis $^{68}$ ), nineteen years (DuCastel ${ }^{54}$ ). The face, hands and feet are usually spared, ${ }^{102}$ although in one case each a tumor was present on the back of the hand (Williams ${ }^{202}$ ), on the tip of the nose (Bondet, ${ }^{16}$ Fulconis $^{68}$ ), and at the point of the chin (Lyon, Case 11).

(e) Personal communication. 
The consistency of the tumors varies from soft, even semicystic, to firm; they may be irregular or indistinctly lobulated and even feel like a varicocele, mamma, or "bundle of worms." On deep palpation small firm lumps or "nuclei"102 are sometimes felt. In some instances the tumors are described as mixed or of different varieties, some clearly diffuse, others circumscribed lipomata (Du Castel ${ }^{54}$ ), common subcutaneous fibro-fatty tumors (Hutchinson ${ }^{90}$ ). The size and consistency of the tumors have been repeatedly described as subject to spontaneous fluctuations. They have never been observed to disappear completely, ${ }^{102,}{ }^{113}$ although in a few instances they have become almost unrecognizable. An exception to this rule is perhaps found in the case reported by Kiliani, ${ }^{94}$ who said that "one large lipoma of the abdomen had disappeared spontaneously." After excision they never recur locally, although new formation may develop from the periphery (Madelung). Marçais, however, says that they "often recur"-probably a mistake.

The duration of their growth varies from a few months to many years, as long as thirty-one years in Case 10. Like simple lipomata, they are not influenced by changes in the general nutrition. ${ }^{102,113}$ There is no necessary relation to obesity and in general the subjects are apt to be of normal weight, sometimes even spare. ${ }^{102,113,202}$.

The first appearance of the tumors is usually after the age of 20 , from $211 / 2$ to 58 years, ${ }^{102,202}$ although exceptions occur. ${ }^{39}$ The disease began at puberty in Patient $\mathbf{1 1}$ and her two sisters.

Unlike simple lipoma and adiposis dolorosa, it occurs chiefly in the male sex, only occasionally in females. Instances in females have been reported by Bochroch, ${ }^{15}$ Koenig, ${ }^{96}$ Dartignolles, ${ }^{39}$ Lejars, ${ }^{105}$ Langer, ${ }^{99}$ Launois and Bensaude, ${ }^{103}$ Dercum, ${ }^{43,46}$ Bondet $^{16}$ and myself (Case 11); and other less typical instances in females have also been reported.

It may be pointed out that diffuse symmetrical lipomatosis, while exhibiting a distinct predilection for the region of the neck, does not invariably or necessarily invade that region. As shown above, the deposits have appeared on other parts of the body as long as nineteen years before any involvement of the neck was shown. In many instances similar diffuse symmetrical deposits of fat occur on the trunk or extremities exclusively, as in Case 12. Such cases cannot be differentiated from those presenting deposits in the neck. Furthermore, the deposits may be so diffuse and generalized as to cover the body more or less widely, as in the cases of MacCormac ${ }^{112}$ (Clutton's observation), Baker and Bowlby ${ }^{7}$ (Case 7 ), Jeanselme and Bufnoir, ${ }^{92}$ Müller, ${ }^{134}$ Lexer, ${ }^{109}$ Langer ${ }^{99}$ Dercum $^{43 .}{ }^{46}$ (two cases), Dercum and McCarthy, ${ }^{47}$ Bochroch, ${ }^{15}$ Morsaline. ${ }^{135}$ 
Nearly all writers have noticed the frequency of alcoholism in the history of the patients and many have attributed to it an etiological relation to the affection.

Previous writers have not emphasized the constitutional symptomatology of this form of lipomatosis, merely mentioning the occasional occurrence of general symptoms. I shall, therefore, direct attention to this subject. As in simple obesity and simple lipomatosis, a majority of cases present no marked constitutional disturbances. A minority, however, show the same general and special symptomatology exhibited by exceptional cases of obesity and of circumscribed lipomatosis, as already described.

The range of this simptomatology is illustrated in the following cases:

Hennivgsen..$^{83}$-Anidrosis.

Rosenstiry. ${ }^{160}$ - Anidrosis.

Müller. ${ }^{334}$-Man, aged 43. Tachyeardia, impotence, loss of sexual desire.

DuCASTEL. ${ }^{34}$-Man, aged 66 , rheumatic, rheumatic family history. For years very marked pain on outside of right thigh.

Lyon (Case 10).-Man, aged 71. Typical fatneck beginning at 40 years of age and developing uninterruptedly until death. From the age of 40 , when the fatneck began, repeated arthritic attacks and attacks of double sciatica, continuing to the time of death.

WilliaMs. ${ }^{202}$ - Man, aged 40 . Loss of memory.

SCHCCHARDT. ${ }^{170}$-Required to give up work on account of the weakening of mental faculties.

Hutchisson." -Man, "excitable to the verge of insanity."

PEAN. ${ }^{142}$-Man, aged 32. Duration of tumors two years. Loss of strength and rapid emaciation, coinciding with the constant growth of the tumors.

LANGer. ${ }^{99}$ - Woman, aged 55. The disease began six years ago as "painful reddened tumors." "The reddening and pains soon disappeared."

BAKER AXD Bowlry." (Case 8).-Man, aged 41. "For two years has noticed swellings in his neck and says that for the last year they have been very painful."

MARÇAIs." - "One may find in certain patients pains of variable intensity, sometimes amounting to almost nothing, in other cases very definite and seated at well-determined points. One finds them specially in the form of lancinating pains and referred by the patient to a deep location; they seem to him to radiate from the angle of the jaw towards the clavicle below, the parotid region above, and the shoulder behind."

CoLlixs $^{32}$ (Case 2).-Man, aged 36, alcoholic. Tumors for five years, not involving lower extremities except above Poupart's ligaments, and a "suspicious mass" on each quadriceps femoris. "His legs had been weak for about three years so that he had not been able to walk alone securely since his thirty-second year, and during this period he had suffered from severe cramp-like pains in the legs," paroxysmal. "For the past two months... he has been complaining of very severe stabbing, burning pains in the legs, from which he could not get relief. He stated that if he was touched with the point of a pin he immediately felt severe pains." Wasting of the extremities for twelve weeks, following vomiting and pains in the stomach. Emaciation. marked asthenia, increased patellar reflexes. 
Collixs $^{32}$ (Case 3). -Man, aged 55. For six years pain in the right arm and tenderness of the right shoulder-blade, also a burning sensation; occasionally similar pain in left shoulder and arm; pains paroxysmal, made worse by work. Tumors in painful areas. Considerable arteriosclerosis. History of alcoholism up to six years ago.

CoLlins $^{32}$ (Case 4). Man, aged 48. Tumors for ten years, in back of neck and over scapulx. For nineteen months severe tearing and shooting pains in the lower legs, made worse by exercise. For six months following the begining of the pains delirium, which "would sometimes cease for a brief time and he would be fully appreciative of his surroundings and of his condition, and then without attributable reason he would become confused. Sometimes this confusion would come on while he was in the street and he would lose his way." "Multiple neuritis, particularly of the lower extremities, and predominantly of the sensory type." "He admitted alcoholic habits."

Lyon (Case 12).-Woman, aged 40. Diffuse symmetrical fatty deposits below ankles and on inside of knees and a single similar mass on right buttock, all slightly tender on pressure. Ready fatigue. Attacks of neuralgia or neuritis.

DALCH $\hat{\mathrm{E}}^{37}$-Weakness in arms and legs, asthenia, intelligence limited, memory lost; patient is apathetic, responds slowly, melancholic.

Dartignolles. ${ }^{39}$ - Woman, aged 21. Neuropathic, severe migraine, sciatica, marked weakness in legs, general asthenia.

LAUnois AND Bensaude. ${ }^{100},{ }^{101},{ }^{102}$-Man, aged 32. Marked cachexia, marked asthenia, limited intelligence, distrust, unaccountable attacks of anger.

Lauxois And Bensaude. ${ }^{102}$ (Observation 22, Bouvet's case).-Man, aged fortytwo years. Cleer on back of right foot and a perforating ulcer on plantar surface of left foot with anesthesia of left foot. Exaggerated patellar reflexes. Epileptoid symptoms.

Lauvois axd Bensaude ${ }^{102}$ (Observation 23, Demon's cases).-Man, aged 48. Melancholia. Network of dilated veins over tumor of the neck.

Ewald. ${ }^{63}$-Man, aged 47, weight $1981 / 2$ pounds. Pads of fat on the nape of the neck, in the region of the nipples, and about the umbilicus. "Drawing pains that suggested the pains of neuritis." Anidrosis, palpitation, dyspnea. Treatment by thyroid caused improvement in the general health, in the dyspnea and palpation, and a loss of weight of $181 / 2$ pounds in six and a half weeks. (Considered by Ewald as Dercum's disease.)

Mills. ${ }^{128}$ _Man, aged 33. First appearance of tumors between three and onehalf and four years ago. Attacks of acute articular rheumatism every winter for five years. "He has some feelings of distress or pain in the arms after hard labor, and at some examinations has complained of very moderate pain on pressure, particularly along the swellings in the upper arm. .. . He thinks he is not as strong as he was before the beginning of these swellings." Varicosities on legs and thighs. Defective hearing in boths ears. Anemia: reds, 2,950,000; hemoglobin, 60 per cent.

SToLL. ${ }^{177}$-Man, aged 33, presenting typical fatneck. "The patient's mother has had for ten years a painless tumor on the shoulder. His mother's brother has had for several years painless tumors in the same places as the patient" (heredity).

Lyos (Case 11).-Woman, aged 33. Typical fatneck began at puberty in herself and two sisters (heredity). Slight tenderness of the fatty deposits in the patient, not in the sisters, asthenia, deficient mentality, chronic sciatica from the beginning of the fat deposits, "rheumatism," hemorrhages, anidrosis, dysmenorrhea. One of the sisters with fatneck is insane. Chronic "rheumatism" in a brother and a sister, chronic sciatica in another brother. 
Dercum And MCCarthy ${ }^{47}$ (Case 1).-Man, aged 39. After an acute illness, fifteen years ago, began to grow stout and later symmetrical deposits, "exquisitely painful to the touch," developed on the body. "He noticed also that as the deposits of fat grew he became excessively weak and easily fatigued." "His flesh would bruise very easily" and "slight blows would bring about black-and-blue marks," in two instances leading to ulceration. Similar black-and-blue marks occurred without trauma. Three years ago severe epistaxis. For five years major epilepsy. Height, 4 feet $101 / 2$ inches. Weight, 206 pounds. Diffuse symmetrical fatty deposits involving chiefly the trunk, abdomen, hips and buttocks, causing a grotesque contrast with the relatively small legs and arms. "There is also a dependent fold of fat beneath the chin." "Everywhere these masses of fat are exquisitely painful to pressure." "The skin is dry." "Irregular flushing, with here and there tendency to lividity, is also observed over various parts of the body. Here and there also the veins are somewhat prominent." Certain changes in the eyes. Death from erysipelas. Autopsy: "The testicles are undeveloped, the penis small, and there is a very scanty growth of hair on the pubis." Separate encapsulated lipomata embedded in the general fatty deposit. Hemolymph glands in the lipomata and in the diffuse fat. Interstitial neuritis of the nerve fibers in the subcutaneous fat. Adenocarcinoma of the pituitary body. Acute parenchymatous nephritis. Thyroid gland normal microscopically. Telangiectatic angioma and slight interstitial hyperplasia of the spleen. Anomalous arrangement of the convolutions of the brain. Fatty infiltration of the heart and liver. Right suprarenal gland twice the normal size, normal microscopically; left suprarenal not found. (This case was reported as one of adiposis dolorosa. The description and location of the fat deposits and the photographs seem to bring it within the group of diffuse symmetrical lipomatosis with predilection for the neck.) MeCarthy, ${ }^{123}$ in his latest publication on adiposis dolorosa, practically admits this, saying: "This forms a connecting link between adiposis dolorosa, adiposis cerebralis, and symmetrical adenolipomatosis."

Dercum. 48 -Woman, aged 61. Nervous prostration at 18 and again one year later. Present illness began ten years ago, manifested by weakness in the legs and in the back. "Some six or eight months after the beginning of the weakness in the legs, a painful lump of fat made its appearance at the back of the neck and immediately between and above the shoulder-blades. Subsequently, another painful mass of fat made its appearance over the left collar bone, and at various times thereafter numerous lumps, more or less diffuse in character, made their appearance on the left arm, on the right arm and, finally, over and about both knees. At the same time that the painful masses of fat made their appearance about the knees, the patient began to suffer from swelling in the joints. ... Motion was attended with considerable pain. These symptoms reached a maximum amount of intensity about five years ago." "There is a lipoma on the back of the neck which is painful to pressure. There are painful supraclavicular lipomata on either side. There is a diffuse deposit of fat on the back, which is especially heaped up over the shoulder-blades. There are also very extensive and diffuse deposits over the abdomen, ... arms, ... forearms, ... thighs and buttocks, ... both knees." "In both arms the deposit of fat contains numerous lumps which are doubtless independent lipomata," similarly over the knees. These lumps are "painful to pressure." Face, hands and feet free. "The fatty deposits are everywhere painful to pressure, more so in some situations than in others." Mild dementia, marked asthenia, flushing of cheeks, forehead, palms and soles, extensive and widespread involvement of the joints, bursæ and tendons, patellar reflexes absent. (This case was reported as one of adiposis dolorosa, which admittedly it is. The diffuse lipomata on the back of the neck and in each supraclavicular space, etc., establish its identity with fatneck.) 
Dercum $^{43}$ (Case 3).-Female, aged 60, widow, no pregnancies. "Many years ago a lump appeared at the back of the neck." "At various times thereafter swellings made their appearance in various situations." Menorrhagia, occasional hematemesis and epistaxis. Menopause at 46. Mental impairment for two years. Anidrosis for years. Tumors: "Examination reveals soft, fatlike masses or swellings in various situations. Thus a large soft mass is found over either biceps, and others, somewhat smaller, over the outer and posterior aspect of either upper arm. Two large masses are found over the belly, separated above the umbilicus by a deep transverse crease. Another gives excessive prominence to the mons veneris. From the back of the neck, at its lower part, springs a big mass like a hump, while a diffuse swelling gives a cushion-like coating to either half of the back, and extensive deposits give unnatural prominence to either hip;" no deposits in hands, forearms, face, buttocks, thighs, legs and feet. The deposits varied in consistence, some being "firm and resistant," others "quite soft," "elastic" and "nodular." "Further it was discovered at once that these masses were painful to the touch, the patient complaining very much when only moderate pressure was exercised. This was especially true of the deposits over the arms and back of the neck. In addition, the patient complained of stabbing pains in the deposits, more marked in the regions just mentioned. She complained also of headache." Skin dry. Purpuric spots on forearms, thighs, legs and back. Cutaneous sensibility generally diminished; a few patches of anesthesia. "Patient is excessively feeble. For some two weeks past has been unable to walk. Lies, for the most part, in a quiet apathetic state, though when aroused answers questions intelligently, but slowly. Is, in addition, somewhat deaf." "Her dementia gradually deepened" until "she finally died in a comatose state." The autopsy showed enlargement, sclerosis and calcification of the thyroid gland, chronic nephritis, chronic gastritis, emphysema of the lungs, fatty infiltration of the heart and liver, slight thickening of the aortic and mitral valves, edema of the pia and brain. No microscopic examination. (This case was reported by Dercum as Case 3 in his first publication on "adiposis dolorosa.")

Воснвосн. ${ }^{15}$-Woman, aged 56. "There is a fatty deposit the size of an egg under the chin, which is painful to pressure." There are also diffuse symmetrical deposits of fat in the upper arms (fat-bags), breasts, abdomen, hips and thighs, everywhere decidedly painful to pressure. "Constant, sharp, shooting pains in the arms and hands. She is quickly fatigued, and presents symptoms of a neurasthenic character." "The asthenia is typical in degree." "The mental symptoms are also typical, though they are not pronounced." "Her memory is impaired." She weighed less than 100 pounds at 19 years of age, when she was married; her present weight is 236 pounds. "Shortly after her marriage she noticed an accumulation of fat over both hips and over the upper parts of her arms and legs." Menopause six years ago. "Seven or eight years ago she noticed that she became easily bruised, a blow of the slightest intensity causing pain, attended by black-and-blue discolorations." One child is feeble-minded. "The case presents the four cardinal symptoms noted by Vitaut." "The case must be classified in the group termed by Vitaut the localized diffuse form." (This case was reported as a case of adiposis dolorosa. It is certainly such a case. The "fatty deposit the size of an egg under the chin" and the diffuse symmetrical deposits elsewhere also bring this case within the group of fatneck.)

BONDET $^{16}$ (also reported by Fulconis ${ }^{68}$ ). - Woman, aged 50. Severe traumatism on head and back at 38 years. At 38 left salpingo-ovariotomy, followed five or six months later by pains on inner side of left leg, just above knee, and after a few months by a tumefaction at the site of the pains. Similar phenomena in the right leg at the corresponding location and later by degrees in other parts of the body, always symmetrical. Menses ceased at 44 and thereafter the disease progressed 
more rapidly. The pains were spontaneous, tingling and stabbing, localized in the tumors and also radiating along the course of nerves, paroxysmal, varying in intensity. The intensity of the pains diminished with the growth of the tumors. Tenderness to pinching or light pressure over the tumors. Location of tumors: legs, inguinal folds, buttocks, arms, shoulders, supraclavicular fossæ, submaxillary, preauricular, point of nose. Character of tumors; diffuse, ill-defined limits, feel doughy, pinching tumors cause ready ecchymosis. Marked asthenia, marked mental phenomena, change of character, attempt at suicide. Vasomotor instability indicated by repeated attacks of epistaxis and frequent flushing of the extremities. No obesity. Treatment by iodin and $x$-ray resulted in marked reduction in the size of the tumors and improvement in all the symptoms. The tumors on the neck and face appeared twelve years after those on the legs. (This case was reported as one of Dercum's disease. The preauricular and submaxillary tumors which finally appeared establish its identity with fatneck.)

McMullax. ${ }^{125}$ - Woman, aged 61 , weight about 168 pounds, ten children, good health until five years ago, when she commenced to suffer from "numbness of the hands and arms, followed later by pain of an aching character, and subsequently by symmetrical fatty deposits in both upper arms." In the course of time the deposits "attained considerable dimensions," and the pain and numbness "increased to such an extent that the patient was unable to undertake even the slightest household duties." Later "pain and numbness were experienced across the back and ehest and lately in the thighs just above the knees." For two years "severe hematemesis on several occasions and nine months ago uncontrollable hemorrhage following on extraction of a tooth." The patient is pale, sallow, "evidently suffers from debility," "is fairly bright and intelligent but complains of some loss of memory." Gums spongy; skin dry and harsh, perspiration very deficient; marked hyperesthetic areas over both arms. "Large diffuse deposits of fat, pendulous and flabby in consistence, which involve both upper arms, and to a lesser extent the upper portions of the forearms," a similar deposit over the upper portion of the manubrium sterni, and "symmetrical fatty deposits over either scapular region and extending as low as the tenth or eleventh rib." No deposits below the waist-line; legs slender. No deposits in the neck, but the photographs show that the diffuse deposits in the arms continue up over the shoulders and across the back above the shoulders. Numbness, tingling and aching pains over the fat deposits and near the knees. "The pain is very much aggravated by using the limbs. The arms are tender wherever the fatty tissue is present, and even slight injuries cause bruising and discoloration."

Thyroidin was administered and "thus far, a period of scarcely two weeks, the result has been very satisfactory. The pains have almost disappeared, the numbness and tingling have been very much alleviated, and there is a distinct reduction in the size of the right arm of almost one-half inch. She herself states that she feels very much better, and can sleep and do a little work much better than she could for several months previously." (Reported as a case of adiposis dolorosa. The description and photographs indicate clearly that the case is one of symmetrical diffuse lipomatosis, belonging to the group here under consideration.)

After the citation of the above cases it wonld be superfluous to dwell further on the constitutional symptomatology frequently exhibited by this clinical group of cases. The remarks made on the symptomatology of simple obesity and of simple nodular lipomatosis might almost be transposed so as to apply here. 
Pains, both spontaneous and induced by pressure, asthenia, mental symptoms, neuralgias, neuritis, arthritic and rheumatoid manifestations, vasomotor phenomena such as fluctuations in the size and consistency of the tumors, local blueness over the tumors, flushings, a tendency to blackand-blue discolorations, hemorrhages, anidrosis, the influence of the function of the generative glands on the development of the masses, changes in the thyroid gland, benefit from thyroid medication, the influence of heredity, the intermingling in the same case of different types of fat deposit, etc., are all represented in this group of cases, many of them so frequently and conspicuously as to eliminate the factor of chance as an explanation.

In other words, the constitutional symptomatology of general adiposity, nodular lipomatosis, and diffuse symmetrical lipomatosis is essentially one and the same. Within each of these clinical groups there are represented in individual cases every conceivable variation and gradation of symptoms from none at all to the full picture of adiposis dolorosa, so that cases of diffuse symmetrical lipomatosis have, in fact, been reported as adiposis dolorosa. Furthermore, there is not infrequently such an overlapping and blending of types between these groups that individual cases cannot be classified as belonging strictly to any one of them. In such cases the groups break down as entities and fuse into unity. In all there is a common process. In each there is a tendency to individualization, but not, however, strong enough to constitute morbid entities, but only clinical varieties.

Pathology.-Launois and Bensaude believed that they had established a special pathology for diffuse symmetrical lipomatosis by the presence of lymphoid or adenoid nuclei within the fatty masses, and accordingly they named the affection adéno-lipomatose, "adenolipomatosis." subsequent writers have in general followed this conception of the disease. 'The only grounds worthy of mention on which Launois and Bensande based their position were the presence in certain cases within the diffuse fatty tumors of small firm nodules, perceptible by palpation, and the finding in Hayem's ${ }^{\text {s2 }}$ single case of small, blackish lymphatic clusters in the diffuse fatty masses. But these facts seem to lose all significance in this connection in view of the following: The small palpable lumps situated in the diffuse fatty deposits are nothing but invasions of connective tissue, as shown by operation in many cases. Exactly similar structures are common in all varieties of diffuse adiposity and diffuse lipomatosis, as already shown. The description of the small blackish lymphatic structures in Hayems case corresponds to that of hemolymph glands, which they probably were. Similar bodies, identified as hemolymph 
glands, have been found by McCarthy ${ }^{47,122}$ in two cases, both reported as adiposis dolorosa, although one of them probably belonged to the group of diffuse symmetrical lipomatosis. I have not been able to find in the Iiterature any other cases of diffuse symmetrical lipomatosis in which lymphatic tissue, even traces of it, was found within the fatty deposits. It was not found in the cases of Dentu, ${ }^{42}$ Schwartz, ${ }^{171}$ Marçais, ${ }^{116}$ nor, when specially searched for by careful microscopic examination, in the single cases of Desmons, $(f)$ Dieulafoy, ${ }^{52}$ Launois and Bensaude, ${ }^{103}$ Lejars, ${ }^{105}$ Mollard and Petitjean, ${ }^{131}$ Morsaline, ${ }^{133}$ Quéry, ${ }^{153}$ Reclus, ${ }^{15 \overline{5}}$ Tuffer, ${ }^{189}$ the two cases of Nélaton, ${ }^{(g)}$ the two cases of Tapie, ${ }^{184}$ and the three cases of Marotta. ${ }^{118}$

The development of lymphoid structures and especially hemolymph nodes in adipose tissue has been specially studied by Warthin, ${ }^{195}$ who has observed them commonly in a wide range of conditions, e. g., fetal life, pregnancy, lactation, carcinoma, pernicious anemia, splenic anemia, leukemia, chronic inflammation, after splenectomy, etc. The occasional development of lymphoid or hemolymph structures in the fat deposits of diffuse symmetrical lipomatosis, adiposis dolorosa and allied conditions would appear, therefore, to be without great significance and would not warrant the assumption made by Launois and Bensaude of a special pathology connected with these glands and a special designation based thereon. The term "adenolipomatosis" should, therefore, be abandoned.

That this group of cases, like Dercum's syndrome, may show significant changes in the glands of internal secretion (pituitary, thyroid, adrenal, generative, etc.) is proved by the autopsy findings in two cases-the only instances in which the post-mortem examination included a careful microscopical investigation of these organs-reported by Dercum and McCarthy ${ }^{47}$ and by Dieulafoy. ${ }^{52}$ The findings in Dercum and McCarthy's case have been abstracted above. Dieulafoy's patient was a typical example of fatneck with wide distribution of the tumors. He presented no unusual symptoms and died from alcoholic cirrhosis of the liver with terminal tuberculous peritonitis. The autopsy showed: peritoneum, tuberculous; liver, cirrhotic and fatty; spleen, cirrhotic; pancreas, enlarged and cirrhotic; kidneys, congested and hemorrhagic; adrenals, congested; heart, dilated; thyroid, congested, adenomatous hypertrophy; pituitary, enlarged and congested; brain, congested, with typical dissemination of tuberculous granulations in the Sylvian and Rolandic areas; nervous system, "intact;" spinal cord, normal. The diffuse fatty masses infil-

(f) Cited by Dieulafoy, ${ }^{52}$ p. 755 .

(g) Nélaton: Cited by Pestemazoglu. ${ }^{14}$ 
trated deeply and extensively into the surrounding tissues. No traces of lymphatic tissue could be found anywhere in these masses, but connective tissue invasion was present in places.

GROUP V. NEUROPATHIC EDEMA, PSEUdo-EDEMA, PSECDO-LIPOMA, LIPOMA, ETC.

It is necessary to mention a motley group of cases, little understood, still poorly classified, and described under many designations, e. g., oedème hystérique (Charcot, Warde) ; oedème bleu des hystériques (Charcot) ; oedème blanc et bleu (Charcot, Strübing); oedème névropathique (Mathieu); oedème névropathique éléphantiasique (Lourier); oedème segmentaire (Debove); pseudo-oedème catatonique (Dide); pseudoéléphantiasis névropathique (Mathieu); trophoedème chronique (Meige); lipomes symétriques d'origine névropathique (Mathieu); dystrophies cellulo-conjonctives vasculaires (Dide). The cases described under these and similar designations represent various subcutaneous infiltrations that appear at first sight, many of them, quite unrelated to the subject of this paper. A more careful study, however, suggests that the pathological process concerned in these cases may be related to the development of fatty deposit. I shall refrain from expressing a personal opinion and confine myself to presenting the views of others, in abstract, on the relations of these various cases. Briefly stated, the assertion of the French writers is that the process is one of gradual transition from neuropathic edema or pseudo-edema to pseudolipoma and finally to true lipoma (Potain, ${ }^{148,149}$ Mathieu ${ }^{119}, 120,121$ ).

It is strange, as Strübing ${ }^{179}$ observed, that a considerable literature on this subject should have developed almost exclusively in France, "although here a certain one-sidedness has been exhibited in the view of its genesis. Charcot, ${ }^{28}$ who in his observations found the infiltration of the skin especially in persons with functional disturbances of the nervous system, invested it, therefore, with the name oedème hysterique."

The earliest reference to this subject appears to have been made by Sydenham, ${ }^{182}$ who observed: "Hysteria affects not only all the internal organs but involves also sometimes the external parts of the body and causes sometimes pains, sometimes swellings, the most distinct of which are those of the lower legs. The swelling neither yields to the impress of the fingers nor leaves a mark. The swelling so closely resembles dropsical swelling in size and surface that the patients are with difficulty convinced that it is not dropsy" (Charcot ${ }^{26}$ ). 
Brodie $^{(h)}$ observed the same phenomena: "Repeatedly a swelling develops on the thighs and buttocks, either as a result of a turgescence of the blood-vessels or an infiltration of the cellular tissue, but principally as a result of turgescence of the blood-vessels, for the affected parts show no trace from the pressure of the fingers."

Edemas, described as "neuropathic" or "hysterical," have long been recognized in disease of the spinal cord, apoplexy, etc. (Strübing ${ }^{179}$ ). "Chronic elephantiasis-like edema may follow certain lesions of the central nervous system, cerebral hemorrhage, softening, acute myelitis, cerebral tumors, spinal cord diseases, ataxia, Parkinson's disease, sciatica, rheunatism and rheumatoid affections." "In short, one has encountered neuropathic edema following all the known lesions of the cerebrospinal system, neuroses, in cases showing no symptoms of nervous affection" $\left(\right.$ Lourier $\left.^{110}\right)$.

Similarly, "the influence of the nervous system on the more or less abundant production of fat is, in fact, indisputable. Duchenne of Boulogne has called attention to adiposity of the subcutaneous connective tissue in paralytics" (Chantemesse and Podwyssotsky ${ }^{25}$ ). Landouzy ${ }^{98}$ has pointed out the existence of localized subcutaneous adipose deposits in the muscular atrophies secondary to neuralgias, cerebral tumors, medullary lesions, etc. (Sellerin ${ }^{172}$ ). "Chronic edema evolves into sclerosis when it is inflammatory, into lipoma when it is neuropathic" (Milian $\left.^{198}\right)$. "Recently published works of the Societé médicale des hôpitaux: (Bucquoy, ${ }^{22}$ A. Siredey, ${ }^{175}$ A. Mathieu ${ }^{139}$ ) have established relations between neuropathic edema, pseudolipoma and lipoma, which constitute an uninterrupted series of anatomical conditions related to each other." "Symmetrical lipomata can be considered as examples of localized obesity" (Chantemesse and Podwyssotsky ${ }^{25}$ ).

According to Chuffart," "the circumscribed edema that pits on pressure, the circumseribed edema that does not pit, and the true lipoma constitute three stages, the three degrees of erolution of one and the same tumor" (Lourier $\left.{ }^{110}\right)$. Mathieu ${ }^{119,120,121}$ considers the process one of gradual transition from neuropathic or arthritic edema to pseudolipoma and finally to true lipoma. Potain, ${ }^{148,}{ }^{149}$ Desnos, ${ }^{48}$ and Antony ${ }^{5}$ hold the same view. According to Potain, ${ }^{149}$ "the serous infiltration makes the ground for and excites the accumulation of fat and of fat cells" (Lourier $\left.{ }^{110}\right)$.

Cheinisse ${ }^{28}$ believes that the different forms of lipomatosis and the neuropathic edemas cannot be separated, but constitute a common group of related cases. "For the explanation of the genesis of the elephantiac

(h) Cited by Warde, ${ }^{19:}$ p. 11. 
form of obesity; the same view must be considered as assumed for the genesis of symmetrical lipomata," i. e., a "trophoneurosis" (Strübing ${ }^{179}$ ). "Bucquoy" considers the diffuse symmetrical lipomata as being of nervous origin, due to a trophoneurosis, leading to dystrophies of the fat tissues which develop into lipomata" (Lourier ${ }^{110}$ ).

"Potain" ${ }^{149}$ has shown that in a rheumatic subject a transformation from edematous pseudolipomata to true fatty lipomata can take place; for Potain, in the firm edema, the serum does not develop in the interstitial spaces, but within the cells of the connective tissue" (Lourier ${ }^{110}$ ). According to Potain, ${ }^{149}$ "arthritism is, in fact, a predisposing cause of these edemas, it is important to note. Most of the subjects who show nervous edemas are arthritic or rheumatic; often they are subjects of hereditary gout" (Lourier ${ }^{110}$ ). "I, too, have been struck by the relatively frequent coincidence of such joint affections and the infiltrations of the skin" (Strübing ${ }^{170}$ ).

Lourier" concludes: "The vasomotor disturbances that belong to the pathology of the neuropathic edemas can finally produce an elephantiasis in the affected region. The nervous edema develops as a complication in a great number of affections of the nervous system or more frequently in subjects of neuropathies. It is much more frequent in women than in men. Once developed, the condition of elephantiasis is incurable. - . Neuropathic pseudo-elephantiasis and arthritic pseudolipoma have a certain degree of relationship: both are arthritic-neuropathic manifestations."

Miquel"129 concludes: "All these morbid conditions have a common origin, in changes in the nervous system and in the different glands of the vascular system. They are probably, then, only varieties or stages of the same affection which constitutes the category of dystrophics celluloconjonctives vasculaires (Dide). Adiposis dolorosa ought to be brought into the class of these different pathological conditions, and it does not seem to constitute a well-defined clinical entity."

Many of the French writers, following the view of Charcot, have laid much stress on hysteria as a cause of these infiltrations. Charcot ${ }^{26}$ said: "Not often do I find described a form of edema, which we may call the pale edema of hysterics (the white edema of Sydenham), which in its changes resembles hydropsical edema except for the fact that in this latter, at least as a rule, a mark is left by the impression of the finger. Just as rarely have I found mentioned another form of edema, which, like that of Sydenham, presents itself as a swelling, which does not yield to the pressure of the fingers, but which differs from Sydenham's form in two evident signs, namely, by a lowering of the local temperature and 
by a blue-violet color, which, sometimes very dark, sometimes only lilac, gave its name to the blue edema (l'oedème bleu), which I have proposed, because the change of color, so to speak, strikes the eye more than any other fact."

Similarly Warde ${ }^{193}$ concluded: "Among the trophic disorders of hysteria, one of the more important is edema, which can be of two kinds: white or blue. It develops in subjects with hysterical stigmata, showing a vasomotor diathesis. It is differentiated from other edemas by the firm consistence, the special color, the absence of serum. . . . "Strïbing ${ }^{179}$ said: "I have repeatedly found in these patients a reddish and bluish discoloration of the skin of the extremities, especially the lower legs and forearms. That these vasomotor disturbances are of accidental nature admits of no doubt, for with infiltrations of equal intensity they are sometimes present, sometimes absent." "Hysterical manifestations of various kinds frequently complicate the disease picture, especially in patients of the better class, but are entirely absent in others."

"Correspondingly Lourier"10 also gives a wider range to the etiology of this edema. 'One is especially impressed with the neuropathic edema as the result of all known diseases of the cerebrospinal system, as the result of neuroses, and finally in cases in which the patient shows no symptom of a nervous disease; but whether the edema occurs with one or another of these conditions the method of its onset and its clinical appearances are quite constant'" (Strübing ${ }^{179}$ ).

"Therefore, one must conclude, say Mathieu and Weil," that always the same physiological mechanism is disturbed in spite of the variation of the precedent condition in the different cases" (Strübing).

Strübing ${ }^{179}$ has reviewed very critically the relation of these so-called edemas to adiposis dolorosa and has established to his own satisfaction their essential identity. The same symptomatology may be shown in both conditions. As to pain and tenderness in the affected parts, they may be absent or present and in every degree of intensity, corresponding in general to the intensity of the process. Mathieu ${ }^{120}$ has directed special attention to pain in neuropathic pseudo-elephantiasis both diffuse in the lower extremities and especially along the course of the sciatic nerves. Fluctuations in size and exacerbations in the intensity of the swellings and pains may occur (Mathieu, ${ }^{120}$ Milian, ${ }^{127}$ Strübing ${ }^{179}$ ). Dide ${ }^{51}$ has reported marked benefit from thyroid medication both in the infiltrations and the mental condition. Puncture or incision of the skin over the infiltrations has been made in many cases without obtaining the fluid of edema. Strübing excised the subcutaneous fat in one of his cases and 
found that it was not edematous, much more firm and compact than normal, and the fat cells very large as sometimes they are found in lipoma.

"The designation of Charcot, oedème blanc et bleu, is scientifically objectionable, because it emphasizes the idea of edema which is not applicable to the pathological condition present in the skin of this affection" (Strübing).

GROUP VI. CEREBRAL ADIIOSITY, "ADIPOSITAS CEREBRALIS," "DYSTROPHIA ADIPOSO-GENITALIS," "SYNDROME HYPOPHYSAIRE ADIPOSOGÉNITAL,” FRÖHLICH'S SYNDROME, ETC. ${ }^{\dagger}$

Although the association of cerebral tumor or other cerebral disease with general adiposity had been previously recognized, the present interest in this relation dates from the publication of Fröhlich's ${ }^{67}$ paper in 1901. This writer reported the case of a boy of 14 years with certain localizing cerebral symptoms (optic atrophy) and in addition a condition of general adiposity and sexual infantilism (hypoplasia of the genital organs), leading to the diagnosis of tumor of the hypophysis, which was confirmed by a subsequent operation by von Eiselsberg.55, 56 This and allied observations collected from the literature led Fröhlich to attribute the condition of adiposity and sexual infantilism to disease of the hypophysis and to regard this association of phenomena as constituting a new syndrome, to which later writers have applied the designations, dystrophia adiposo-genitalis," syndrome hypophysaire adiposo-génital, 104 "Fröhlich's syndrome," etc. Many similar cases have since been reported. A few of these cases have been operated on successfully; von Eiselsberg and von Frankl-Hochwart ${ }^{56}$ excised the hypophyseal tumor in two cases, including Fröhlich's original case, with the result that in each the delayed sexual signs subsequently appeared. In one of these cases a slight loss of weight $(1.6 \mathrm{~kg}$.) occurred after the operation, in the other some increase.

Subsequently Erdheim, ${ }^{59}$ Bartels ${ }^{11}$ and others reported cases presenting the clinical features of Fröhlich's syndrome with tumor involving the duct of the hypophysis (Hypophysenganggeschwülste), the infundibulum or overlying parts, but not the hypophysis itself, and were led

† The most important papers relating to the subject of adipositas cerebralis in its different aspects are the following: Fröhlich, ${ }^{87} 1901$; Erdheim, ${ }^{\text {,8* }}$ 1904; Bartels, ${ }^{12 *}$, 1906; Uhthoff, ${ }^{189}, 1907$; Tandler and Gross, ${ }^{183}$ 1908; Marburg, ${ }^{115 *}$ 1908; Cushing, ${ }^{35} 1909$; Delille, ${ }^{41 *} 1909$; Launois and Cléret, ${ }^{104} 1910$. The best bibliographies of the subject are found in the above references that are marked with an $\left(^{*}\right)$. A complete bibliography is also promised by Launois and Cléret in the forthcoming Paris thesis of E. Grahaud, entitled Le syndrome hypophysaire adiposo-génital. 
thereby to suggest that the trophic disturbances of Fröhlich's syndrome were due not to lesion or irritation of the hypophysis, but rather of some unknown trophic center located in or near the infundibulum at the base of the brain. This suggestion was met by the counter-suggestion that in Erdheim's case and similar cases the hypophysis was indirectly affected in its secretory function by the pressure of the overlying tumor.

Later, in 1908, Marburg ${ }^{114,115}$ reported a case and collected a few other cases from the literature of tumor of the pineal gland associated with general adiposity, without evident gross or microscopic alteration of the hypophysis, and on these observations he advanced the hypothesis that the adiposity and certain other trophic phenomena (i. e., genital hyperplasia) were related to disease of the pineal gland, as a trophic center.

In still other rare instances, tumors or other disease of the brain in general have been associated with marked adiposity and other trophic phenomena.

All such instances of adiposity have been grouped together, pending the determination of their ultimate etiological relations, under the general designation "adipositas cerebralis." Of the several groups of cases in this eategory, those belonging to the hypophyseal group-involving the hypophysis itself (Fröhlich's group) or its connection with the base of the brain (Erdheim's group) - are by far the most conspicuous and characteristic. Marburg ${ }^{115}$ was able to tabulate thirty-five instances, in 1908, and since then many others have appeared in the literature. Instances of the other varieties are distinctly rare. Only a few of the forty-four cases of disease of the pineal gland collected by Marburg ${ }^{115}$ presented any marked adiposity. Therefore, the adrocates of the hypophyseal origin of the adiposity have been inclined to ignore the other cases in which the hypophysis was not involved by the tumor or to explain such cases as indirectly hypophyseal in nature by reason of a supposed secondary effect on the hypophysis by pressure.

The supposed relation of disease of the pituitary (or pineal) gland to adiposity or other dystrophy led to the proposal ${ }^{114}{ }^{115}$ of a hypothetical scheme of explanation of the symptomatology, suggested by the analogy of the thyroid gland, as follows:

\begin{tabular}{|c|c|c|}
\hline Dysthyroidism. & $\left\{\begin{array}{l}\text { hyperthyroidism } \\
\text { hypothyroidism } \\
\text { athyroidism }\end{array}\right.$ & $\begin{array}{l}=\text { exophthalmic goiter. } \\
=\text { cretinism, myxedema. } \\
=\text { cachexia thyeopriva. }\end{array}$ \\
\hline Dyspituitarism. & $\left\{\begin{array}{l}\text { hyperpituitarism } \\
\text { hypopituitarism } \\
\text { apituitarism }\end{array}\right.$ & $\begin{array}{l}=\text { gigantism, acromegaly. } \\
=\text { adiposity, genital hypoplasia. } \\
=\text { cachexia hypophyseopriva. }\end{array}$ \\
\hline Dyspinealism. & $\left\{\begin{array}{l}\text { hyperpinealism } \\
\text { hypopinealism } \\
\text { apinealism }\end{array}\right.$ & $\begin{array}{l}=\text { adiposity. } \\
=\text { genital hyperplasia. } \\
=\text { cachexia pinealipriva. }\end{array}$ \\
\hline
\end{tabular}


I shall not enter here into a discussion of the views above briefly outlined, deferring this for consideration below under etiology, but it seems appropriate in this place to call attention to the possibility of more comprehensive relations of adiposity and genital hypoplasia to the different glands of internal secretion than is embraced in the conception of a limited hypophyseal etiology.

Acromegaly and gigantism (hyperpituitarism?) frequently exhibit wide-spread pathological alterations in the various glands of internal secretion besides the hypophysis. Hypoplasia of the generative glands (sexual infantilism) is especially common. General adiposity may also develop concurrently with acromegaly or gigantism, and "lipomas often occur in the skin" (Dock)..$^{53}$ Wurmbrand ${ }^{203}$ has reported an instance of acromegaly characterized by the concurrent development of adiposity, and in addition the case presented lipomata over the shoulder-blades. Strümpell ${ }^{180}$ has reported a similar combination-acromegaly, general adiposity and a lipoma over the base of the neck in a young woman. Other instances of this association ${ }^{158,159,41}$ will be mentioned below. In giantism with sexual infantilism, "there is no case as yet on record in which the administration of pituitary gland substance has started the delayed sexual development"' (Thomson). ${ }^{186}$

As already stated, Marburg ${ }^{114}$ has attributed the adiposity in his cases to tumor of the pineal gland, as a trophic center.

Infantilism is common in diseases of the thyroid gland, i. e., myxedema, cretinism, and is cured in general with other manifestations by thyroid medication. Moreover, in the absence of frank signs of myxedema, infantilism associated with adiposity of the feminine type may oceur and be cured by thyroid treatment. Hertoghe, ${ }^{85}$ Brissaud, ${ }^{19}$ Apert, ${ }^{6}$ Meige, ${ }^{126}$ Hutinel ${ }^{91}$ and others have reported many instances. As is well known, myxedema and cretinism are not infrequently characterized by more or less adiposity, either general or localized, and distinct lipomatous formations are not rare. Rogers' observations in this connection have already been given (under Group III).

A pancreatic form of infantilism has been claimed by Bramwell ${ }^{18}$ and Rentoul, ${ }^{161}$ who have reported cases presenting also a certain degree of the feminine type of adiposity and persistent diarrhea. These patients were cured, after thyroid treatment had completely failed, by the continued administration of pancreatic extract; the diarrhea ceased and adolescence and normal growth became established.

Hypertrophic biliary cirrhosis in young people is not infrequently complicated by a condition of infantilism, in some instances with a cer- 
tain degree of adiposity. Lereboullet ${ }^{10 z}$ and other French writers have called special attention to this association.

Disease of the adrenal glands may also rarely exhibit the same association. Morlat ${ }^{132}$ reported three instances of Addison's disease complicated with infantilism, one of which was greatly benefited by the prolonged use of adrenal preparations. Marchand ${ }^{(i)}$ reported a case of hermaphroditism with atrophy of the ovaries and hypertrophy of the adrenals. On the other hand, adrenal tumors may be associated with excessive development of the genitals, hair and fatty tissue [Woolley, Bullock and Sequeira $\left.{ }^{(j)}\right]$, or even with general precocious development $\left[\right.$ Linser $\left.^{(k)}\right]$.

In status lymphaticus, adiposity and hypoplasia of the genital organs are common and "a condition of infantilism may persist after the age of puberty" (Warthin ${ }^{196}$ ). In a large autopsy material Bartel ${ }^{10}$ found this condition, which he calls the "hypoplastic constitution," often characterized by "adipositas universalis," genital hypoplasia, colloid hyperplasia of the thyroid, hyperplasia of the thymus, and other trophic disturbances; no mention is made of the finding of pathological changes in the hypophysis.

An intimate relation between the function of the generative glands and adiposity is well known and will be considered below, under etiology.

All the facts, above cited, seem to imply that not only the pituitary gland, but also many of the glands of internal secretion (pituitary, generative, thyroid, thymus, pancreas, adrenal, liver, pineal, etc.) may be concerned, directly or indirectly, in the production of adiposity and genital hypoplasia, symptoms which bave been specially emphasized as characterizing hypophyseal tumor, i. e., Fröhlich's syndrome.

I have not had the opportunity to review critically the group of cases of Fröhlich's syndrome with reference to the special object of this paper. It is desirable that this be undertaken. The impression that $I$ have received from a somewhat intimate acquaintance with the literature of these cases is that they do not constitute a separate entity, but are related both in symptomatology and pathology to the other groups of abnormal fat deposits. This view is based on the presence, in certain of these cases, of mental disturbances, asthenia, pain and various nervous, sympathetic and vasomotor symptoms and also on the fact, already presented, that autopsies in several cases of "adiposis dolorosa" have shown tumor or other changes in the pituitary body and atrophy of the generative

(i) Dock, i3 p. 354.

(j) Dock, ${ }^{53}$, p. 359 .

(k) Dock, ${ }^{53}$, p. 354 . 
organs (ovaries) and in one case reported as "adiposis dolorosa," and coming within the group of diffuse symmetrical lipomatosis, tumor of the pituitary body and atrophy of the testicles and penis.

In a case of "degeneratio adiposo-genitalis," reported by von Eiselsberg and von Frankl-Hochwart, ${ }^{56}$ the patient operated on was mentally dull and had "diffuse pains over the ribs and the joints of the extremities."

White's ${ }^{200}$ case, reported as "adiposis dolorosa," probably is essentially identical with Frölich's cases. Preceding the establishment at 12 of the menses, which remained quite irregular, the patient began to grow obese and at 13 weighed 280 pounds. Simultaneously with the development of the obesity, spontaneous paroxysmal pains appeared in different parts of the body, including the head and eyes. At 15 the patient's mind began to be affected and she had periodical attacks of dementia ushered in by epileptiform fits. At 22, when she was observed by White, she was excessively obese, markedly asthenic, mentally disturbed; the sensations for temperature touch and pain were impaired; and the masses of fat were very tender, so that she could not bear to have them grasped. Under combined thyroid medication and massage continued for nine months there was a loss of $\gamma_{0}$ pounds in weight with improvement of the mental condition. Compare also with this case that reported by Dercum and McCarthy, ${ }^{47}$ abstracted above.

Renon, Delille and Monier-Vinard ${ }^{159,41}$ have reported the case of a man of 36, with retarded sexual development, scant growth of hair on the face, axillæ and genital region, intellectual torpor, polyuria, pronounced obesity, voluminous breasts, atrophy of the thyroid, enlarged sella turcica (observed by $x$-ray) and other tissue changes indicating acromegaly. Most of these phenomena had developed during the preceding two years. Located near the knee was a small lipoma, painful to pressure. The same authors ${ }^{158,41}$ have reported the case of a girl of 16 , in whom had developed concurrently during the preceding four years the following complications: acromegaly, optic atrophy, frontal headaches, mental and cerebral symptoms, sexual infantilism and adiposity, especially of the trunk, irregularly lobulated in places and distinctly painful to slight pressure.

Case 11 of the series presented in this paper, belonging to the fatneck group, also throws light on this question. The disease began in this patient and her two sisters at puberty and reached its full development before maturity. In the case of the patient there was dysmenorrhea, imperfect mental development, asthenia, some tenderness in the fatty 
masses, recurrent sciatica, anidrosis, hemorrhages, etc., and one of the patient's sisters having fatneck was insane.

Further, Fröhlich's syndrome varies widely in the different cases in the degree of adiposity and in the genital involvement. The adiposity varies from normal to excessive. Genital atrophy is not constant, being found in only twelve out of thirty-two patients that were examined at autopsy (Marburg). ${ }^{115}$ Finally it may be pointed out that hypophyseal tumors may occur in association with a considerable variety of trophic disturbances $^{(l)}$ or even without any at all.

\section{CONSIDERATION OF THE COMBINED GROUPS}

\section{GENERAL SUMMARY}

It has been attempted to show that the several groups of cases of subcutaneous fat deposit, whether diffuse or circumscribed, do not constitute clinical and pathological entities, but rather varieties in the expression of a common morbid process; that this process may involve a profound and wide-spread disturbance of the organism, with a resulting complex constitutional symptomatology; and that this symptomatology varies within wide limits, tending sometimes to more or less individualization and constituting thereby clinical varieties or groups of cases, not sharply defined.

There remains only to emphasize some of the characteristics in the symptomatology and to consider the etiology of the process.

Age.-No period of life is spared; childhood, adolescence, maturity and senility are all embraced in the period of inception of the process. A majority of cases occur in middle adult life, in women especially at the time of or shortly after the menopause.

Sex.-The sexes tend to be unequally represented in some of the groups; in the group of diffuse symmetrical lipomatosis with predilection for the neck (fatneck), males greatly predominate; in the group of circumscribed nodular lipomatosis, Grosch ${ }^{73}$ found that solitary lipoma occurred in the sexes in the proportion of 100 males to 162 females and in general in this group females somewhat outnumber males; females also predominate greatly in the groups of adiposis dolorosa and neuropathic pseudo-edema.

(l) Acromegaly, gigantism, dwarfism, acromegaly or gigantism with adiposity or lipomatosis, myxedema, cretinism, Addison's disease, general adiposity, genital hypoplasia, general adiposity and genital hypoplasia (Fröhlich's syndrome), general adiposity presenting Dercum's syndrome, diffuse symmetrical lipomatosis presenting Dercum's syndrome, etc. 
Fat Deposits.-These may occur in any of the forms already described or in mixed forms.

Pain.-In all the groups, pain, both spontaneous and induced by pressure, may occur in the fatty deposits. Local pain may precede the development of these deposits of whatever type or variety. Exacerbations in intensity or paroxysms of pain may occur in all. Pain is not frequent in the group of diffuse symmetrical lipomatosis, but may occur and of an intensity equal to that seen in typical cases of Dercum's syndrome.

There are reasons for believing that the pain depends on the presence of a chronic, low-grade, interstitial neuritis of the small nerve fibers distributed in the fatty deposits. Microscopical examination of the painful fat showed this condition in five out of six autopsies on cases of Dercum's syndrome in which special examination was made, including one case that belonged to the group of diffuse symmetrical lipomatosis; in this case interstitial neuritis was found in the nerve fibers both of the diffuse fat and within certain circumscribed lipomata included in the diffuse fat.

Examination for nerve fibers within painful nodular lipomata has been made by Vitaut, ${ }^{192}$ Rénon and Louste, ${ }^{160}$ Weiss, ${ }^{198}$ Spitzer ${ }^{177}$ and myself (Case 19), without success. Thimm ${ }^{185}$ identified doubtfully nerve fibers in a painful lipoma, Alsberg ${ }^{3}$ positively succeeded in one case, and in Case $18 \mathrm{I}$ found a definite small nerve bundle within a connective tissue septum of a very small painful lipoma, with changes interpreted as indicating a chronic interstitial neuritis.

Some writers, e. g., Strübing, Thimm, Spitzer, explain the pain as due to congestion or stasis in the fat deposits, causing mechanical interference (tension, pressure) with the surrounding nerves. This factor undoubtedly plays a part in the causation of pain, especially the paroxysmal pain accompanying exacerbations with increase in the size and consistence of the fatty masses. The marked amelioration of pain following profuse hemorrhage, in my Cases 2 and 3 , would tend to support this view. Koettnitz, Riedel and other writers express the view that the lipomata are not primary and the pain secondary, but "both are the product of one and the same cause," i. e., a "trophoneurosis."

Finally, pain may be regarded as an accidental symptom, absent in the majority of cases, but present in certain cases of all groups. It is one of the many constitutional symptoms that characterize this process. Its presence in any case does not distinguish that case from similar cases without pain and does not determine an entity (adiposis dolorosa). 
Asthenia.-This occurs in a minority of cases of all the groups and does not especially distinguish the cases with pain. It is one of the general symptoms.

Mental Symptoms.-These are extremely variable, inconstant, and may occur in cases in all groups. In the great majority of cases they are as good as wanting. When present, even in Dercum's syndrome, they are usually slight in the form of simple nervousness and only exceptionally reach the grade of the major psychoses. Even dementia, insanity, suicide, etc., may occur in cases of lipomatosis without pain.

The so-called accessory symptoms of Dercum's syndrome are exhibited typically and in great variety and combination in all the groups, as shown. Several of these symptoms that have been emphasized as characterizing adiposis dolorosa are prominent in the symptomatology of the other groups, including pigmentation of the skin, anidrosis, hemorrhages, local flushing with red or blue discoloration, tendency to bruising, paroxysms or exacerbations in the intensity of the process with increase in the size and consistence of the masses and in the pains, varicosities, tachycardia, headache, disturbances of sensation, etc.

Arthritism, Rheumatism, Neuralgia, Neuritis. ${ }^{(m)}$-These manifestations occur in the several groups of fatty deposit with such frequency and such close relation to the course of the disease that attention should be directed to them as symptomatic of the morbid process. Striking examples of this relation are seen in Cases 10 and 11, in one of which attacks of sciatica and in the other attacks of sciatica and articular pain and swelling began with the first appearance of the fatty masses and recurred thereafter at short intervals throughout life. The same symptoms are frequently mentioned in the family history of cases.

The occurrence of these symptoms can be no mere coincidence. They belong clearly to the symptomatology of the morbid process, related probably to disturbances of function of the glands of internal secretion.

(m) In directing special attention to this group of symptoms some definition of the terms used is desirable. This is by no means easy as the manifestations cover such a wide range. The terms, "rheumatism," "rheumatic," "rheumatoid," "arth. ritism," "arthritis," "arthritic," "arthralgic," etc., refer to the many articular and periarticular manifestations which still defy scientific medical classification, e. g., pain, stiffness, swelling, flushing, chronic structural changes, hypertrophic and atrophic arthritis, Heberden's nodes, etc., in short the whole array of articular manifestations short of acute rheumatic fever. The terms "neuralgia," "neuralgic," "neuritis," "neuritic," carry their usual signification and imply no greater diagnostic accuracy than is permitted by the symptomatology of any given case. Greater accuracy of definition and statement is not warranted. The essential point is that these manifestations occur in many of the cases and seem clearly to belong to the general symptomatology of the trophic disorder. 
Diamantberger ${ }^{49,50,197}$ has called special attention to a certain degree of etiological relation between disturbances of function of the thyroid gland and "rheumatism," $(n)$ acute, subacute, chronic, and has claimed that thyroid therapy can cure these conditions in some instances. Several writers, ${ }^{(0)}$ notably Léopold-Lévi and de Rothschild, ${ }^{106}$ have corroborated this claim, especially as regards certain types of chronic "rheumatism." Morsaline ${ }^{133}$ has reported cases of "chronic rheumatism" associated with symmetrical lipomata in the region of the affected joints in which, as the result of thyroid medication, not only were the articular manifestations benefited, but also "the lipomata about the joints were reduced in size and in some instances completely disappeared."

Similar arthritic and neuralgic manifestations have been described also, sometimes in recurrent attacks, in other conditions that are dependent on or related to disease or change of function in one or other of the glands of internal secretion, e. g., exophthalmic goiter, myxedema, cachexia strumipriva, Addison's disease, acromegaly, epilepsy, idiocy, obesity, diabetes, menopause, etc., and it should be remembered in this connection that chronic interstitial neuritis is not uncommon in some of these affections, notably in acromegaly. The "growing pains" and arthralgia of adolescence may be recalled in this connection, and the not infrequent development of Heberden's nodes and other forms of hypertrophic arthritis with the menopause.

Heredity.-A neuropathic family history has been noted frequently in all varieties of abnormal fat deposit, but direct heredity or the multiple incidence of the disease in families has been supposed to be excessively rare except in the form of common obesity. Either this opinion is erroneous-and I believe that it is, and because attention has not been directed to this relation-or my personal experience in this regard has been exceptional, for it is shown in no less than seven of the twenty cases, above reported by me, involving twelve different persons. In order to emphasize this relation, I shall present in abstract the different instances that have come to my attention, personal or from the literature, as follows:

Lron (Cases 14 and 15).-A father (Case 14), aged 52 years, had a solitary lipoma excised from his thigh at the age of thirty. It recurred at the same point and is now present, about the size of an orange. His son (Case 15), aged 26 , presents multiple, partly symmetrical, circumscribed lipomata, which have been growing since he was 14 years old.

(n) Lancereaux and Paulesco, Parhon and Papinian, Viala, Claisse, LéopoldLévi and de Rothschild, Sergent, Ménard, Vincent, Acchiotté. Cited by Diamantberger, ${ }^{50}$ pp. 336-337.

(o) Diamantberger ${ }^{50}$ offers an ingenious explanation of the dual etiology of infection and thyroid perversion in these affections. 
Perrén. ${ }^{146}$-Multiple symmetrical lipomata, symptomless, in a man aged 58 years. His mother had had multiple lipomata, not symmetrical.

Murchison..$^{135}$-Multiple lipomata on the arms in corresponding positions in a father and two daughters. Nine sons were free.

RENARD. ${ }^{\text {inz }}$-Subcutaneous tumors, which gradually increased in size, appeared over the whole body, except the face, palms and soles, in a previously healthy mother after weaning a child. The child, a boy, very poorly developed in mind and body, showed very similar tumors with about the same distribution. Petrén, ${ }^{146}$ referring to this case, says: "The lipomatous nature of these tumors seems to me not to be beyond question." Possibly they were instances of von Recklinghausen's disease, neurofibromatosis.

Lxon (Case 16).-Multiple, symmetrical nodular lipomatosis in a strong, healthy man of 49 , first appearing at the age of 18 . Each new growth was preceded by local pain followed in a few days by black-and-blue discoloration and then by the appearance of the tumor. History of multiple attacks of inflammatory rheumatism; neuralgia; phlebitis of the left saphenous vein. Marked rheumatic family history. His father had the same kind of fatty tumors, with the same distribution in the forearms.

Chevers. ${ }^{29}$....Multiple lipomata, widely distributed over body, symptomless except that "before each growth appeared he had an aching sensation at the spot which lasted until a shotty papule made its appearance" in a man aged 75 . The disease began at the age of 40 . "Typical lipomata." "Some of the tumors are as big as a child's head." The hands, legs below the knees, feet and face are spared. His "father had the disease, and died a hale and hearty old man." "One of his living sisters has the disease." Also, "two of his sisters and one brother have been subject to fits ever since they were 10 years old." (Reported as adiposis dolorosa.)

HAMMOND. ${ }^{80}$-Multiple lipomata in a woman, aged 61 . They first appeared in the forearms when the patient was 35 ; subsequently also on the thighs and abdomen. Pain was a marked and persistent feature. Considerable tenderness to touch in the tumors. A sister, 40 years of age, was similarly affected. In her ease the "disease started some years ago, in much the same manner, with local tumors in the arm, and fresh ones are gradually forming elsewhere. Here, again, pain has been a noticeable element." (Reported as adiposis dolorosa.)

BLASCHKo.14-Multiple lipomata, large and small, on different parts of the body, occurring in corresponding positions in a father, his sons and his brother, beginning in all at puberty. The female members of the family and the sons under the age of puberty were free.

Reverdr. $.^{162}-1$. Symmetrical diffuse lipomatosis of the thighs in a woman, aged 20 , and identical tumors in two sisters.

2. Similar lesions, similarly situated on the thighs, in another young woman and correspondingly in her mother.

SToll. ${ }^{178}$ - Symmetrical diffuse lipomatosis in back of neck, typical fatneck, in a man, aged 33. "The patent's mother has had for ten years a painless tumor on the shoulder. His mother's brother has had for several years painless tumors in the same locations as in himself."

Lyon (Case 11).-Diffuse symmetrical lipomatosis, type fatneck, in a woman, aged 33 , and similarly in two sisters, beginning in all at puberty and reaching maximum development before maturity. The patient was dull mentally, asthenic, had dysmenorrhea, recurrent sciatica, hemorrhages, anidrosis, and slight tenderness in the fat deposits, most of these symptoms dating from the onset of the lipomatosis. One of the sisters with fatneck was insane. Arthritic family history. 
Lxox (Case 2).-Dercum's syndrome, elephantiac and diffuse form, in a woman, aged 75 , dating from the age of 25 . A daughter, with symptoms of hys teria, developed in early childhood two lipomata, painless, symmetrically placed, one on each side of the back in the lumbar region, about the size of a hen's egg, which remained unchanged and symptomless until her death at 20 years of age.

Lyon (Cases 3 and 4).-Dercum's syndrome, generalized diffuse and nodular mixed form, in a woman (Case 3), aged 55 years, whose flesh had always from early childhood been tender and painful and subject to ready bruising with blackand-blue discoloration. This peculiarity of tenderness and bruising of the flesh from early childhood has been equally shared by two daughters, aged now 34 and 37 years respectively. One of these daughters (Case 4) shows slight fat-bags in the upper arms, but otherwise no abnormality of fat deposit. She also presents many of the symptoms of Dercun's syndrome.

Lyon (Case 5).-Atypical Dercum's syndrome, localized diffuse and nodular mixed form, in a woman, aged 64. Marked personal and family history of arthritism. Personal history of epistaxis, neuritis, cerebral attacks. Tenderness and bruising of the flesh from childhood, a peculiarity shared equally by three sisters and one daughter. During the past five years development of subcutaneous lipomata, painful spontaneously and on pressure, and during the same period loss of strength. During the past year increased adiposity over abdomen and hips. Normal mentality.

A cousin, son of the patient's father's brother, aged 51 , is somewhat obese and presents symmetrical lipomata in the lumbar and dorsal regions, painful spontaneously and on pressure. The subcutaneous fat everywhere is slightly but definitely tender on pressure and has been markedly subject to easy bruising. Several attacks of cervico-brachial neuralgia; hyperidrosis; headache; neurasthenic mentality; no asthenia.

SIEvert. ${ }^{174}$-Type, adipositas cerebralis. Marked general adiposity, involving especially the breasts, abdomen, mons veneris and buttocks, associated with optic atrophy, occurring in both brother (aged 15) and sister (aged 9). No evidence of genital hypoplasia, enlargement of the sella turcica ( $x$-ray), acromegaly, gigantism, or other trophic disturbances. Family history negative for obesity.

These cases illustrate the heredity or family incidence of circumscribed lipomatosis, solitary, multiple, symmetrical; of circumscribed symmetrical lipomatosis with the symptoms of Dercum's syndrome; of diffuse symmetrical lopomatosis, both involving the neck (type fatneck) and not involving the neck, some with and some without the symptoms of Dercum's syndrome; of diffuse adiposity with all or many of the symptoms of Dercum's syndrome; of adipositas cerebralis; and of mixed and crossed types. Certain of these cases are of such a character as clearly to exclude the factor of accident or coincidence and to require the recognition of heredity as the only reasonable explanation.

\section{ETIOLOGY}

Many views have been suggested to explain the morbid process in one or other of its forms, most of which may now be regarded as obsolete (e. g., the skin-gland hypothesis of Grosch, ${ }^{73}$ the adenoid-gland hypothesis of Launois and Bensaude ${ }^{102}$ ) or inadequate. The views, frequently advanced, that alcoholism, syphilis, rheumatism, traumatism, nervous 
shock, etc., are causes are clearly inadequate to explain the great majority of cases. That such conditions may perhaps play some part as predisposing or exciting factors in the etiology of individual cases cannot be denied; and, indeed, there are good reasons for attributing to them such influence. Various infections and intoxications are known to have important effects on the peripheral and central nervous system and on the glands of internal secretion, e. g., thyroid, pituitary, adrenals. The relation of traumatism and nervous and mental shock to the development of adiposity and lipomatosis is too intimate and frequent to be dismissed as accidental. But, admitting the probability that these conditions may act in certain instances as predisposing or exciting factors, they cannot be accepted as operative and adequate in the cases as a whole.

Only two views have received wide acceptance, and these two may perhaps be resolved into one. According to these views, the process depends on primary disturbances of the nervous system or on disturbance of function or disease of one or more of the glands of internal secretion, producing secondarily a dystrophy or trophoneurosis through the agency of the nervous system. Most of the facts cited in support of a primary nervous cause apply equally to the other view, such, for instance, as the influence of heredity, the symmetrical distribution of the fatty deposits, and the general symptomatology evidencing a disturbance of function of the nervous system. It seems more in accord with the facts, so far as at present known, to accept the nervous hypothesis as modified by the second view, although, it must be admitted, such a position is only tentative and subject to revision. For it is impossible with our present rudimentary understanding of this complicated subject to distinguish clearly between primary and secondary etiological factors in the interrelation of the nervous system and the system of glands of internal secretion. ${ }^{(p)}$ Probably these factors are primary or secondary only in a relative sense and vary in different cases.

THE GLANDS OF INTERNAL SECRETION-PITUITARY, THYROID, GENERATTVE GLANDS, ETC.

The facts that seem to incriminate these glands as the underlying cause of the pathological process may be summarized as follows:

In six autopsies on cases of Dercum's syndrome, in which the hypophysis was examined microscopically, it was found grossly diseased in three, microscopically altered in two, normal in one. In Fröhlich's syndrome also the hypophysis or its connections has regularly been found diseased.

( $p$ ) For a discussion of this problem in reference to exophthalmic and other types of goiter, see papers by Marine and Lenhart, ${ }^{\mathbf{1 1 7}}$ and Rogers, ${ }^{164}{ }^{165}$. 
Operations on the hypophysis in Fröhlich's syndrome have in a few instances caused a marked effect on the symptoms.

Marburg's observations seem to indicate that tumor of the pineal gland ${ }^{(q)}$ may be related to abnormal adiposity, although another explanation of these cases is possible, as already suggested.

The thyroid gland was found more or less altered in seven out of eight autopsies, normal in one, in cases of Dercum's syndrome. Therapeutically, thyroid substance has been found to benefit all forms of adiposity and lipomatosis in certain instances.

The condition of the generative organs was mentioned in four of the autopsies on Dercum's syndrome; in two the ovaries were atrophied, in one an ovarian cyst and hydrosalpinx were found, in one the testicles were undeveloped and showed no evidence of functional activity. Dercum's syndrome has repeatedly been observed to follow the natural menopause, and even oophorectomy, as in two cases in young women reported by Sicard and Roussy. ${ }^{173}$ Similarly, all forms of adiposity and lipomatosis have been observed to follow disturbances of the generative organs, e. g., puberty, the menopause, after castration or oophorectomy. In Frölich's syndrome sexual infantilism (hypoplasia of the genital organs) has been emphasized as a symptom of hypophyseal tumor. Genital atrophy was found at autopsy in twelve out of thirty-two cases of "hypophyseal adiposity," collected by Marburg."15 As has been shown in Group VI, genital hypoplasia and adiposity are probably also related directly or indirectly to disturbances of many of the glands of internal secretion, e. g., pituitary, pineal, thyroid, thymus, panereas, adrenal, generative, liver.

The spleen was cirrhotic in two autopsies on Dercum's syndrome, and in both cases new-formed hemolymph glands were present in the fat deposits; in one of these cases also one of the adrenal glands was hypertrophied.

The kidneys showed marked lesions in seven of the nine autopsies on Dercum's syndrome, chronic nephritis in five and acute nephritis in two cases.

Similarly, extensive involvement of the glands of internal secretion (pituitary, thyroid, adrenal, generative, pancreas, spleen, etc.) has been demonstrated in diffuse symmetrical lipomatosis, as shown above.

These and other facts to be mentioned make it probable that the complex morbid process starts in disturbances of function or disease of

(q) Of the physiology of the pineal gland practically nothing is known. See Dixon and Halliburton: The Pineal Body, Quart. Jour. Exper. Physiol., Lond., 1909, ii, 283-285; and Marburg. ${ }^{115}$ 
these glands, one or more. See also above, under Group VI, the citation of many observations suggesting a relation of adiposity and lipomatosis to many of the glands of internal secretion.

The Thyroid Gland.-That disease of the thyroid is the primary and principal cause of the trophic disturbance seems highly improbable in view of the great mass of evidence that we possess relating to the physiology and pathology of this organ. $(q)$ On the other hand, that this gland may bear some indirect relation to the process, as one of the mutually related and important glands of internal secretion, is suggested by the facts that pathological changes in the thyroid are common in Dercum's syndrome and other forms of adiposity and lipomatosis, and that thyroid medication has in many instances benefited these conditions. See Group VI.

The Generative Glands.-That the generative glands bear an intimate relation to the process is suggested by many facts. At puberty girls acquire the special feminine type of subcutaneous fat deposit. At the time of the menopause women frequently grow stout. Double oophorectomy is followed by distinct obesity in about 50 per cent. of women. ${ }^{18:}$ Dercum's syndrome has also been observed to follow oophorectomy in young women. ${ }^{173}$ Eunuchs often are obese and the deposits of. fat sometimes show a special distribution, as in the Skopzi. ${ }^{183}$ Many of the clinical types of adiposity and lipomatosis have been observed in many instances to follow marked menstrual disturbances or the menopause.

It should be noted that the weight of evidence points to the fact that the trophic mechanism of the sexual glands resides not in the generative elements of these glands, but rather in certain interstitial cells, possibly the interstitial cells ( $Z$ wischenzellen) of Leydig, as Tandler and Gross ${ }^{183}$ have specially emphasized in observations on animals. The functional activity of these special cells appears to determine the internal secretion of the generative glands, which in turn controls their trophic mechanism. If this view becomes accepted, it will require a new investigation of the whole problem of the trophic relations of the generative glands which is now so obscure.

Whether the relation of the generative glands to the trophic process is direct or indirect, essential or accessory to other glandular disturbance, cannot be told definitely. The general evidence, however, tends to support the view that this relation is not simple, but is involved in compli-

(q) On the trophic relations of the thyroid gland, especially in hyperthyroidism, see Holmgren (Ueber den Einfluss der Basedow'schen Krankheit und verwandter Zustande auf das Langenwachstum nebst einigen Gesetzen der Ossifikation, Metzger \& Wittig, Leipsic, 1909). 
cated interrelations with other glands of internal secretion, probably in a special degree with the pituitary gland.

In the attempt to unravel the knot of problems involved in the interrelations of the generative glands and the pituitary and other glands of internal secretion to the trophic disturbances that characterize the cases under consideration, the chief point of inquiry has been to determine which of these glands, the generative or the pituitary, is the primary source of the interglandular disturbance. This problem is still undetermined, with the weight of evidence favoring the view that the primary glandular disturbance varies in different cases. Further evidence supporting this view will be presented below.

The Pituitary Gland.-Whether the pituitary gland initiates the process cannot be answered definitely at present. That it may do so, or at least be intimately concerned therein in certain cases, is suggested by the pathological findings in cases of Fröhlich's syndrome, Dercum's syndrome, diffuse symmetrical lipomatosis, ete. It may be said, however, that no observer, except Cushing, has yet claimed to have produced the general constitutional symptomatology described above as characterizing the several groups of abnormal fat deposit, either by grafts of the pituitary body or the administration in excess of pituitary extract (hyperpituitarism), or by partial or total hypophysectomy (hypopituitarism). Paulesco's ${ }^{139}$ conclusions on this point, based on a very large number of hypophysectomies in animals performed by himself and many other experimenters, were as follows: fatal.

The hypophysis is an organ indispensable to life-its absence being rapidly

The removal of part of the cortical substance of the epithelial (anterior) lobe of the hypophysis permits the indefinite survival of the animal and causes no manifest disorder. On the contrary, the removal of all this portion of the hypophysis is equivalent to total hypophysectomy. The removal of the nervous (pos. terior) lobe of the hypophysis is compatible with the indefinite survival of the animal and is followed by no apparent disturbance.

Insufficiency of function of the hypophysis, resulting from total or almost total hypophysectomy, manifests no particular or characteristic symptom and, in case of prolonged survival, produces no appreciable trophic disturbance in the extremities.

Cushing $^{34,35}$ alone claims to have observed any significant increase in weight (adiposity) or other important symptoms in his animals after partial hypophysectomy. His statement is as follows:

Now, it is otherwise with the anterior lobe, for its partial removal, supposedly equivalent to a condition of hyposecretion of this part of the gland, though not incompatible with life, nevertheless leads in some cases to profound alterationsnotably an increase in the deposition of fat. This condition seems to have 
occurred in one of the animals of Pauleseo's $(r)$ series-a chance observation to which especial attention does not seem to have been paid. We have had a number of similar experiences; and indeed believe that we have succeeded in purposefully producing this condition, which we regard as characteristic of lessened secretion. The adiposity has been associated in some eases with polyuria and transient glycosuria, with shedding of hair, occasionally with unmistakable lessening of sexual activities and even with atrophy of testes and ovaries.

Perhaps the discrepancies between the results obtained by Cushing and Paulesco and others may be accounted for by the failure of the latter to devote attention to the special points that interested Cushing. At any rate, Cushing's observations, however interesting they may be, need to be presented in greater detail and to be confirmed and controlled by further work before their relation to the problem under consideration can be fairly judged.

[While proof is being corrected, Cushing's latest contribution to this subject (Crowe, Cushing and Homans: Experimental Hypophysectomy, Bull. Johns Hopkins Hosp., 1910, xxi, 127) has come to hand. In a series of 150 hypophysectomies on canines, "histologically corroborated," the protocols show three instances of marked increase of weight (adiposity) in adult dogs, as follows: Observation 34: partial removal of anterior lobe and stalk separation, gain in weight in six months from 14 to 24 pounds, ovaries normal, uterus infantile. Observation 54: partial removal of anterior lobe and total removal of posterior lobe, gain in weight in three and one-half months from 16 to 27 pounds, no changes in ovaries. Observation 55: partial removal of anterior lobe and total removal of posterior lobe, gain in weight in three and one-half months from 17 to 23 pounds, partial atrophy of testes. Observation 98 cannot be accepted in this connection because the dog was "young" and observation 27 because the thyroid was also removed. The three positive observations cited, while too few to warrant definite conclusions, tend to substantiate Cushing's opinion that a condition of hypopituitarism may lead to "a state of adiposity, accompanied by (or resultant to?) a secondary hypoplasia of the organs of generation" and other trophic changes, at least in certain instances.-I. P. L.]

Of the physiology of the pituitary body little is known. That it is an organ indispensable to life, the vital property residing in the anterior or epithelial lobe, has already been stated. This conclusion, however, has not been reached by all recent investigators. Gemelli, ${ }^{71}$ for instance, found that complete hypophysectomy in cats produced no notable effects. Vassale and Sacchi ${ }^{100}$ have been able to modify slightly the morbid

(r) In Paulesco's ${ }^{130}$ series the only instances of marked increase of weight in adult $\operatorname{dogs}$ were in Experiments lxiii (p. 234) and xix (p. 251). In one case after almost total hypophysectomy the dog survived 355 days. Four months after the operation its weight was 4,900 grams, eight months after the operation, 6,600 grams. Its weight before the operation was not stated. In the other case partial removal of the cortical layer of the epithelial lobe was performed on a dog weighing 14 kilograms. Nearly one year later the dog weighed 17 kilograms. It is easy to account for such moderate increase in weight without attributing it necessarily to hypopituitarism. 
symptoms following hypophysectomy in dogs and cats by injection of pituitary extract, and Cushing ${ }^{34,35}$ has succeeded after total hypophysectomy in dogs in prolonging life "for a time, though not indefinitely, by immediate or antecedent transplantation ${ }^{(s)}$ of the anterior lobe or by post-operative injection of its extract." Howell ${ }^{88}$ has shown that the posterior or nervous lobe contains a blood-pressure-raising principle, and Schäfer and Herring ${ }^{168}$ that the posterior lobe extract when injected into the blood causes a dilatation of the renal vessels and diuresis. Herring ${ }^{84}$ has shown that this internal secretion of the posterior lobe comes probably from the epithelial cells of the pars intermedia and perhaps also from the ependymal cells of the posterior lobe.

In acromegaly and gigantism the hypophysis is almost always found altered-hypertrophy, tumor, ${ }^{(t)}$ microscopic increase of the chromophile cells, ${ }^{(u)}$ etc., leading many writers to the view that acromegaly and gigantism are caused by a condition of hyperpituitarism. No one has succeeded in producing symptoms of acromegaly by grafts of the hypophysis or by administration of its extract, its prolonged administration hypodermatically in growing animals producing in general no positive effect on their development, although in rare instances some retardation is noted (Caselli, ${ }^{24}$ Ballet and Laignel-Lavastine ${ }^{9}$ ). Further, the administration of pituitary extract in the treatment of acromegaly is without apparent effect, $(v)$ although some exceptions $(v)$ to this rule may be admitted. On the other hand, the idea of hyperpituitarism in acromegaly receives some support from the effects of partial or subtotal hypophy-

(s) No successful transplantation of the hypophysis in man or animals has yet been reported. Complete destruction of the transplanted organ occurs within a few days or weeks. ${ }^{31},{ }^{34}$

( $t$ ) Erdheim ${ }^{58}$ has reported a case of acromegaly without tumor of the hypophysis but with a tumor situated beneath the sella turcica in the sphenoid bone, composed of chromophile cells identical with those characterizing the anterior lobe of the hypophysis. The importance of this observation as a possible explanation of other instances of acromegaly in which gross and microscopic changes in the hypophysis are wanting is apparent. The location of the tumor in Erdheim's unique case is readily understood in view of Haberfeld's ${ }^{77}$ studies showing that small remnants of hypophyseal tissue are constantly found at all ages at the point of origin and in the path of migration of the embryological hypophysis (anterior lobe), which arises from the buccal mucous membrane by evagination passing upward through the site of the sphenoid bone by the craniopharyngeal canal to its final position in the sella turcica.

(u) Lewis ${ }^{108}$ reported a case of acromegaly in which the hypophysis appeared normal grossly but microscopically showed hyperplasia of the chromophile cells. Similar findings have since been reported.

(v) Marinesco, Mendel, Cyon, Favorski, Schultze and Joris, Witmer, Kester. Cited by Paulesco, ${ }^{139}$ pp. 117-118.

(w) For example, the cases mentioned by Axenfeld, Elschnig, and Fleischer in the discussion of Lhthoff's ${ }^{189}$ paper and the case of Osborne eited by Dock. ${ }^{153}$ 
sectomy in cases of acromegaly, definite reduction in the overgrowth of bone and soft tissue resulting (Hochenegg, ${ }^{64,86,181,203}$ two cases; Cushing, ${ }^{35,36}$ one case). But equally marked effects on the symptomatology have followed similar operations, i. e., excision of tumors with partial hypophysectomy, in cases of Fröhlich's syndrome, which has been represented as a condition of hypopituitarism. Hence apparently both acromegaly and Fröhlich's syndrome should be regarded as related to hyperpituitarism (or hypopituitarism) or else no valid conclusions should be based on these few cases as to the nature of the functional disturbance, whether hyperpituitarism, hypopituitarism or dyspituitarism or some other unknown process.

No hormone has yet been isolated capable of stimulating the hypophysis to permanent overactivity or pathological excess or alteration of secretion. Transplantations of the pituitary body into animals "have signally failed in this respect" (Cushing).

The pituitary body reacts to acute and chronic intoxications, e. g., pilocarpin, ichthyotoxin, diphtheria toxin, endogenous toxins, showing histological changes interpreted as augmentation or diminution of secretory activity (Guerrini ${ }^{\mathbf{7 4}, 75}$ ).

It may be concluded, then, that, while there are weighty reasons for attributing to the hypophysis an important rôle in the etiology of the process, the available evidence does not yet justify the assumption, made by some, that the relation of the hypophysis to the process is either primary or exclusive.

\section{INTERRELATION OF THE VARIOUS GLANDS OF INTERNAL SECRETION}

On the other hand, there are many reasons for viewing disturbances of function of the several glands of internal secretion as interrelated and interdependent, a disturbance in one leading to secondary changes in others and in consequence a diverse symptomatology. This interrelation is shown in part by the following facts:

Pituitary and Thyroid Glands.-In diseases of the thyroid gland, e. g., goiter, cretinism, myxedema, cachexia strumipriva, changes in the pituitary body regularly occur, namely, hypertrophy, hyperplasia of the chromophile cells, atrophy, increase of colloid, etc. ${ }^{(x)}$ Thyroidectomy causes hypertrophy of the hypophysis $(y)$ and likewise hypophysectomy

(x) Schönemann, Comte, Pisenti and Viola, Boyce and Beadles, Burckhardt, Vassale, Coulon, Ponfick. Cited by Paulesco, ${ }^{130}$ pp. 87-88.

(y) Rogowitsch, Stieda, Tizzoni and Centanni, Horsley, Eiselsberg, Lusena, Gley, Hofmeister, Leonhardt. Cited by Paulesco, ${ }^{139}$, p. 88. See also Delille, ${ }^{41}$ part ii, chap. $x$. 
causes hypertrophy of the thyroid. ${ }^{(z)}$ In acromegaly and gigantism the thyroid gland is usually altered, hypertrophied, atrophied, etc., ${ }^{(a a)}$ and acromegaly has been known to be complicated by exophthalmic goiter or myxedema. In Dercum's syndrome, Fröhlich's syndrome and other clinical forms of fat deposit, the thyroid gland is frequently altered and in all of these conditions the administration of thyroid extract has been followed, at least in some instances, by marked improvement in the various symptoms. Both the pituitary gland (Guerrini ${ }^{74}$ ) and the thyroid gland (Vincent, ${ }^{191}$ Diamantberger ${ }^{50}$ ) react to infections and intoxications. According to Wells, ${ }^{199}$ the human pituitary contains iodin ${ }^{(b b)}$ in the proportion of about one to fifty of the amount contained in the thyroid.

Pituitary and Generative Glands.-In acromegaly and gigantism, functional or organic changes are frequently noted in the genital organs, e. g., amenorrhea, anaphrodisia, impotence, sterility, atrophy of testicles, ovaries, uterus, mammary glands. ${ }^{(c c)}$ Many giants are as good as castrated in consequence of the lack of development or atrophy of the generative organs. $(c c)$ The first symptoms of acromegaly in women may date from a previous pregnancy, and not infrequently disturbances or cessation of the menses are the earliest symptoms and may precede by many years definite signs of acromegaly. ${ }^{183}$ The elongation of the legs and the abnormal epiphyseal development, which characterize gigantism, are observed also in castrated men ${ }^{(d d)}$ and animals. ${ }^{(e e)}$ In eunuch ${ }^{183}$ enlargement of the sella turcica has been observed. Fichera ${ }^{65}$ found excision of the testicles or ovaries in animals regularly followed by

(z) Cushing, ${ }^{35}$ p. 252.

(aa) Hinsdale, Fournival, Lancereaux, Murray, Launois and Roy, Bassoe. Cited by Paulesco, ${ }^{139}$ p. 88 .

$(b b)$ Schnitzler ${ }^{100}$ also found iodin in the human pituitary, but Baumann ${ }^{12}$ in the human and Halliburton, Candler and Sikes ${ }^{70}$ in the human and the bovine pituitary failed to find iodin.

[Since the foregoing was written, Wells (The Presence of Iodin in the Mruman Pituitary Gland, Jour. Biol. Chem., 1910, vii, 259) has recorded new observations on this subject. He found traces of iodin in the pituitary glands of three patients who had received iodids before death, but was unable to demonstrate iodin in the pituitary glands of twenty-two patients who had not received iodin before death. He therefore concludes that the presence of iodin as a normal constituent of the human pituitary gland must be regarded as still unproved. Simpson and Hunter (Proc. Soc. Exper. Biol. and Med., 1909, vii, 11) were also unable to demonstrate iodin in the pituitary glands of thyroidectomized sheep.]

(cc) Paulesco, ${ }^{139}$, p. 116.

(dd) Lortet, Ecker, Becker, Godard, Pittard, Poncet, Sellheim, Briau, Pirsche. Cited by Paulesco, ${ }^{138}$ p. 116 . Also Tandler and Gross. ${ }^{183}$

(ee) Fichera. Cited by Paulesco, ${ }^{139}$ p. 117. 
changes in the pituitary body, i. e., hypertrophy, hyperplasia of the chromophile cells, congestion, etc. Subcutaneous injections of testicular extract in castrated cocks caused the pituitary body to resume the normal type found in uncastrated cocks, this modification disappearing promptly when the injections were stopped. Several observers have noted characteristic changes in the pituitary body during pregnancy both in women $(f)$ and animals. ${ }^{(g g)}$ In Fröhlich's syndrome pathological changes in the hypophysis may be accompanied by sexual infantilism. Similarly, autopsies in cases of Dercum's syndrome show changes in the pituitary body and in some instances atrophy of the ovaries or testicles; furthermore, Dercum's syndrome, as well as all forms of adiposity and lipomatosis, are frequently associated with or follow on changes of function of the generative glands, i. e., menopause, oophorectomy, etc.

Pituitary and Adrenal Glands.-There is an intimate physiological relation between the pituitary and adrenal glands, evidenced by many facts. The chromaffin tissue that seems especially to characterize the adrenals is found also in the hypophysis (Wiesel). Both glands contain a blood-pressure-raising principle (Howell). Both react to infections and intoxications. Adrenalin glycosuria is well known (Blum, Herter), and glycosuria frequently occurs in affections of the hypophysis, e. g., acromegaly, tumors, partial or total hypophysectomy. Pigmentation of the skin, characteristic of Addison's disease, occurs commonly in acromegaly (Brooks), has been observed in a case of traumatic destruction of the hypophysis (Wasdin), and not infrequently in Dercum's syndrome and other clinical forms of adiposity and lipomatosis. Acromegaly is characterized by overgrowth of certain structures and similarly adrenal tumors have been known to be associated with excessive development of the genitals, hair and fat [Woolley, Bullock and Sequira( ${ }^{(h h)}$ ]. Hypertrophy of the hypophysis was observed in a case of Addison's disease by Pansini and Benenati $(h \boldsymbol{h})$ and likewise has been found after adrenalectomy in some instances by Boinet, ${ }^{(i i)}$ Marenghi ${ }^{(i i)}$ and others. In acromegaly the adrenals are sometimes atrophied (Dock) and in one case of Dercum's syndrome adrenal hypertrophy has been noted.

Pituitary and All the Glands of Internal Secretion.-Cushing ${ }^{35}$ says: "It is impossible to remove-probably partially to remove-the hypo-

(ff) Comte, Launois and Mulon, Morandi. Cited by Paulesco, ${ }^{139}$ p. 117 ; also Erdheim and Stumme. ${ }^{\circ 0}$

( $g g$ ) Guerrini, Morandi. Cited by Paulesco, ${ }^{139}$ p. 117.

( $h h$ ) Cited by Dock, ${ }^{53}$ p. 359.

(ii) Cited by Paulesco, ${ }^{139}$ p. 89. 
physis without producing marked alterations in all the other glandsthyroid, parathyroid, adrenal, testicle, ovaries, islands of Langerhans, and thymus," and likewise the reverse is probably true. ${ }^{(j j)}$

\section{MUTUAL RELATIONS BETWEEN MANY OF THE GLANDS OF INTERNAL SECRETION}

In addition to the above facts showing especially relations existing between the pituitary and the thyroid, generative and adrenal glands, a still wider interrelation of the glands of internal secretion is indicated in part by the following facts :

The adrenals are known to have close relations with many other glands of internal secretion. This has already been shown for the pituitary gland. Eppinger, Falta and Rudinger ${ }^{5 \tau}$ have conclusively demonstrated intimate mutual relations between the adrenals (chromaffin system), pancreas and thyroid, $(k k)$ which may be summarized as follows: (a) the thyroid and pancreas inhibit the action of each other; (b) the pancreas and chromaffin system inhibit the action of each other; (c) the thyroid and the chromaffin system increase the action of each other. In Addison's disease there may be persistent thymus, hypertrophied spleen and atrophied thyroid. Hypoplasia of the adrenals and of the entire chromaffin system may occur in status thymicus (Dock, Hedinger) Hart ${ }^{(l l)}$ found the adrenals enlarged in animals injected with the juice of a persistent thymus. Relations between the adrenals and generative glands is suggested by the occurrence of pigmentation of the skin in many ovarian and uterine disorders and by the facts that in osteomalacia the adrenals have been found hyperplastic in some instances and either oophorectomy or the administration of adrenalin (Bossi and others) has been found to benefit the condition in some cases. In osteomalacia a relation to the thyroid also is indicated by the frequent complication of simple goiter and even in some instances of exophthalmic goiter. The pigmentation of the skin that is frequently noted in many conditions having known or supposed relations with certain glands of internal secretion, e. g., acromegaly, exophthalmic goiter, myxedema, Dercum's syndrome, adiposity and lipomatosis, von Recklinghausen's reurofibromatosis, arthritis deformans, bronzed diabetes, uterine and ovarian affections, etc., suggests a possible relation to the adrenal glands or to the chromatfin system in general.

( $j j)$ Delille, ${ }^{41}$ part 2, chap. $\mathrm{x}$; Perrier: Contribution a l'étude des réactions de l'hypophyse à la suite d'ablations glandulaires, 1909, Paris, H. Paulin \& Cie.

(kk) Confirmed by Grey and Sautelle, ${ }^{52} \mathrm{King},{ }^{35} \mathrm{McCurdy} .{ }^{124}$

(ll) Cited by Dock, ${ }^{53}$ p. 355 . 
The relation of the thyroid to the generative glands is shown by the common occurrence of hypertrophy of the thyroid with puberty, menstruation, pregnancy, lactation, etc. In pregnancy the pituitary, thyroid and adrenals are all hypertrophied, as a rule. ${ }^{(\mathrm{mm})}$

Very intimate relations are well known to exist between the thyroid and parathyroid glands. Both these glands contain iodin and removal of one is usually followed by changes in the other.

Many facts suggest the relation of the thymus to the other glands of internal secretion. Some of these have been pointed out. "The thymus gland is in a state of evolution until the age of puberty. It then undergoes regressive changes, at first abruptly, later more gradually. It is, in all probability, a functional organ throughout life" (Pappenheimer $^{138}$ ). Castration causes delay of involution of the thymus (Henderson) and excision of the thymus causes accelerated development of the testes (Paton). In status lymphaticus the thymus is almost always hyperplastic, the thyroid usually shows colloid hyperplasia, the genital organs are often hypoplastic (Barte ${ }^{10}$ ). Changes in the thymus occur commonly in many affections of the ductless glands, e. g., goiter, exophthalmic goiter, myxedema, cretinism, acromegaly, Addison's disease, etc. (Warthin, ${ }^{196}$ Pappenheimer ${ }^{138}$ ). Like many of the other ductless glands, the thymus reacts characteristically to acute and chronic infections and intoxications (Pappenheimer. ${ }^{138}$ ).

Relations between the spleen and pancreas have been established by Schiff, Herzen and others, ${ }^{(n n)}$ who have shown that the spleen furnishes to the blood an internal secretion that is capable of activating the pancreatic zymogen into trypsin.

Tigerstedt and Bergman ${ }^{187}$ and others ${ }^{13,144}$ have demonstrated that the kidney produces a blood-pressure-raising principle, and $\mathrm{Pi}$ Suñer ${ }^{147}$ and others assert that the kidney produces also an internal secretion that is concerned in general metabolism, the absence of which after nephrectomy causes uremia. There are other reasons for thinking that the kidney may belong to the system of glands of internal secretion and this relation may perhaps have an important bearing on the etiology of the chronic nephritis that occurs frequently in acromegaly, myxedema, Dercum's syndrome, etc.

Many of the glands of internal secretion, e. g., thyroid, ovary, testicle, adrenal, pituitary, when administered to animals, stimulate the oxygenation of the tissues.

$(\mathrm{mm})$ Guerrini, Morandi, Comte, Launois and Mulon. Cited by Paulesco, ${ }^{139}$ p. 117.

(nn) Cited by Lyon, ${ }^{111}$ p. 737. 
In acromegaly the hypophysis and the thyroid are almost always abnormal; the generative glands are often hypoplastic or degenerated; the thymus is often persistent or enlarged; the kidneys are often cirrhotic; the adrenals and pancreas are sometimes cirrhotic; and the parathyroids, pineal gland and spleen are sometimes hypertrophied (Dock). Acromegaly is sometimes complicated by exophthalmic goiter, myxedema, diabetes, epilepsy, adiposis, lipomatosis, etc.

The above facts are sufficient to indicate the complexity of the problem to be solved in determining the relations of the different glands of internal secretion to the pathological process involved in adiposity and lipomatosis. That such relations exist is evident. What they are is beyond our ability to understand at present. To argue from the presence of pathological changes in one of these glands or from the benefit resulting from the administration of a glandular extract that the corresponding gland is specifically and exclusively related to the etiology of the morbid process is hazardous and not based on a comprehensive conception of the intricate mutual relations existing between many of these glands. Is the hypophysis essentially and are the other glands only secondarily or indirectly concerned? Is the varying symptomatology of the process, as exhibited by the several clinical groups, as well as within each of these groups, dependent on variations in the degree of involvement of these different glands? If so, what determines the unequal involvement? Can primary disturbances in any one of these different glands initiate the morbid process? To all such questions we must answer: Ignoramus. Our knowledge of the trophic relations of these glands is fragmentary and consists mostly of "guesses and gaps," as Foster said of our knowledge of metabolism in general. We must await future investigation for elucidation of these, the deepest secrets of biological chemistry. But in taking this conservative stand let us not blind our eyes to possibilities and refuse to be interested in any working hypothesis, however partial it may be, that can help to encourage investigation and thus ultimately to establish the truth.

It may be carnestly hoped that investigation may be advanced by the exact report of the clinical and pathological findings in a larger number of cases of abnormal fat deposit, whether they conform to some type or syndrome picture or not. Irregular and atypical cases ought especially to be studied and reported, as they will surely be found to throw light on the nature of other cases that conform to one of the several varieties heretofore generally represented as typical or constituting distinct disease entities. In autopsies the hypophysis and other glands of internal secretion should be examined not only grossly but also microscopically 
and by a pathologist familiar with the physiological and pathological variations in these glands. Especially does this apply to the hypophysis, whose cellular variations are at present so little understood that it is impossible to interpret them. This fact is aptly expressed by Cushing in the statement: "There are no normal pituitary glands."

In this connection it may be pointed out that multiple neurofibromatosis (von Recklinghausen's disease) shows many and striking analogies in its symptomatology to the process of abnormal fat deposit and possibly will be found to be closely related etiologically to this process. Multiple neurofibromatosis ${ }^{81,150,152,154}$ is characterized by the wide dissemination over the body and in some instances within the central nervous system of fibromata arising from proliferation of the connective tissue of the peripheral nerves or of the central nervous system. The tumors are usually painless, but pain, both spontaneous and induced by pressure in the tumors, may be a feature in certain cases. Constitutional symptoms may be exhibited, including various psychic, nervous, motor, vasomotor, sensory and trophic disorders. Heredity plays a distinct part, about 20 per cent. of cases occurring as a family disease, sometimes including several generations. A study of the possible relations of this disease to the important glands of internal secretion might prove profitable, and throw Iight on the same problem in the process of abnormal fat deposit.

And finally it may be suggested that the subcutaneous fibroid nodules of inflammatory rheumatism and certain rheumatoid affections may be symptomatic of disturbed function of the hypophysis, thyroid or other glands of internal secretion. This possibility is suggested by the facts that these nodules are sometimes distinctly lipomatous (as in the second group of Futcher's ${ }^{69}$ classification), sometimes painful; that rheumatoid symptoms frequently characterize all classes of abnormal fat deposit; that arthritis in certain forms may be at least partially related, etiologically, to disturbances of function of the thyroid gland and can be benefited by thyroid medication (Diamantberger ${ }^{5 \theta}$ and others), and that toxic agents are capable of producing changes in the functional cells of the hypophysis, thyroid and adrenal glands.

Treatment.-Enough has already been said to indicate our therapeutic poverty in these cases. Perhaps the future may have in store for us a potent and scientific therapy derived from the pituitary or other glands of internal secretion. The indications of etiological relation between functional derangement or disease of these glands and the pathological process under consideration justify their experimental use. In the absence of a more promising glandular therapy, thyroid may be tried. In many instances its use continued for many months has been followed by 
amelioration of symptoms, not only in cases presenting more or less of Dercum's syndrome, but as well in cases belonging to the other clinical groups. Its beneficial effects may perhaps depend on a secondary activation (or depression) of other glands of internal secretion, e. g., pituitary, generative, as many have suggested. Its administration and dosage ought to be regulated carefully for each case, as its indiscriminate use is dangerous. In general, small doses (one-quarter to one-half of a grain of the desiccated gland daily) should be first employed and the dosage gradually increased and always kept well within the limit of tolerance. It is also advantageous to suspend the use of the drug one out of every four weeks when it is used over a long period. The desiccated substance or extract of the separate lobes, especially the anterior lobe, of the pituitary body ${ }^{(0 o)}$ should receive a thorough clinical trial. Cases presenting definite signs of tumor of the hypophysis have already proved amenable to relief by surgical measures, either excision of the tumor with partial hypophysectomy or simple incision of the dural investment of the hypophysis, the latter procedure, however, effecting only relief from the intractable headache by removal of its usual cause, i. e., distention of the dural pocket enclosing the gland (Cushing). The clear relief from distressing tenderness and pain of the fatty deposits following profuse hemorrhage in two of the cases above reported (Cases 2 and 3 ) suggests the therapeutic use of free bleeding in suitable cases. Other symptomatic remedies have already been mentioned and will suggest themselves according to the special indications encountered.

\section{CONOLUSIONS}

In brief, the following facts and conclusions may be stated:

1. A series of twenty personal observations, embracing a wide variety of cases, is recorded.

2. The following clinical groups of fatty deposit are considered: (1) Dercum's syndrome ("adiposis dolorosa"); (2) simple adiposity or obesity; (3) nodular circumscribed lipomatosis, solitary, multiple or symmetrical; (4) diffuse symmetrical lipomatosis, including "fatneck" (Madelung) ; (5) neuropathic edema, pseudo-edema, pseudolipoma, lipoma; (6) "adipositas cerebralis," including Fröhlich's syndrome.

3. These several clinical groups are compared with one another and especially with Dercum's syndrome, adiposis dolorosa, in reference to their clinical symptomatology, constitutional relations, pathology, etiolagy and treatment. In these respects they are thought to be not only

(oo) Commercial preparations of the separate lobes of the pituitary body are now available from American manufacturers. 
dcsely related, but essentially identical, being only variations of a common morbid process. They do not constitute clearly defined entities, but rather varieties, phases, or case-groups of a common morbid process. They often blend with one another and exhibit common features, so that individual cases cannot be exactly classified in any single group.

4. Dercum's syndrome characterizes certain cases selected from all groups and is not a clinical or pathological entity.

5. Fröhlich's syndrome is not an entity, but merely a grouping of special symptoms in selected cases of hypophyseal tumor.

6. Diffuse symmetrical lipomatosis, including Fetthals (Madelung), or adéno-lipomatose symétrique à prédominance cervicale (Launois and Bensaude), is shown to have no special pathogenic relations with lymphatic tissues, and the designation, adenolipomatosis, applied by Launois and Bensaude and most subsequent writers, is consequently unjustified and should be abandoned. The symptomatology is that of the other groups, some cases showing the full picture of Dercum's syndrome.

\%. Nodular, circumscribed, encapsulated lipomatosis, whether solitary, multiple or symmetrical, is characterized chiefly by the discreteness of the fatty deposits and the investment of connective tissue. These features determine only a variety, shared partly by cases belonging to other groups. The general symptomatology is similar to that of the other groups, many cases agreeing in all respects with Dercum's syndrome.

8. Neuropathic edema, pseudo-edema, pseudolipoma and lipoma have been described chiefly by French writers, who represent them as stages of evolution in a common morbid process. 'Their symptomatology is that common to all groups. Some of the cases agree essentially with Dercum's syndrome. They are poorly classified and probably represent only variations.

9. All the groups show a strong tendency to be characterized by constitutional symptoms embracing a wide variety. It is out of these symptoms that certain ones have been selected and attributed to certain syndrome-case-groups. But the same symptoms in every possible variation and combination are common to all the groups.

10. These symptoms include especially many psychic, sensory, motor, vasomotor, secretory and trophic manifestations.

11. Special attention is called to various arthralgic and arthritic and neuralgic and neuritic manifestations as belonging to the constitutional symptomatology of the morbid process.

12. The etiology of the process, thus broadly considered, is unknown. Only two views, connecting the process with disturbances of the nervous system or of the glands of internal secretion, seem broad enough to har- 
monize with all the facts. These two views are not necessarily opposed, but can be resolved into one, by assuming that the nervous system is secondarily disturbed by primary disturbances in the glands of internal secretion, or vice versa.

13. The pathological findings and the general evidence suggest the view that the process is related to alterations in the glands of internal secretion. Many of these glands have been found altered.

14. Special importance has been attached by many writers to the pituitary gland in the pathogenesis, and the evidence tends strongly to support this view, but the facts at present known do not justify the assumption that this gland is exclusively concerned in the process.

15. The complex mutual relations between all of these glands are considered and the view suggested that one or more or all of them may be concerned in the pathogenesis, and that the variation in the symptomatology of the different groups and cases may depend on the varving degree of involvement of these several glands and the nervous system.

16. Heredity as a factor in the etiology is pointed out and the cases exhibiting this relation are reviewed.

17. The treatment is unsatisfactory. Thyroid preparations have given the best results. Other forms of glandular therapy should be tried.

In conclusion, I take pleasure in acknowledging my grateful appreciation of the kind interest and valuable assistance of Dr. Grover W. Wende in the study of several of the personal observations recorded.

531 Franklin Street.

\section{BIBLIOGRAPHY}

1. Adler: Symmetrical Localized Hyperplasias of the Subcutaneous Fat, Pacific Med. Jour., 1893, xxxvi, 529.

2. Alger: A Case of Adiposis Dolorosa, Med. News, New York, 1901, lxxviii, 91.

3. Alsberg: Ueber Neurolipome: Ein Beitrag zur Kenntnis der falschen Neurome, Inaug.-Diss., Berlin, 1892.

4. Anders: Adiposis Tuberosa Simplex, Am. Jour. Med. Sc., 1908, exxxv, 325.

5. Antony: Lipomes multiples et symétriques, Bull. et mém. Soc. méd. d. hôp. de Paris, 1892, series 3, ix, 178.

6. Apert: Obésité, etat eunuchoïde, cryptorchidie, traitement thyroïdien, guérison, Bull. Soc. pédiat. de Paris, 1901, iii, 108, 114; Infantilisme, Traité des maladies de l'enfance, edited by Grancher and Comby, Paris, 1904, Ed. 2, i, 993.

7. Baker and Bowlby: Diffuse Lipoma, Med.-Chir. Tr., London, 1886, lxix, 41.

8. Ballet: L'adipose douloureuse (maladie de Dercum), Presse méd., 1903, i, 285 .

9. Ballet and Laignel-Lavastine: Un cas d'acromégalie avec lésions hyperplasiques du corps thyroïde et des capsules surrenales, Nouv. iconog. de la Salpêtrière, 1905, xviii, 176 ; cited by Paulesco, ${ }^{139}$ p. 117.

10. Bartel, J.: Ueber die hypoplastische Konstitution und ihre Bedeutung, Wien. klin. Wchnschr., 1908, xxi, 783.

11. Bartels, M.: Lieber Plattenepithelgeschwïlste der Hypophysengegend (des Infundibulums), Ztschr. f. Augenh., 1906, xvi, 407, 530. 
12. Baumann: Ueber das Thyrojodin, München. med. Wchnschr., 1896, xliii, 311.

13. Bingel and Strauss: Blutdrucksteigernde Substanz der Niere, Deutsch. Arch. f. klin. Med., 1909, xevi, 476.

14. Blaschko: Eine seltene erbliche Lipombildung, Virchows Arch. f. path. Anat., 1891, cxxiv, 175 .

15. Bochroch: A Case of Adiposis Dolorosa (Dercum's Disease), Am. Jour. Med. Sc., 1902, cxxiv, 569.

16. Bondet: Lipomatose symétrique douloureuse et maladie de Dercum, Bull. méd., Paris, 1904, xviii, 817.

17. Bouju: Des lipomes multiples symétriques d'origine nerveuse, Thèse de Paris, 1892.

18. Bramwell: Case of Infantilism, Clinical Studies, Edinburgh, 1902-3, new series, i, 157; Pancreatic Infantilism; Remarkable Improvement (Growth of Body and Sexual Development) as the Result of the Administration of Pancreatic Extract, ibid, 1903-4, new series, ii, 348; Case of Pancreatic Infantilism; Results of Treatment, Scot. Med. and Surg. Jour., 1904, xiv, 321.

19. Brissaud: Leçons sur les maladies nerveuses, Paris, 1893, i, 605; 1899, ii, 417 .

20. Brodie: Clinical Lectures on Surgery, Delivered at St. George's Hospital, Philadelphia, Lea and Blanchard, 1846, pp. 201-202.

21. Bryk: Zur Casuistik der Geschwülste. Arch. f. klin. Chir, 1874, xvii, 555.

22. Bucquoy: Lipomes diffus multiples et symétriques; présentation de malade,

Bull et. mém. Soc. méd. d. hôp. de Paris, 1891, series 3, viii, 300.

23. Burr: A Case of Adiposis Dolorosa, with Necropsy, Jour. Nerv. and Ment. Dis., 1900, xxvii, 519.

24. Caselli: Riv. sper. di freniat., 1900, xxvi, 120, 176, 468. Cited by Paulesco, ${ }^{139}$ p. 117.

25. Chantemesse and Podwyssotsky: Pathologie générale et expêrimentale: Les processus généraux, Paris, 1901, i, 274-277.

26. Charcot: L'oedème bleu des hystériques, Progrès méd., 1890, series 2, xii, $259,275$.

27. Charriêre: Contribution à l'êtude de l'absence congénitale du corps thyroïde et de ses conséquences dans l'arrêt du développement physique et intellectuel, Thèse de Paris, 1907.

28. Cheinisse: L'identité de la lipomatose symétrique douloureuse avec la maladie de Dercum, Semaine méd., 1903, xxiii, 221.

29. Chevers: A Case of Adiposis Dolorosa (Dereum's Disease) in a Male, Brit. Med. Jour., 1904, i, 781.

30. Chuffart: Des affections rhumatismales du tissu cellulaire sous-cutané, Thèse Agrégat., 1886, Paris, F. Alcan; cited by Lourier. ${ }^{10}$

31. Clairmont and Ehrlich: Ueber Transplantation der Hypophyse in die Milz von Versuchsthieren, Arch. f. klin. Chir., 1909, lxxxix, 596.

32. Collins: Symmetrical Adenolipomatosis, New York Med. Jour., 1907, lxxxv, 916.

33. Coplin: Jour. Nerv. and Ment. Dis,, 1909, xxxvi, 108.

34. Crowe, Cushing and Homans: Effects of Hypophyseal Transplantation Following Total Hypophysectomy in the Canine, Quart. Jour. Exper. Physiol., London, 1909, ii, 389.

35. Cushing: The Hypophysis Cerebri: Clinical Aspects of Hyperpituitarism and of Hypopituitarism, Jour. Am. Med. Assn., 1909, liii, 249.

36. Cushing: Partial Hypophysectomy for Acromegaly, with Remarks on the Function of the Hypophysis, Ann. Surg., 1909, L, 1002.

37. Dalché: Adipose localisée a la région des museles droits abdominaux; tumeurs symétriques multiples pseudo-lipomateuses, Bull. et. mém. Soc. méd. d. hôp. de Paris, 1897 , series 3 , xiv, 1168 .

38. Danlos and Sourdel: Adéno-lipomatose symétrique à prédominance cervicale, Bull. et mém. Soc. mêd. d. hôp. de Paris, 1908, series 3, xxv, 563. 
39. Dartignolles: Lipomes diffus multiples chez une jeune fille, Bull. et mém. Soc. méd. d. hôp. de Paris, 1891, series 3, viii, 374.

40. Debove: Lipomatose douloureuse, Gaz. d. hôp., 1904, lxxvii, 1069

41. Delille: L'hypophyse et la médication hypophysaire, Paris, G. Steinheil, 1909.

42. Dentu: Bull. et mêm. Soc. de chir. de Paris, 1904, new series, xxx, 56.

43. Dercum: Three Cases of a Hitherto Unclassified Affection Resembling in Its Grosser Aspects Obesity, but Associated with Special Nervous SymptomsAdiposis Dolorosa, Am. Jour. Med. Sc., 1892, civ, 521.

44. Dercum: Autopsy in a Case of Adiposis Dolorosa, with Microscopical Examination, Jour. Nerv. and Ment. Dis., 1900, xxvii, 419.

45. Dercum: Two Cases of Adiposis Dolorosa: One in a Man, Complicated by Epilepsy; Another in a Woman, Presenting also Circinate Retinitis, Philadelphia Med. Jour., 1902, i, 396.

46. Dercum: A Case of Adiposis Dolorosa, with Involvement of the Joints, Philadelphia Med. Jour., 1902, ii, 1007.

47. Dercum and McCarthy: Autopsy in a Case of Adiposis Dolorosa, Am. Jour. Med. Sc., 1902, cxxiv, 994.

48. Desnos: Un nouveau fait de nombreux lipomes diffuse, symétriques, d'origine arthritique, Bull. et mẹm. Soc. méd. d. hôp de Paris, 1891, series 3, viii, 369 .

49. Diamantberger: Du rhumatisme noueux (polyarthrite déformante) chez les enfants, Thèse de Paris, Nov. 4, 1890, Paris, 1891.

50. Diamantberger: Pathogénie thyroïdienne des rhumatismes, Bull. et mém. Soc. méd. d. hôp. de Paris, 1908, series 3, xxv, 335.

51. Dide: Oedème spécial rappelant celui du myxoedème chez une démente précoce catatonique, Presse méd., Nov. 14, 1903, ii, 795.

52. Dieulafoy: Manuel de pathologie interne, Paris, 1908, Ed. 15, iv, 747.

53. Dock: Diseases of the Ductless Glands, Osler's Modern Medicine, Philadelphia, Lea Brothers \& Co., 1909, vì, 351.

54. Du Castel: Lipomes symétriques généralisés, Bull. Soc. franç. de dermat. et de syph., 1896, vii, 579.

55. Von Eiselsberg and von Frankl-Hochwart: Ueber operative Behandlung der Tumoren der Hypophysisgegend, Neurol. Centralbl., 1907, xxvi, 994.

56. Von Eiselsberg and von Frankl-Hochwart: Ein neuer Fall von Hypophysis operation bei Degeneratio Adiposo-genitalis, Wien. klin. Wehnsehr., 1908, xxi, 1115.

57. Eppinger, Falta and Rudinger: Ueber die Wechselwirkungen der Drüsen mit inner Sekretion, Ztschr. f. klin. Med., Berl. 1908, lxvi, 1.

58. Erdheim: Ueber einen Hypophysentumor von ungewöhnlichem Sitz, Beitr. z. path. Anat. u. z. allg. Path., 1909, xlvi, 233.

59. Erdheim: Ueber Hypophysenganggeschwïlste und Hirncholesteatome, Sitzungsb. d. k. Akad. d. Wissensch. Math.-naturw. Cl., Vienna, 1904, exii, 537. 60. Erdheim and Stumme: Ueber die Schwangerschaftsveränderung der Hypophyse, Beitr. z. path. Anat. u. z. allg. Path., 1909, xlvi, l.

61. Eshner: A Case of Adiposis Dolorosa, Philadelphia Med. Jour., 1898, ii, 737.

62. Eshner: A Case of Adiposis, Medicine, Detroit, 1901, vii, 1006.

63. Ewald: Ueber einen durch die Schilddrüsentherapie geheilten Fall von Myxödem nebst Erfahrungen über anderweitige Anwendung von Thyreoideapräparaten, Berl. klin. Wchnschr., 1895, xxxii, 55.

64. Exner: [Patientin mit Akromegalie] Wien. klin. Wchnschr., 1909, xxii, 108; Beiträge zur Pathologie und Pathogenese der Akromegalie, Mitt. a. d. Grenzgeb. d. Med. u. Chir., 1909, xx, 620.

65. Fichera: Sulla ipertrofia della ghiandola pituitaria consecutiva alla cas. trazione, Bull. d. r. Accad. med di Roma, 1895, xxxi, 91, 155. Cited by Paul. esco, ${ }^{139}$ p. 117. 
66. Fressineau: Contribution à l'êtude de l'adipose douleureuse, Thèse de Bordeaux, 1905.

67. Fröhlich: Ein Fall von Tumor der Hypophysis Cerebri ohne Akromegalie, Wien. klin. Rundschau., 1901, xv, 883, 906.

68. Fulconis: Maladie de Dercum et lipomatose douloureuse symétrique, Thèse de Lyon, 1904.

69. Futcher: A Study of Subcutaneous Fibroid Nodules, Bull. Johns Hopkins Hosp., 1895, vi, 133.

70. Garand: Note sur le traitement des lipomes multiples par l'extrait de corps thyroïde, Loire mêd., 1901, xx, 140.

71. Gemelli: Sur la fonction de l'hypophyse, Arch. ital. de biol., 1908-9, L, 157.

72. Grey and Sautelle: The Relations of the Thyroid Glands to Glycosuria, Jour. Exper. Med., 1909, xi, 659.

73. Grosch: Studien iiber das Lipom, Deutsch. Ztschr. f. Chir., 1887, xxvi, 307.

74. Guerrini: Sulla funzione della ipofisi: Ricerche experimentali, Sperimentale, 1904, lviii, 837.

75. Guerrini: Di alcune recenti ricerche sulla funzione della ipofisi, Arch. di fisiol., 1905, ii, 384 .

76. Guillain and Alquier: Etude anatomo-pathologique d'un cas de maladie de Dercum, Arch. de. méd. expér, et d'anat. path., 1906, xviii, 680.

77. Haberfeld: Die Raschendachhypophyse, andere Hypophysengangreste und deren Bedeutung für die Pathologie, Beitr. z. path. Anat. u. z. allg. Path., 1909, xlvi, 133.

78. Hall and Walbrach: Adiposis Dolorosa, with Report of Three Cases, Am. Jour. Med. Sc., 1904, exxviii, 318.

79. Halliburton, Candler and Sikes: The Human Pituitary Body, Quart. Jour. Exper. Physiol., 1909, ii, 229.

80. Hammond: An Instance of Adiposis Dolorosa in Two Sisters, Brit. Med. Jour., 1904, ii, 121.

81. Harbitz: Multiple Neurofibromatosis (von Recklinghausen's Disease), ThE ARChives INT. MED., 1909, iii, 32.

82. Hayem: Présentation d'un malade atteint de lymphadénie aleucémique avec lipomatose périganglionnaire, Bull. et mém. Soc. méd. d. hôp. de Paris, 1897, series 3 , xiv, $\mathbf{3 3 5}$.

83. Henningsen: Beitrag zur Statistik der Fettgeschwïlste. Inaug.-Diss., KieJ, 1888.

84. Herring: The Effects of Thyroidectomy upon the Mammalian Pituitary : Preliminary Note, Quart. Jour. Exper. Physiol., 1908, i, 281.

85. Hertoghe: De l'influence des produits thyroïdiens sur la croissance, Bull. Acad. roy. de mêd. de Belg., 1895, series 4, ix, 897; Nouvelles recherches sur les arrêts de croissance et l'infantilisme, ibid, 1897 , series 4 , xi, 750 .

86. Hochenegg: Wien. klin. Wehnschr., 1908, xxi, 409.

87. Houée: Contribution à l'étude de la maladie de Dercum (adipose douloureuse génêralisée), Thèse de Paris, 1904.

88. Howell: The Physiological Effects of Extracts of the Hypophysis Cerebri and Infundibular Body, Jour. Exper. Med., 1898, iii, 245.

89. Huckins: A Unique Non-Capsulated Fatty Tumor of the Neck-Removal, with Ligation of All the Jugular Veins Except the Left Internal--Recovery, Med. Rec., New York, 1889, xxxv, 487.

90. Hutchinson: Tr. Ophth. Soc. U. Kingdom, 1884, iv, 42.

91. Hutinel: L'infantilisme, Gaz. hebd. de méd., 1902, new series, vii, 37.

92. Jeanselme and Bufnoir: Cited by Launois and Bensaude, ${ }^{102}$ p. 44.

93. Johnson: Surgical Diagnosis, New York, D. Appleton \& Co., 1909, i, 228.

94. Kiliani: Multiple Symmetrical Lipomatosis, Ann. Surg., 1909, L, 643.

95. King: The Influence of the Thyroid on Carbohydrate Metabolism, Your. Exper. Med., 1909, xi, 665. 
96. Koenig: Lehrbuch d. spec. Chir., 1893, Ed. 6, i, 542.

97. Koettnitz: Ueber symmetrisches Auftreten von Lipomen. Deutsch. Ztschr. f. Chir., 1893, xxxviii, 75 .

98. Landouzy: De l'adipose du tissu conjunctif sous-cutané des membres atteints d'atrophie musculaire deuteropathique, Rev. mens. d. méd. et chir., Paris, 1878 , ii, 11 ; cited by Sellerin, ${ }^{172}$ p. 61 .

99. Langer: Zur Casuistik der multiplen, symmetrischen Lipome, Arch. f. klin. Chir., 1893, xlvi, 899 .

100. Launois and Bensaude: De l'adéno-lipomatose symétrique, Bull. et mém. Soc. mêd. d. hôp. de Paris, 1898, series 3, xv, 298.

101. Launois and Bensaude: L'adéno-lipomatose symétrique à prếdominance cervicale, Presse méd., 1898, i, 293.

102. Launois and Bensaude: L'adéno-lipomatose symétrique a prédominance cervicale, Nouv. iconog. de la Salpêtrière, 1900, xiii, 41, 184, 243.

103. Launois and Bensaude: Bull. et mém. Soc. méd. d. hôp. de Paris, 1901, series 3 , xvii, 675 .

104. Launois and Cléret: Le syndrome hypophysaire adiposo-génital, Gaz. d. hôp., 1910, lxxxiii, 57.

105. Lejars: Bull. et mém. Soc. de chir. de Paris, 1904, new series, xxx, 56.

106. Léopold-Lévi and de Rothschild: Rhumatisme chronique thyroïdien (prêsentation de deux malades), Bull. et mém. Soc. méd. d. hôp. de Paris, 1908, series $3, \mathrm{xxv}, 585$.

107. Lereboullet: Sur un cas de cirrhose biliaire anictérique, Bull. Soc. de pédiat. de Paris, 1901, iii, 89; Les cirrhoses biliaires, Thèse de Paris, 1902, p. 76.

108. Lewis: Hyperplasia of the Chromophile Cells of the Hypophysis as the Cause of Acromegaly, with Report of a Case, Bull. Johns Hopkins Hosp., 1905, xvi, 157.

109. Lexer: Lehrbuch der allgemeinen Chirurgie, 1908, ii, 257.

110. Lourier: Etude sur l'oedème nêvropathique êléphantiasique, Thèse de Paris, 1897.

111. Lyon: Diseases of the Spleen, Osler's Modern Medicine, Philadelphia, Lea Brothers \& Co., 1908, iv, 735-778.

112. MacCormac: Four Cases of Symmetrical Development of Fat at the Back of the Neck, St. Thomas Hosp. Rep., 1884, new series, xiii, 287.

113. Madelung: Ueber den Fetthals (diffuses Lipom des Halses), Arch. f. klin. Chir., 1888, xxxvii, 106.

114. Marburg: Die Adipositas Cerebralis, Wien. med. Wchnschr., 1908, lviii, 2617.

115. Marburg: Zur Kenntnis der normalen und pathologischen Histologie der Zirbeldriise. Die Adipositas cerebralis, Arb. a. d. neurol. Inst. a. d. Wien. Univ., 1908, xvii, 217.

116. Marçais: Contribution a l'êtude des lipomes diffus du cou et de la nuque, Thése de Paris, 1894.

117. Marine and Lenhart: Relation of Iodin to the Structure of Human Thyroids. Relation of Iodin and Histologic Structure to Diseases in General; to Exophthalmic Goiter; to Cretinism and Myxedema, The Archrves Ixt. Med., 1909 , iv, 440.

118. Marotta: Cited by Morsaline, ${ }^{133}$ p. 292.

119. Mathieu: Lipomes symétriques d'origine névropathique, Gaz. d. hôp., 1890 , lxiii, 721 .

120. Mathieu: Sur une forme particulière d'oedème névropathique (pseudoélêphantiasis névropathique), Ann. de dermat. et de syph., 1893, series 3, iv, 11 .

121. Mathieu and Weil: Etude sur certains oedèmes névropathiques, Arch. gén. de méd., 1885, i, 656 ; ii, 171.

122. MeCarthy: The Formation of Hemolymph Glands from Adipose Tissue in Man, Jour. Med. Research, 1903, ix, 241. 
123. MeCarthy: Adiposis Dolorosa (Dercum's Disease), Osler's Modern Medicine, Philadelphia, Lea Brothers \& Co., 1909, vi, 570.

124. MeCurdy: The Influence of Thyroidectomy on Alimentary Glycosuria, Jour. Exper. Med., 1909, xi, 798.

125. MeMullan: A Case of "Dercum's Disease," Brit. Med. Jour., 1909, ii, 516.

126. Meige: L’infantilisme, Gaz. d. hôp., 1902, lxxv, 207.

127. Milian: Pseudo-lipomes et lipomes multiples, Gaz. d. hôp., 1895, lxviii, 1273.

128. Mills: Adenolipomatosis, with the Report of a Case, Univ. Penn. Med. Bull., I908, xxi, 286.

129. Miquel: De la valeur nosologique de la maladie de Dercum, Thèse de Paris, 1904.

130. Mitchell: Jour. Nerv, and Ment. Dis., 1902, xxix, 427.

131. Mollard and Petitjean: A propos d'un cas de lipomatose diffuse symétrique à prédominance cervicale, Rev. de méd., 1907, xxvii, 276.

132. Morlat: Infantilisme et insuffisance surrénale, Thèse de Paris, 1903.

133. Morsaline: Lipomatose symetrique. Etude anatomoclinique et therapeutique, Rev, Soc. méd. argent., 1908, xviii, 281.

134. Müller: Ein Fall von diffusem Lipom, Arch. f. klin. Chir., 1889, xxxix, 652.

135. Murchison: Cases of Hereditary, Multiple, Fatty Tumors, Edinburgh Med. Jour., 1857, ii, 1091 ; cited by Petrên, ${ }^{145}$ p. 561.

136. Oddo and Chassy: Adipose douloureuse accompagnée de troubles vasomoteurs et de sclérodermie, Rev. neurol., 1902, x, 73.

137. Papi : Contributo alla casuistica della adiposis dolorosa, Gazz. d. osp., 1902, xxiii, 222.

138. Pappenheimer: A Contribution to the Normal and Pathological Histology of the Thymus Gland, Jour. Med. Research, 1910, xxii, 1.

139. Paulesco: Contribution à la morphologie de l'hypophyse du cerveau, Jour. de mêd. int., 1907, xi, 6; 22, 41, 53; Recherches expérimentales sur la physiologie de l'hypophyse du cerveau, ibid, 86, 103, 115; L'hypophysectomie, ibid, 152, 165, $182,197,211,231,251,271$.

140. Paulesco: Recherches sur la physiologie de l'hypophyse du cerveau;

l'hypophysectomie et ses effets, Jour. de physiol, et de path. gên., 1907, ix, 441.

141. Paulesco: L'hypophyse du cerveau, Paris, 1908.

142. Péan: Tribune mêd., Paris, 1898 , series $2, \mathrm{xxx}, 147$; cited by Launois and Bensaude. ${ }^{102}$

143. Pearce, F. S.: Adiposis Dolorosa, Jour. Nerv. and Ment. Dis., 1902, xxix, 427 .

144. Pearce, R. M.: An Experimental Study of the Influence of Kidney Extracts and of the Serum of Animals with Renal Lesions upon the Blood-Pressure, Jour. Exper. Med., 1909, xi, 430.

145. Pestemazoglu: Lipomatose symétrique diffuse; son intervention chirurgicale, Presse méd., 1900, ii, 131.

146. Petrén: Ein Fall von multiplen, symmetrischen, hereditären Lipomen, Virchows Arch. f. path. Anat., 1897, exlvii, 560.

147. Pi y Suñer: Ueber die antitoxische Kraft der Nieren, Zentralbl. f. des. Physiol. u. Path. d. Stoffwechs, 1907, ii, 3.

148. Potain: Note sur une variêté de tumeur lipomateuse intermédiare entre le pseudo-lipome et le lipome vrai, Bull. et mém. Soc. méd. d. hôp. de Paris, 1891, series 3, viii, 369 ; Semaine méd., 1891, xvi, 285.

149. Potain: Clinique médicale de la Charite, Lesons et mémoires, par le professeur Potain et ses collaborateurs, Ch. A. Francois Franck, E. Suchard, H. Vaquez et P. J. Teissier, Paris, 1894 ; cited by Lourier. ${ }^{110}$

150. Preble and Hektoen: A Case of Multiple Fibromata of the Nerves, with Arthritis Deformans, Am. Jour. Med. Sc., 1901, cxxi, 1. 
151. Price: Adiposis Dolorosa: A Clinical and Pathological Study, with the Report of Two Cases with Necropsy, Am. Jour. Med. Sc., 1909, cxxxvii, 705.

152. Pruden: Contributions to the Structure and Clinical History of the Multiple Neuroma, Am. Jour. Med. Sc., 1880, lxxx, 134.

153. Quéry: Contribution à l'étude de la lipomatose diffuse symétrique à prédominance cervicale, Thèse de Paris, 1902.

154. Von Recklinghausen: Ueber die multiplen Fibrome der Haut und ihre Beziehung zu den multiplen Neuromen, Berlin, 1882.

155. Reclus: Bull. et mém. Soc. de chir. de Paris, 1904, new series, xxx, 55.

156. Rehns: L'adéno-lipomatose diffuse symétrique à prédominance cervicale, Thèse de Paris, 1898.

157. Renard: Beschreibung zweyer Menschen, Mutter und Sohn, welche an den meisten Stellen des Körpers eine grosse Menge Fetthautgeschwülste haben, Med.chir. Ztg., Salzburg, 1815, ii, 251.

158. Rénon, Delille and Monier-Vinard: Syndrome polyglandulaire par hyperactivitê hypophysaire (gigantisme avec tumeur de l'hypophyse et par insuffisance thyro-ovarienne), Bull. et mém. Soc. méd. d. hôp. de Paris, 1908, series 3, xxv, 701.

159. Rénon, Delille and Monier-Vinard: Syndrome polyglandulaire par dyshypophyse et par insuffisance thyro-testiculaire, Bull. et mem. Soc. méd. d. hôp. de Paris, 1909, series 3, xxvi, 204.

160. Rénon and Louste: Un cas d'adipose douloureuse a forme nodulaire, Bull. et mém. Soc. mêd, d. hôp. de Paris, 1902, series 3, xix, 1130.

161. Rentoul: Pancreatic Infantilism, Brit. Med. Jour., 1904, ii, 1694.

162. Reverdin: Note sur les lipomes symêtriques, Bull. et mém. Soc. de chir. de Paris, 1904, xxx, 97.

163. Roberts: A Case of Adiposis Dolorosa, Philadelphia Med. Jour., 1902, i, 761 .

164. Rogers: The Significance of Thyroidism and Its Relation to Goiter, Ann. Surg., 1909, L, 1025.

165. Rogers: The Results of "Specific" Remedies in Diseased States Accompanied by Hypertrophy of the Thyroid, Ann. Surg., 1910, li, 145.

166. Rosenstirn: On Lipoma of the Tongue, Multiple Symmetrical Lipomata, and Their Etiology, Med. Rec., New York, 1893, xliv, 385.

167. Roux and Vitaut: Maladie de Dercum (Adiposis Dolorosa), Rev. neurol., $1901, \mathrm{ix}, 881$.

168. Shäfer and Herring: The Action of Pituitary Extracts upon the Kidney. Phil. Tr. Roy. Soe. London, 1906, B., cxeix, 1.

169. Schnitzler and Ewald: Ueber das Vorkommen des Thyreojodins im menschlichen Körper, Wien. klin. Wchnschr., 1896, ix, 657.

170. Schuchardt: Berl. klin. Wchnsehr., 1897, xxxiv, 215.

171. Schwartz: Bull. et mêm. Soc. de chir. de Paris, 1904, new series, xxx, 56.

172. Sellerin: Contribution à l'étude de l'adipose douloureuse (syndrôme de Dercum), Thèse de Paris, 1903.

173. Sicard and Roussy: [Deux cas d'adipose douloreuse, suite d'ovariotomie] Presse méd., 1903, ii, 740.

174. Sievert: Ueber das Zusammentreffen von Sehnervenatrophie und Adipositas universalis bei einem Geschwisterpaar, Ztschr. f. Augenh., Berl., 1908, xix, 544.

175. Siredey: Lipomes multiples et symetriques chez un malade atteint de rhumatisme articulaire subaigu avec purpura des membres inférieurs, Bull. et mém. Soc. méd. d. hôp. de Paris, 1892, series 3, ix, 454.

176. Spiller: Report of Three Cases of Adiposis Dolorosa, Med. News, New York, 1898, lxxii, 268.

177. Spitzer: Lipoma Multiplex Symmetricum, Wien. med. Wchnschr., 1906, lvi, 714. 
178. Stoll: Beiträge zur Kasuistik der Lipome, Beitr. z. klin. Chir., 1892, viii, 597 .

179. Strübing: Ueber "Adiposis dolorosa" (Dercum) und das "Oedème blanc et bleu" (Charcot), Arch. f. Dermat. u. Syph., 1902, lix, 171.

180. Strümpell: Ein Beitrag zur Pathologie und pathologischen Anatomie der Akromegalie, Deutsch. Ztschr. f. Nervenh., 1897, xi, 51.

181. Stumme: Akromegalie und Hypophyse, Arch. f. klin. Chir., 1908, lxxxvii, 437.

182. Sydenham: Opera universa Lugd. Batav., 1726, p. 391 ; cited by Warde, ${ }^{193}$ p. 6.

183. Tandler and Gross: Untersuchungen an Skopzen, Wien. klin. Wchnschr., $1908, \mathrm{xxi}, 277$.

184. Tapie: Contribution à l'êtude de la lipomatose symêtrique à prédominance cervicale, Thèse de Paris, 1899.

185. Thimm: Adipositas dolorosa und schmerzende symmetrische Lipome, Monatsh. f. prakt. Dermat., 1903, xxxvi, 282.

186. Thomson: Infantilism, Allbutt and Rolleston's System of Medicine, London, Macmillan \& Co., I908, iv, Part 1, p. 486.

187. Tigerstedt and Bergman: Niere und Kreislauf, Skandin. Arch. f. Physiol., 1898, viii, 223.

188. Tuffier: Lipomatose symétrique, Bull. et mém. Soc. de chir. de Paris, 1904, new series, xxx, 54.

189. Uhthoff: Beitrag zu den Wachstums-Anomalien bei der temporalen Hemianopsie resp. den Hypophysis-Affektionen, Ber. ï. die xxxiv Versamml. d. ophth. Gesellsch., 1907, p. 140.

190. Vessale and Sacchi: Sulla distruzione della ghiandola pituitaria, Riv. sper. di freniat., 1892, xviii, 525-561; Ulteriori esperienze sulla ghiandola pituitaria, ibid, 1894, xx, 83-88; cited by Paulesco, ${ }^{139}$ p. 166.

191. Vincent: Le signe thyroïdien dans le rhumatisme aigu, Bull. et mêm. Soc. méd. d. hôp. de Paris, 1906, series 3, xxiii, 598.

192. Vitaut: Maladie de Dercum (adiposis dolorosa), Thèse de Lyon, 1901.

193. Warde: L'oedème hysterique, Thèse de Paris, 1897.

194. Warren: Surgical Pathology and Therapeutics, Philadelphia, W. B. Saunders \& Co., 1895, p. 761 .

195. Warthin: The Development of Hemolymph Nodes in Adipose Tissue, Proc. Path. Soc. Philadelphia, 1903, new series, vi, 229.

196. Warthin: Diseases of the Thymus, Osler's Modern Medicine, Philadelphia, Lea Bros. \& Co., 1908, iv, chap. xviii, 779.

197. Weill and Diamantberger: Goître exophthalmique et rhumatisme, Bull. Soc. de méd. prat. de Paris, 1891, p. 582.

198. Weiss: Ueber Adiposis dolorosa (Maladie de Dereum), Wien. klin. Wehnschr., 1903, xvi, 496.

199. Wells: The Physiology and Therapeutics of the Thyroid Gland and Its Congeners, Jour. Am. Med. Assn., 1897, xxix, 1011.

200. White: A Case of Adiposis Dolorosa, Brit. Med. Jour., 1899, ii, 1533; postscript, 1769 .

201. Williams, L.: A Case of Diffuse Lipoma (Adiposis Dolorosa?) in a Man, Tr. Clin. Soc. London, 1904, xxxvii, 209.

202. Williams, W. R.: Diffuse Pseudo-Lipoma: with Analytical Summary of Thirty-two Cases and Remarks, Tr. Path. Soc. London, 1890, xli, 289.

203. Wurmbrand: Histologische Untersuchungen an drei operierten Fällen von Akromegalie mit Hypophysentumor, Beitr. z. path. Anat. u. z. allg. Path., 1909, xlvii, 187. 